\title{
The Representation of Violence in Khaled Hosseini's Novels
}

\author{
Mustafa Wshyar Abdullah Al-Ahmedi
}

Ph.D. dissertation

\author{
Supervisor \\ Cristian Réka, Ph.D., dr. habil.
}

Szeged, 2021

University of Szeged (SZTE)

Faculty of Arts

Doctoral School for Literary Studies 


\section{Table of Contents}

Acknowledgements

1. Khaled Hosseini and His Works............................................................................ 1

2. Trauma, Narratology and the Representation of Violence: The Literary Violence Triangle 11

3. Representing Direct Violence in A Thousand Splendid Suns ........................................... 50

4. Traumatic Experiences and the Narration of Violence in The Kite Runner ........................ 70

5. Representing Violence and the Role of the Narrator in And the Mountains Echoed .......... 100

6. The Literary Violence Triangle in the Novels of Khaled Hosseini .................................. 129

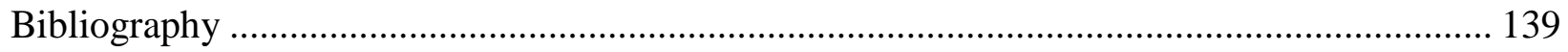




\section{Acknowledgements}

First of all, I would like to extend my sincere thanks to my supervisor, Dr. Réka Cristian, without whom this work would not have been possible; most of the credit goes to her for her enormous support from the first day of my doctoral studies in a foreign country. Her guidance and assistance made me gain courage throughout demanding times. I also owe Dr. György Szönyi and Dr. Attila Kiss for their continual guidance and support in the administration and for giving me feedback for my research progress. I am grateful to Dr. Anna Kerchy and Dr. Ágnes Zsófia Kovács for their fruitful feedback during the courses I had with them; they helped a lot.

My family has been the greatest support, they have always been with me during difficult times and unconditionally supported me. I am genuinely grateful for their presence in my life.

My wife, Skala, has truly enlightened my life by providing vital motivation for me to finish my thesis in challenging times. I am indebted to her love and presence that accompanied me throughout my academic journeys and beyond. I will always be grateful to her. 


\section{Khaled Hosseini and His Works}

In this research, I aim to examine the visible and invisible representation of violence in Khaled Hosseini's three novels, The Kite Runner (2003), A Thousand Splendid Suns (2007), and And the Mountains Echoed (2013). Significantly, I will analyze different types of violence in these novels through narratological approaches. Also, I will inspect the hidden and untold scenes in the novels and the role of trauma in violence representation in the narratives. Furthermore, I will deduce how invisible violence paves the way to a visible one.

I am writing on Hosseini's works as there is no reception on his novels in his country yet in my knowledge and insignificant reception in Anglophone countries. There are newspaper and magazine reviews, but the critical studies are minimal. Through my researches, no monograph appeared on his works; that is why it is essential. It is essential to talk about Hosseini's works on violence representation as it is a cultural memory processing that is important for conflict resolution. By reading Hosseini's novels, I will map the paradigms of violence representation because his works employ a multiphase representation of violence. This paradigm will incorporate notions of narratology, trauma theory, and Johan Galtung's theory to represent violence in Hosseini's first three published novels.

The objective is to analyze the representation of violence through the lens of trauma and narratological studies. Readers of narratives generally read about what happens in a novel or a short story. However, these narratives have elements that are barely visible at first sight, hence categorized as the disnarrated and unnarrated parts of a narrative. What does not happen or is not represented in a narrative, generally a hidden or camouflaged representation, is a consequence of violent representation. More importantly, mapping the representation of violence on the visible and invisible levels of the narrative and the connection among the types of violence can help the readers better understand the representation of violence in literature in a broader perspective.

In the first and second chapters, I will survey Khaled Hosseini's life and works; discuss background concepts related to trauma, conflicts as side facets of violence, and narratology. I will identify some key concepts and build the theoretical background to later test to analyze the following chapters' selected novels. Further, the first two chapters will include a summary of 
conflict studies alongside various types of violence, peculiarly the modal of the violence triangle defined by Johan Galtung. At the end of the second chapter, I will also explore the narratological modes of the unnarrated and disnarrated.

Following the introduction, I will dedicate three chapters to analyze Hosseini's novels $A$ Thousand Splendid Suns, The Kite Runner, and And the Mountains Echoed. Finally, the last chapter will conclude my research on the representation of violence in Khaled Hosseini's three novels.

Violence has consistently been one of the main themes in Khaled Hosseini's writing and other South Asian writers, like Tehmina Durani, Ambalavaner Sivanandan Taslima Nasrin, and many more. This type of representation is predominantly the result of the geography and history of the area, which has witnessed conflicts due to ethnicity and religion's heterogeneity. These regions have also been a central area for the international powers to intervene in exerting their hegemony and politically influencing regional powers. It is not only armies and superpower countries that create violence; instead, the social, economic, religious, ethnic, and family structures have aided the violent developments. As a result, conflict and violence have inspired writers to represent it through their fictional works. Durani (1953- ) is a Pakistani writer who wrote extensively on social justice, domestic violence, and women's rights. Her first book, written about her life, My Feudal Lord (1991), was translated into forty languages and received many awards. In her novel, Blasphemy (1998) represents torture and humiliation against Muslim women to the broader public. Sivanandan (1923-2018) was a Sri Lankan novelist and wrote about race and identity issues. The influence of racism on violence creation is the central theme of his novels and other non-fictional works. Nasrin (1962) is a Bangladeshi-Swedish writer. She is well-known for works that focus on issues of women and criticism of religion. The theme of struggle is another focus in her novels, and she singularly depicts the case of Hindus trying to survive in the Muslim majority Bangladesh. The works of these writers, Nasrin as an example, represent the issues of their communities. Geographically analyzing, in the past decades, Afghan literature seemed to flourish in trying to represent the Afghan population's condition to the outside world. Novelists like Mahmud Tarzi, Ahmed Rashid, Asne Seierstad, Atiq Rahimi, Ayesha Jalal, Gayle Tzemach Lemmon, Hamida Ghafour, and Khaled Hosseini were influenced by the significant political and military outbreaks in the country. Hosseini, moreover, has been influenced by his own past life in 
Afghanistan, America, and the struggle his people witnessed. His novels show the violence and struggle, just like many other authors in the region.

Khaled Hosseini is an Afghan-American novelist. He was born in 1965 in Kabul, Afghanistan, and moved to the USA in 1980. He is the author of The New York Times bestsellers and published four bestselling novels until now: The Kite Runner (2003), adapted into a film in 2007, A Thousand Splendid Suns (2007), And the Mountains Echoed (2013), and Sea Prayer (2018). I choose only the first three novels as primary texts of this thesis as the fourth book is a graphic novel, and I do not find it relevant in my dissertation. Hosseini's works have sold more than forty million copies in more than seventy countries. Hosseini is also a U.S. Goodwill Envoy to the United Nations Refugee Agency (UNHCR). In 2007, he established The Khaled Hosseini Foundation, a nonprofit organization assisting the Afghani people; Hosseini states that he has earned a lot by narrating those people's stories, and it is time to make something in return to them. Hosseini was raised in Afghanistan and is the eldest of five siblings; his father was a civil servant, and his mother taught Farsi and history in a high school in Afghanistan, where she was later promoted to the vice-principal rank. He was only eleven years old when his father was transferred to Paris for a diplomatic mission, and the family moved to France. When communist forces took power due to a military coup in 1978 and then the Soviet invasion, the family realized that they could not go back, and the corrupt political situation looked permanent in Afghanistan. They decided to flee to the USA with the help of his father's contacts and seek political asylum there. Hosseini learned English in the USA and was enrolled at Independence High School in San Jose, California. In 1988, he earned his first bachelor's degree in biology, and following his graduation, he enrolled in a medical school and graduated in 1993, becoming a medical doctor. He served as a practitioner for a year and a half when he published his first novel (Hosseini n.d.; Ghilzai 2016; Famous Authors n.d.; Luebering and Pallardy n.d.).

Hosseini pictures a torn and marginalized country that is yet to recover from the years of injustice. Many scholars have tried to identify his works as a mere representation of "Muslim other." The recognition of Muslims in the present has increasingly become constricted, mainly due to Muslims' political representation post 9/11. Amid the negative portrayal, Muslims worldwide have suffered from deep contradictions and inconsistencies regarding their vexed identities. In this context, the Muslim diaspora writers strived to negotiate between their Muslim 
identities and the ethnic and diaspora cultural identities. Hosseini writes about a mix of his experiences as an Afghan living in Afghanistan, diaspora, fleeing his home and seeking asylum, and the stories of his people in Afghanistan and other countries as refugees. His traumatic memories lead him to construct the stories in novels depicting violence (Netto 2009, 55). There are many factors responsible for the present plight of the country. Afghanistan had been a mere victim of its history and geography. Over the last three decades, imperialist intervention in Afghanistan has been aimed to free the country from poverty, patriarchy, and feudalism, which were regarded as the sign of backwardness by the western population. Before the communist coup of 1978 and the Soviet invasion of 1979, Afghanistan was considered the most peaceful country in the Asian continent. Considering the geographical positioning in Central Asia, in the $19^{\text {th }}$ century, the country fell prey to the rivalry between the British and Russian empires. Russian invasion into Central Asia added to India's British rule made Afghanistan a potential bait for both.

Its conflicting geopolitical environment has constituted Afghanistan. It also became the ground for conflict between the United States funded Mujahedeen and the Soviet-supported Communist government. Afghanistan has always remained in the grip of conflict and has even been strongly isolated within the Muslim world. The country's permeable geographic boundaries made it easy at stake in the hands of the potential opponents. Iran has made the country a hub of sophisticated networks, forming indigenous groups and disciplined forces creating internal pressure. On the other side, Saudi Arabia has a close alliance with the United States and Pakistan to oppose the Soviet occupation in Afghanistan, which Iran considered a significant security threat. As someone knowing the novels, life of the novelist, and life in Afghanistan, it is complicated to deny that the novelist is narrating real stories of himself or other Afghanis living there or in the diaspora. The violence reported in real life and nonfiction is the same or at least very similar to the violence represented in the novels of Hosseini. The novels peculiarly represent the violence in Afghanistan and Afghanis faced and facing rather than showing the issue. Representation upholds authenticity, which is more robust than indicated as the author's fictional texts; it reveals to be more heart touching than treating them as a simple literary work. However, they are still the author's imagination products and are dealt with and analyzed as fictional works (Penguin Random House n.d.). I deal with the novels as fictional narratives and, in my thesis, there is no 
attempt to connect them to the non-fictional context. Hence, I would like to show similarities in the novels' violence with the existing violence in the non-fictional context, and I mainly use this approach in the second and fourth chapters to show a different narrative interpretation style. This approach can introduce a more in-depth analysis of the fictional narratives to explore the representation of violence in a literary form.

Khaled Hosseini writes his novels after the United States overthrow of the Taliban regime in Afghanistan in 2001, which has been governed poorly. The country's insurgency had drastically increased ever since, with an increasing part of the country in the Taliban's hands. For decades, war-Torn Afghanistan continues to be a hub of growing tension between the United States and other counterparts such as Russia, Pakistan, and Iran. Hosseini started writing his first novel, The Kite Runner, in 2001, but it was only published in 2003, and it is the first Afghan novel written in English (Tranter 2013). Reading about the ban of the kite running by the Taliban in Afghanistan inspired Hosseini to write this novel. Following watching the news in 1999 that the group bans running kites in the country of which Hosseini says that it was an activity he had during his childhood, he writes a short story of twenty-five pages talking about two boys running kites of which he expanded into a novel later (Brooks 2012). The novel narrates Amir and Hassan's story, who are biological brothers from the same father, which is revealed towards the end of the novel. There are many social, cultural, and religious issues covered. Violence is the central theme in the novel, similar to Hosseini's other novels; The Kite Runner represents various types of violence. The text's most dramatic scene is Hassan's rape by another child who is older than him. Another intense scene is the stoning of a man and a woman who had sexual affairs without marrying each other. Thus, Hassan's legal status as an illegitimate child remains the novel's core issue, although no one knows about this until the narrative ends. After learning that Hassan is his biological brother to search for his nephew, Amir goes back to Afghanistan, as the Taliban have now killed Hassan.

One of the issues Hosseini covers in his work is concerns related to ethnicity in Afghanistan. Pashtun is the majority in the country, while there are minorities such as Hazara and Tajik. He refuses all the talks mentioning that he narrates his life in The Kite Runner as he does not see himself belonging to only one of those groups "I'm not pure anything ... There's a Pashtun part of me, a Tajik part of me" (Tranter 2013). The novel is an inclusive text of many ethnic groups 
in Afghanistan, and the author does not favour anyone specifically. He instead tries to build a story dealing with peace and coexistence for everyone in the country and the world. Hosseini claims that the novel is not about his life, especially when comparing Amir to the author, but he admits that Baba's characteristics are the same as his father's (Tranter 2013). He also does not deny that his childhood and his head's voice greatly influence his narratives; he admits that his life in America has the primary influence on his writings (Mustich 2008). Hosseini is aware that there are novels in Afghanistan but written differently from the ones written by Western writers and Afghan writers who have been living in diaspora for a long (Mustich 2008).

In Hosseini's The Kite Runner, violence's representation encourages the reader to relate it to the non-fictional context when the scenes are compared to Afghanistan and Afghanis' available knowledge. Thus, The Kite Runner, but all his other novels, have had mixed receptions, especially by Afghani people, as Hosseini's claims exaggerate in many parts. Hence, he never claims that he is documenting any reality or nonfiction; he tries to narrate a story in the form of a fictional narrative, using his life experiences and identities both as an Afghan and American.

There are various types of violence represented in The Kite Runner. There are multiple types of violence found, but violence theories can also be implemented and studied through this fictional work. That is true that the novel is only narrating imagined stories, but it cannot be denied that the story is inspired by real stories as well as the experience of the author. This is a strong point on which to start building claims and analyze the text using non-literary theories. Those who are not Afghanis and never lived there can relate the novel to what they hear and see from the news. Many elements make the novel connected to the non-fictional life, such as the ban of the running kites, stoning adulterous people, and conflict between Hazaras and Pashtuns. Those are the novel's core issues that the author tries to expand and make them read to get non-Afghan audiences' attention by referring to things they may have heard of on the news. The author represents its troubled geography and history responsible for the present state, the debilitated state, carrying decades of trauma and aims to fictionalize the difficulties of the Afghan people's life and himself once had similar suffering fleeing the county living in exile under challenging circumstances. The novel provides hope for the characters in the text and war-torn Afghanistan (CharlieB 2014). Hosseini tries to build hope in the reader's eyes that Afghani people can make it towards a better life wherever they live despite all the difficulties in Afghanistan. The novel 
reminds the reader how long those people have been living in such difficult circumstances with all the country's existing violence (Hower 2003). The author's situation shows a collective trauma case that he is traumatized like other people in his country. Jeffery Alexander claims that collective traumas "have no geographical or cultural limitations" (Alexander 2004, 27). Although Hosseini flees Afghanistan when he is a teenager and spends a more significant part of his life in a Western country, there is no escape from cultural trauma.

After his first novel's great success, Hosseini started writing the second novel, A Thousand Splendid Suns (2007), as a full-time novelist, quitting his job as a medical doctor. Jonathan Yardley, a critic in The Washington Post, writes: "in case you're curious, just in case you're wondering whether in yours truly's judgment it's as good as The Kite Runner, here's the answer: No. It's better" (Yardley 2007). Hosseini shows how life is for women in a society that sees women as reproducing tools. Towards the end, the author shows the importance of defeating the Taliban as life starts to return to the country's people (Walter 2007). Like the previous novel, violence is the main issue represented through different incidents. Everything starts with the legal status of a girl, Maryam, who is born as an illegitimate child. Her mother works as a servant in the house of a wealthy man who already has two wives. When the sexual affair and pregnancy are revealed, he blames her for pushing herself on him.

Consequently, the woman is sent to live in a village with her illegitimate daughter. As a result of no support from anyone when she is a teenager following the suicide of her mother, Maryam is forced to marry a much older man than herself while she is still not in the legal age. Her illegitimate status remains a traumatic event in her life until she is stoned to death as a punishment for murdering her husband. Her illegitimate status leaves her without any family support that is significant in a dominant masculine society. The Taliban's political system favours masculinity. There is no right and support for the illegitimate children as they are seen as "Haramis," illegitimate and unwanted children born from a sinful sexual act out of marital structures according to the Taliban's beliefs and laws.

Violence again is a prominent theme in this novel. The issue is represented, and various aspects of the issue known mainly in Afghan society are portrayed. However, the represented violence in the novel does not solely belong to Afghan society. The violence through the novel is an issue in 
many countries and cultures in which human rights are less protected and places that uphold patriarchy. This novel invites a feminist reading as the issue of equality is the central question the author tackles. In the absence of human rights and equality, Maryam and many girls like her suffer, including another main character, Layla. It is not only women who suffer due to the absence of those fundamental human rights, but also the male characters; Layla's lover is an example.

Hosseini clearly says that he wants to discuss politics through his novels (Stuhr 2009, 106). It is not only the politics, but all the other social issues and violence like in this novel, and he aims to help "breathe life, depth, and emotional subtext into the two-dimensional image of the Afghan woman in a burqa walking down the street" (Mustich 2008). Hosseini is aware that he cannot change the world in the blink of an eye or a miracle, but issues can be represented in narratives. Fiction becomes a medium for the author to change or at least be the subaltern's voice. This is a statement to build an argument that Hosseini aims to make the reader aware of how people live in some parts of the world and to voice out their suffering: most of the characters in his fictional works are Afghanis either living in Afghanistan or people who flee the country to the western countries seeking asylum and looking for a safe life. In A Thousand Splendid Suns, the gender violence against females must have pushed the author to dedicate most of the novel to the issue. Afghanistan is portrayed to the west by the media as the third world with its wars and terrorism, yet Hosseini shows a different Afghanistan whose people have their issues and problems (Kakutani 2007; Kohistani 2005).

Hosseini's third novel is, And the Mountains Echoed (2013). Here the author goes deeper into the family structure, connecting it to the society, culture, and political system. Family is more concentrated on in this novel. It is the story of two siblings, Abdullah and Pari, who are separated from each other since their childhood as Pari is given into adoption to a wealthy family because her own family cannot look after her due to poverty. Pari leaves Afghanistan with her adoptive family due to the country's security and problems and settles in France, where she becomes a successful writer, while Abdullah flees the country to the USA and starts running a restaurant with his family. They find each other after a long time, but Abdullah is ill and cannot remember anything about the past. Thus, family ties are a central issue in the novel. Violence is a primary issue again, as in Hosseini's previous novels, but different types of violence are represented. 
There is much violence related to the state and other groups, but social/structural and cultural violence are more evident in this novel, as the core issue which the novel starts with is giving away a child into adoption due to poverty. Additionally, drawing on "universal signifiers of myth and symbol" states Hosseini's effectiveness as a storyteller (Hore 2013). Hosseini uses fantasy as a myth at the beginning of this novel, which he has not experimented with in his previous novels. According to Helen Brown (Brown 2013), Hosseini listens to his critics, as he was criticized for his first two novels ending unrealistically. In this novel, he sums up his work more neatly. This makes the end of the novel more peaceful, while the ending of the previous ones was more violent, especially in A Thousand Splendid Suns, in which the stoning of the main character was the final scene.

In this novel, Hosseini keeps the family stories central to his narration. Like his previous works, violence is represented, but the representation is different. This time, the novel focuses more on the structure of relations within the family how the circumstances influence this, as Hosseini says in a statement: "My new novel is a multi-generational family story as well, this time revolving around brothers and sisters, and how they love, wound, betray, honour, and sacrifice for each other" (Driscoll 2012). The social structure directly influences building the siblings' relationship as Pari is given into adoption, and she is separated from her brother. The structure of society violates the fundamental rights of siblings to grow up together. This is related to the power and economic distribution within a society in which some become poor, to the extent that they cannot look after their children, while others are so rich that they can adopt the children of those who are less fortunate. The entire social construction builds a cultural trauma that identifies human suffering (Alexander 2004, 1). And the Mountains Echoed explores the influence of violence of economic inequality on family formation and how the relations formulated in the absence of justice and fair opportunities. Although there are many other issues and types of violence covered, such as invasion, terrorism, and war, the family and the violence committed against family structure remain the novel's central issues

Trauma is a theme we frequently see in this novel; the author attempts to show the effect of trauma on the people who stay in Afghanistan, those who flee, and those who return to the country (Linklater 2013). Indeed, trauma is a language that people use to explain what happens about themselves and the groups they belong to within society (Alexander 2004, 2). Marcela 
Valdes (Valdes 2013) praises And the Mountains Echoed, saying that it deals with many emotional aspects such as honesty, loneliness, beauty, and poverty and that it is a novel of "the transformation of emotions into physical ailments." The theme of sacrificing as a reason for global unfairness and structural violence remains the most touching to the reader. A quote in the novel clearly explains this situation "A finger had to be cut, to save the hand" (Hosseini 2013, 14). Something must always be done unwillingly to let the others or a more prominent part survive. Cutting a finger is one of the violent actions that have to be taken to prevent the giant act of violence of losing a hand.

Michiko Kakutani (Kakutani 2013) describes this novel as "more fluent and ambitious" than The Kite Runner and "more narratively complex" than A Thousand Splendid Suns. This novel is more precise and focused when addressing the issues, while the previous ones addressed gender and war issues more generally. And the Mountains Echoed considers the smallest parts of a community, the individuals forming a family, and their relationships to each other are looked at and looking at the violent factors shaping these relationships. Saying all these, if The Kite Runner was mainly the story of a father with his son, A Thousand Splendid Suns were the story of a mother and a daughter, then And the Mountains Echoed is the story of two siblings. As a result, while all the novels are stories of some individuals and are all dealing with particular issues, the last one is more specific when addressing the issues and conveying the detailed scenes using different narrative techniques. 


\section{Trauma, Narratology and the Representation of Violence: The Literary Violence Triangle}

There is hidden information in fictional texts. Not only what is narrated and shown, but rather what is not shown and represented, should be explored and discussed. Connecting the texts to non-literary theories helps the reader better understand the approaches and see that literary texts are wide-ranging, covering other fields. Literature is a simplified and fictionalized version of life that is complicated and difficult to comprehend.

In this thesis, I will look at Khaled Hosseini's novels to see how violence is represented through a non-literary theory called the violence triangle by Johan Galtung. Galtung is a Norwegian philosopher who is named mainly by the scholars the father of peace studies. Looking at the representation of violence, I use trauma studies and narratology and some other theories, approaches, and models like the theory of mind, significant quest theory, and few others that I introduce in later parts of this dissertation. The non-literary sources are not used as a part of the theoretical background. They are somewhat used to clarify the literary terms and literary violence triangle, which is the novelty of this thesis and the supporting purpose of testing literary theories' process on the selected novels.

When there is violence, there is an unhealed or unaddressed trauma. Trauma and violence are connected because both cause each other in a circular process. It is impossible to determine which would come first and which one is the leading cause. In general, when a traumatic event occurs, issues that are not dealt with may transfer into violence. Furthermore, there is a hidden or invisible cause for anything. The invisible and hidden causes are not sufficiently considered, yet no problem can be dealt with unless we go deep to solve the issue from the roots. Violence is one of those issues that are usually not dealt with from the roots and thus dealt with improperly. There are millions of acts of violence every day, including killing, rape, and bullying. We cannot solve the issue; it is even impossible to punish each person individually by committing an act of violence. The violence triangle is a theory that targets the roots of an issue rather than just identifying types of violence alone and dealing with each case individually.

Trauma studies are a part of this thesis that I often consult to analyze the characters' behaviours and psychological behaviour. When it comes to trauma, there is extensive literature mainly 
dealing with non-fictional context in a quantitative approach; nevertheless, scholars are connecting both fields such as Geoffrey Hartman, Anne Whitehead, and Laurie Vickroy (Schönfelder 2013, 31). Following consulting narratological resources, it can be argued that even non-literary literature of trauma studies can be used to analyze the primary sources of this thesis.

I aim to look at the representation of violence mainly and issues like trauma and conflict in the works of Hosseini. The purpose of my research is to explore how we see his works as a representation of the current issues of Afghanis. The majority of this thesis will explore Hosseini's selected narratives' invisible level to see how this offers an alternative representation of violence.

Here in this section, I start explaining trauma as a violence prediction method. Post-traumatic stress disorder can be a starting point in trauma studies when building a framework for analyzing a text. This method can be used in reading the author as well as the fictional characters in the novels. Violence and trauma are inseparable as they each cause the other. Mainly trauma causes violent actions, which are the outcomes of some causes. Vice versa, violence causes traumatic experiences to the person exposed to the act and the character who commits a violent act.

Sigmund Freud's psychoanalytical work (in Lapsley and Stey 2012) explaining the characteristics-building process of an individual paves the basis for trauma. If trauma is caused by conflict exposure to an undesired situation, then the person's conflict to the self explains this clearly. The very first conflict experience someone may experience can be the battle with the self. Freud's categorization, id, ego, and superego, lay the ground for the framework. The id is a part of a human's unconscious, which asks for all the desires, acceptable and unacceptable by the social norms, to be practiced. In contrast, the superego stands on the opposite side and tries to stop all the desires from being visible, as it does not seem legitimate to be declared or unearthed. The mediator, which Freud calls the ego, comes to save the situation and solves the issue. The ego tries to find a middle way between the id and superego, to let them reach an agreement and let the person decide logically what reveals and what to not. It is worth mentioning that Freud uses the term "repression," signifying the defense mechanism. The amount of repressed incidents inside human minds is the main element of their starting to have psychological issues. Freud's identified process prepares the first steps of trauma, which makes the person reveal it in a way or 
another, mostly in verbal language representing the other forms of emotions. This does not mean that there is no other reason for trauma, but this case is one of the apparent situations while there are many other reasons explored in later parts.

Trauma comes from a Greek word meaning wound; the term is widely used in the medical field, especially for the injuries in which the skin is broken, and the internal organs are affected caused by violence as an agent (Laplanche and Pontalis 1973, 470-471). External forces cause internal injuries, including psychological ones: soft or hard. Recognition of PTSD in the medical field was after the Holocaust and Vietnam War (Andreasen 2010, 70). While the Greeks used the word only for physical wounds, nowadays, the term is used for psychological and emotional wounds. The term is well expanded and organized under a framework named post-traumatic stress disorder "PTSD." Trauma commonly occurs following stressful events such as various types of abuse, wars, and disasters. There are many possible symptoms, such as flashbacks, nightmares, anxiety, and depression. After Freud's psychoanalysis, trauma is a central concept used in clinical psychology to identify and diagnose psychological injuries.

A question worth exploring is when the trauma starts or the time it can be experienced. According to Cathy Caruth:

trauma is not locatable in the simple violent or original event in an individual's past, but rather in the way that its very unassimilated nature - the way it is precisely not known in the first instance - returns to haunt the survivor later on. (Caruth 1996, 4)

Trauma is long-term and occurs after a traumatic event; this can be why treatment is brutal. Trauma hides but never goes away; it instead comes back later to "haunt the survivor." Trauma is a lifelong enemy and can influence the individual anytime, and this may lead to undesired consequences such as social problems and mental illnesses. These conditions and characteristics of trauma make it very hard to identify the problem in its early stages, and it also makes the treatment complicated and difficult. Additionally, media violence and representing violence significantly affect social behaviour (Kansteiner 2004, 210).

In the book Trauma: A Genealogy (Leys 2000), Ruth Leys divides trauma studies according to the experience of the traumatized victims, which are "mimetic" and "anti-mimetic." According 
to the mimetic type, the traumatized individual is behaving, and s/he is not hypnotized. The victim unconsciously imitates the person who caused the trauma, and the victim cannot avoid the experienced trauma. This way, the victim completes the existing violence - or in other words, the violence continues through the victim. The victim is identified with the wrongdoer, and they have directly connected now. The anti-mimetic type has another interpretation for trauma; in this type, the victim observes and sees the trauma who once experienced. The victims here are not identified with the offenders, but they are still observant of the violent scenes they experienced before.

Trauma directly relates to the individual's power, as it is the person's level of strength that decides how they can deal with the issue. Judith Herman claims:

[psychological] trauma is an affliction of the powerless. At the moment of trauma, the victim is rendered helpless by overwhelming force. When the force is that of nature, we speak of disasters. When the force is that of other human beings, we speak of atrocities. Traumatic events overwhelm the ordinary systems of care that give people a sense of control, connection, and meaning. (Herman 1992, 24)

The individual's courage to address the issues affects the traumatic experience. If the person is powerless or weak concerning the problems s/he faces, then trauma becomes more severe and damaging, while if the person is courageous or there is some available help, trauma can be survived with minimal damage. Being "powerless" is not the only factor that affects the trauma, but it is sometimes more about the external force that causes the trauma. Human beings cannot stop many external forces, such as natural disasters, wars, or parental issues. We can indeed resist together, but in reality, it is not possible to gather everyone under the same umbrella to react against the common issues. For example, humans cannot gather into groups sufficient to stop the conflicts caused by superpower countries, climate change, and many other issues. Those issues will be the reasons for the traumatic experiences on a global scale in the future. However, an individual's power can be discussed, motivating the person to solve the traumatic experience. Even if not solving, this at least minimizes the damage. This is not named power; it somewhat relates to courage and self-motivation. It is essential to be powerful to obtain those 
characteristics; however, if we specify the characteristics, it is easier to know our aims rather than generalizing things.

The support of the people around us can make us powerful and confident as we work to overcome issues. At the same time, trauma can reverse this support, as traumatic events can "breach the attachments of family, friendship, love, and community. They shatter the construction of the self that is formed and sustained in relation to others" (Herman 1992, 38). Trauma can make someone fall into a deep depression, isolating the person as it cuts the person off from social and family ties. Then, the power to resist trauma cannot mainly come from the people around us but also internal.

As claimed before, there are many traumatic events unstoppable, and they can seriously affect someone even if there are people to support him/her. It is trauma that isolates the traumatized person and breaks the relationships between the affected person and the other contacts. Therefore, internal power and strength are the main elements one should have to face traumatic events and to solve the issues related to them. Support is still necessary as it can be very motivational and creates or increases the necessary internal power. Herman herself supports this argument by adding that "highly resilient people have the best chance of surviving relatively unscathed" (Herman 1992, 43). However, according to the survivors, there is another element: "the most important factor universally cited by survivors is good luck" (Herman 1992, 43). She gives an incident of a man who survived a murder attempt as one of the examples: "I was lucky in a lot of ways. At least they didn't rape me. I don't think I could have lived through that" (Herman 1992, 43). It seems the survivors try to overcome the problematic situations by portraying the worst situations resulting from similar incidents someone might face. Humans do that quite often as they comfort themselves by knowing that there are worse incidents than they experience. Hence, remaining without emotional support makes the situation more complicated, and Robert Lifton $(1983,91)$ argues that survivors suffer deeper scars than the traumatic event if they receive no social support or are blamed for the incident that caused their traumatization.

Trauma can be repetitive for captives, as the abuse will continue; this is the case, for example, in prisons, concentration camps, and places with slavery circumstances (Herman 1992, 54). Here, Herman introduces the term "single traumatic event," which can occur anytime and anywhere. 
We cannot escape from trauma, and it is possible to be traumatized at any given time. The more severe case is the continual trauma in which a victim is abused continually, as there is no method to escape. In this case, treatment is more difficult and complicated, while with past trauma, the victim can be healed much more quickly. The term "captive" reveals the status of trauma as it makes it continual for the victim to be abused. The captivity can result from being bordered, fenced, and chained or any obstacles, including social, financial, political, and racial. Trauma can also have positive effects as it makes the victim stronger and gains more resistance. Sylvia Fraser, who is an author and survival of incest, says:

In retrospect, I feel about my life the way some people feel about war. If you survive, then it becomes a good war. Danger makes you active, it makes you alert, it forces you to experience and thus to learn. I know now the cost of my life, the real price that has been paid. Contact with inner pain has immunized me against most petty hurts. (Herman 1992, 153)

Surviving a difficult time is an experience that is needed so that one knows how to deal with upcoming difficulties. Having some danger and living by them can alert the mind that develops a self-defense system.

Even if there are some positive points about trauma with relation to building some strength in the victim, "traumatic events destroy the sustaining bonds between individual and community" (Herman 1992, 154), and the solution is collectivism:

The solidarity of a group provides the strongest protection against terror and despair, and the strongest antidote to traumatic experience. Trauma isolates; the group re-creates a sense of belonging. Trauma shames and stigmatizes; the group bears witness and affirms. Trauma degrades the victim; the group exalts her. Trauma dehumanizes the victim; the group restores her humanity. (Herman 1992, 154)

The isolation itself is terrible in all the cases, leading to possible abuse, which will change into trauma. Specifically, for women, isolation is a prominent part of abuse formation after cutting the social contact by forbidding them to use communication means such as telephone and talking to friends and relatives (Abrahams 2007, 61). Isolating someone leads them to be traumatized 
easily; as humans, we need support all the time in our various periods of our lives, regardless of the level of our confidence and strength.

A problematic issue with trauma is that it is unavoidable even if we predict childhood traumatic situations. Someone will still face trauma even if s/he knows about the situation very well and has enough knowledge about it. Jane Kilby $(2007,24)$ argues, "knowing about rape, in general, does not prevent the reality being traumatic." There is a traumatization step following being a victim that is not affected by whether we are aware and knowledgeable about the act. Besides knowing about a possible future event, even if the victim accepts and knows what happened, there will still be a situation of traumatization: "imagining what it is like to be a rape victim is no simple matter, since much of what a victim goes through is unimaginable. Still, it's essential to try to convey it" (Brison 2002, 5).

There are various reasons for the victims to be traumatized, and one of them is stalking. Stalking is more likely to result in trauma and violence than jealousy and anger (Morewitz 2003, 109). As Doris Hall (1998, 133) states, "stalking is psychological terrorism." This implies that uncountable means resulting in trauma, and a detailed study are always essential to understand the exact reasons for trauma to look for an effective healing method. There is no reason to underestimate or ignore any cause leading to trauma; all the causes should be taken carefully and thoughtfully to deal with trauma appropriately and effectively. This cause for trauma, as an example, seems simple and less harmful than rape or physical violence, but it can easily lead to violence and physical attack of which leads to injury and even murder.

As there are debates about how trauma can be treated, and there are also claims that trauma is untreatable. The strongest arguments claim that trauma is treatable, but the methods are the subject of argument. Susan Brison $(2002,58)$ claims, "attempting to limit traumatic memories does not make them go away." Nevertheless, there are ways to help the traumatized people, such as "narrating a traumatic memory [which] can help to defuse it" (Brison 2002, 71). Talking about the negative experiences we face in our lives can help us change them for the better. Even if we cannot improve our past experiences, we may stop them from changing into violent actions or depression. Traumatic experiences should not stay in the unconscious level but should be revealed to the conscious level and disclosed to others. Keeping them inside may help them 
further grow to more difficult traumatic situations, leading to worse cases such as depression and violent actions, as stated.

Literature and narratives have an influential role in trauma as all the literary forms, even nonliterary ones, can make trauma visible and discussed. If the trauma was unspeakable, a tool might help make it provide voice, which may help the traumatized characters start a healing process. Stef Craps $(2013,101)$ claims, "trauma narratives may generate solidarity, enabling 'visions of cross-cultural solidarity and justice." Moreover, narratives may be a tool to speak about trauma, but they may also promote trauma among people, positively impacting their attitudes towards the problem itself and the possible solutions. It is always impactful to involve various methods in introducing and publicizing a concern, and literature is an excellent medium for achieving this goal; "its attempt to convey the literality of a specific event and its figurative evocation of the symptomatic response to trauma through formal and stylistic innovation" (Whitehead 2004, 162). Furthermore, innovative ways of representations like fictionalizing a context or narrating a story can be among the most effective ways of addressing trauma. Following the trauma, it is useful to understand conflict and peace before moving to narratological studies, as they can together build a framework to look at the representation of violence in Hosseini's selected novels in this thesis.

Following a detailed account of trauma conflict is the next topic to introduce its connection to produce a theoretical background involving violence as a representation phenomena. The very basic understanding of conflict is the disagreement of two or more parties on a topic; sometimes, only one individual has a conflict with him/herself, which is called conflict with the self. Conflict is not a new phenomenon and has always been present among humans and animals. However, according to new social, religious, and political contexts, the conflict types have changed through history. The importance to look at is not the level of conflict, but the damage it causes. Johan Galtung argues:

Conflicts do not exist at higher or lower levels. All conflicts are born equal and have the same right to be processed, with transcendence ('going beyond') and transformation, so that the parties can live with them. Geopolitical conflicts are not on a 'higher level' because statesmen and diplomats have high social status. All conflicts are equal: they are 
deeply serious for everybody concerned. Conflicts are not a game to be won or lost, but are often a struggle to survive, for well-being, freedom, identity - all basic human needs. (Galtung 2004, viii)

As Galtung states, we should consider all the types of conflicts equally as they each have their significance in their contexts. We commonly avoid some conflicts because we believe they are not as significant as their counterparts. All the conflicts have to be dealt with similarly, without taking any of them into less consideration. The conflicts are all about surviving, not "winning or losing," and this is how we must see them, as this can ease the pressure on us when we face a conflict. There is no need to stress ourselves to combat with the other parties, even when we try to overcome a conflict. According to a Chinese saying, "Life, goal and contradiction are inseparable. 'Conflict prevention', preventing conflicts, is meaningless” (Galtung 2004, 2). We cannot stop all types of conflict, as conflict is a part of our daily life. Nevertheless, we should know how to deal with our differences and use them to benefit, as differences can make life better. Most conflicts have never entirely ended due to not addressing the root issues, including trauma (Jayakumar 2019). It is easy to address a visible level of an issue, but dealing with the invisible part is the key if an issue is in the scope of the solution's target from its roots.

Violence is in direct contact with peace, and they are two topics, which should be studied together. Galtung $(2005,91)$ states, "the opposite of peace is violence." There should be a significant consideration for peace studies. There will be violence when there is no peace; the peace studies help build peace, but it will prevent violence. It is vital to categorize types of violence according to their severity and impact, as this will lead to a better understanding of violence and give us the ability to work towards abolishing, minimizing, or making violence less harmful. Willem Schinkel $(2010,52)$ argues:

One advantage of defining violence ontologically as reduction of being is that violence can now be seen as a sliding scale. It is now possible to distinguish between more and less severe forms of violence based on a substantial criterion, instead of an arbitrary one.

A scale or measurement type is essential to have a clearer vision of any issue or topic. This will help determine possible solutions, categorizing things rather than leaving a topic in a complicated situation, which creates confusion, leading to a loss of complexity. Violence itself is 
interdisciplinary with many other fields such as psychology, trauma, politics, culture, religion, and sociology. Those fields are themselves complicated, and when they discuss violence, there will be a vague situation. There is a focus on the causes of violence rather than on itself; violence is evil, and the reason is the point of consideration (Schinkel 2010, 84). I agree with this approach looking at violence as if we want to deal with the issue seriously and effectively, and we should look at the problem from its roots; this way, we can deal with the problem effectively. This method is a metaphor for cutting the top of the grass: it will grow again in the future because the roots are still there. The grass needs to be removed from the roots if we do not want it there anymore. Violence is the same: the causes should be abolished if we do not want to witness the continual existence of violent action. Hence, Michael Rothberg argues that looking for the origins of violence has two risks which are: "it can lead to the erasure of the specificity of the event, which col-lapses back into its antecedents once its "true" origins have been located; or it can lead into conceptual dead ends that reimport the categories of racist and primitivist anthropologies, as if the origins must be as shocking as the deeds those origins seek to explain" (Rothberg 2009, 106). Nonetheless, it is necessary to look at any violence's origin to understand the phenomena as comprehension of any issue is the first to seek a solution. Unless we explore the causing roots of an issue, solving a problem would be very difficult, and it is a must to take risks to achieve a permanent resolution to a complicated issue such as violence. In other words, we should not avoid seeking a solution not only for violence but anything else just because there are risks and disadvantages as a solution-seeking process is a must when there is a problem.

There are many types of violence, and new forms of violence are continuously introduced: some well-known forms such as domestic violence, sexual violence, racial violence, structural violence, symbolic violence, fictional violence, actual violence, political violence, religious violence. These are all the types of violence identified and introduced in different contexts and situations, and the ones that will be used in this research will be discussed in later parts of this thesis.

The multiple types of violence change according to time, place, and interpretations. Like terrorism, it is not the same as it used to be. Walter Laquer says that there are different faces of terrorism and "many terrorisms" (Laqueur 1996, 25). He continues by saying that violence and terrorism are two related terms that are strongly connected. According to his argument, if there 
were only assassinations and bombing attacks in the past, there are hijacking planes to use in terrorist attacks. Terrorism is even developing more following the technological advancements in which the internet is used to promote terrorism, and not only limited to that; cyber-attacks and biological attacks are considered one of the most dangerous future terror attacks. As terrorism is changing and it has many faces, types of violence are changing as well.

Brian Jenkins $(1987,583)$ argues that many terrorists "want a lot of people watching, not a lot of people dead." Then, we can see here that the forms of violence change directly when the intentions of some terrorists are different. Instead of physical violence, the victims will receive verbal or psychological violence, and this way, they will be traumatized. The violence seems more widespread than expected, as those who commit the violence want more people to be victimized by their deeds in a way that is against the public's expectation, as we in public think the terrorists aim only to kill or injure. As a result, the actual damage of a terrorist attack is impossible to estimate: while we may count the victims of the physical violence, it will be impossible to find out about the actual damage of the verbal or psychological violence, including trauma well. In the case of political violence, terrorists are interested in changing the political system; even if their aims change, the basics of their methods and aims will remain the same (Horgan 2005, 7).

Teressa Laureties $(1989,240)$ claims, "violence as a social fact - it is easy to slide into the reverse notion of a language which, itself, produces violence." Not only violence can produce a violent language, but a violent language can create violence at the same time. Moreover, humans hurt and the ways represented through a violent language, but a violent language creates violence too when it is offensive. Narratives are good examples to be studied to analyze the language in terms of violence creation, either as a creator or product; this way, the role of language can be further explored.

Slavoj Žižek, in his book On Violence, makes the argument that we should "step back" from violence to see the variety and all the issues involved:

At the forefront of our minds, the obvious signals of violence are acts of crime and terror, civil unrest, international conflict. But we should learn to step back, to disentangle ourselves from the fascinating lure of this directly visible "subjective" violence, violence 
performed by a clearly identifiable agent. We need to perceive the contours of the background that generates such outbursts. A step back enables us to identify a violence that sustains our very efforts to fight violence and to promote tolerance. (Žižek 2008, 1)

In this book, Žižek divides violence into two types based on their visibility and invisibility. He names the visible type "subjective violence," and he sees "objective violence" as invisible, which consists of two forms: "symbolic" and "systemic" violence. According to his arguments, there is hypocrisy in the attempts of those who try to abolish violence. Most of the efforts are for visible violence, and there are very few attempts towards the invisible types of violence, which forms its roots. Žižek (2008: 6) urges a "fake sense of urgency that pervades the left-liberal humanitarian discourse on violence." Ann Murphy sees the "fake sense of urgency" by Žižek as mockery and rejects it (Murphy 2012, 119-120). Although she accepts most of the arguments of Žižek on violence, she rejects his understanding of "thinking” and "acting." As argued by Žižek, love can turn into violence as well; when we love someone, we do not love them as they are but rather we expect them to be the person we have always imagined (Žižek 2006). He says that we will find out that we misidentified the person, and love will turn into violence as the person does not match our fantasies. Pierre Bourdieu's symbolic violence also tackles the issue significantly, and he sees this type of violence as non-physical and states that it exists as a result of power differences between groups from different social backgrounds (Bourdieu 2003, 23-26). Hence, he studies it on the invisible level only, while Žižek studies violence more extensively by looking at the visible level and making the study on violence look complete and extensive. Still, there is a gap, especially when looking at the transition stage from invisible to visible. Herman argues that violence is not something we can abolish; we will always feel its presence:

Atrocities, however, refuse to be buried. Equally powerful as the desire to deny atrocities is the conviction that denial does not work. Folk wisdom is filled with ghosts who refuse to rest in their graves until their stories are told. Murder will out. (Herman 1992a, 1)

According to this argument, violence is a reality, and no matter how someone attempts to escape from it, it will always return. Violence should not be denied, but it should instead be accepted and admitted. Accepting is not enough; nevertheless, we should know how to deal with it. Galtung $(2004,2)$ uses a Chinese saying in his arguments: "Life, goal and contradiction are 
inseparable. 'Conflict prevention', preventing conflicts, is meaningless. However, 'violence prevention', preventing violence, is significant and beneficial." According to Galtung's argument, violence prevention is possible in many cases.

But, trauma and violence do not remain in the past as they can revisit anytime again (Caruth 1996, 4)and Michelle Balaev $(2014,8)$ states:

If the larger social, political, and economic practices that influence violence are the background contexts or threads in the fabric of a traumatic experience in the first place, then trauma's meaning is locatable rather than permanently lost.

Traumatic experiences cause violence, and trauma is regarded as one of the main reasons for violence and other reasons such as social, political, and religious reasons. In literature, both violence and trauma cause each other, and there is a direct connection between them.

Although violence is a pervasive field that many scholars have studied intensively, the violence triangle model by Johan Galtung will be the leading theory that this thesis will use to look at the representation of violence in Hosseini's selected novels. Other scholars and studies are directly or indirectly - consulted. The reason for selecting the violence triangle as the leading theory to identify violence in this thesis's primary texts is that this theory is inclusive. Many scholars and theoreticians discuss violence, but Galtung explores violence from its roots on the visible and invisible levels. Žižek is an example of a scholar who distinguishes violence into both levels, but Galtung's theory takes the discussion to a new level by connecting the visible and invisible levels through a medium naming cultural violence. The clarity and inclusivity of the theory are the reasons to select a prominent theory to use in this thesis while also consulting the other scholars' research, like Pierre Bourdieu, on violence. Some other models and studies will be considered to build discussions and analyze violence in the selected novels.

The term violence triangle is relatively new in peace and conflict studies, a recent field. Johan Galtung was named one of the pioneers of the field after establishing the Peace Research Institute Oslo (PRIO) in 1959, and he is also named the father of peace studies. His article titled "Violence, Peace, and Peace Research" is the starting point of his theory. The theory was developed while research was conducted in the field of peace. It is known that, by definition, 
peace cannot exist unless violence is absent. Galtung $(1969,167)$ claims, "the statement peace is absence of violence." Based on this argument, he would instead start studying violence to establish a thesis towards peace because violence abolition is seen as a precondition for peace., Violence should be researched first to bring back peace, as there cannot be peace while violence is present. Moreover, violence cannot be abolished unless studied to remove it from the roots.

Johan Galtung aims to find a solution for violence or lessen it by studying its roots rather than identifying violence types. He identifies the types of violence differently from other researchers and organizations, as they are mainly interested in naming the types of violence, especially visible types of violence, in making them identifiable. Naming the types of violence just for identification would not offer a solution, but exploring violence to find the motivations behind it or the starting point can significantly contribute to developing and promoting a violence-free environment.

Violence triangle, I choose to identify and imply in this thesis to study the reasons behind making violence as I aim to explore the visibly or invisibly represented offered solutions. Galtung divides violence into three types: structural, cultural, and direct violence. These are the necessary parts of his theory, which he then develops to a larger scale by dividing the types of violence into visible (direct) and invisible violence (structural and cultural). The second division attempts to find solutions for the root causes of violence that can have a permanent influence. It does this by looking at the invisibility of an issue, as it can be challenging to find a solution for a problem without knowing the hidden causes.

Galtung starts with the first step of violence, and he names it structural violence. This type of violence is happening on vast scales, and it is veiled. This type of violence occurs between groups with different identities, genders, religions, and ethnicities. The ongoing unresolved conflict and disagreement between these groups is structural violence. The following is a clear example for this definition, "thus, when one husband beats his wife there is a clear case of personal violence, but when one million husbands keep one million wives in ignorance there is structural violence" (Galtung 1969, 171). In structural violence, the issue is between groups rather than individuals. A group of people collectively oppress the group they conflict with, which places the conflict at a higher level rather than simplistic between few individuals. 
Structural violence is not restricted to a specific group, and it has very comprehensive explanations and examples. Another example by Galtung is medical treatment. People would die from tuberculosis in the past, and that would not be violence, but if someone dies today from tuberculosis, it is structural violence. Such an illness is treatable now, and if it is treated but not conducted, then this is violence because the lack of treatment is caused by global injustice. In other words, when a negative outcome is avoidable but is not avoided due to human reasons, then this is a clear sign of ignorance. Causes of this type of structural violence might be class differences, poverty, corruption, social injustice, and the like. As a result, if people may die or suffer while there is a chance to survive under other circumstances, this is structural violence.

The categorization of violence is changeable according to the situation and the type stated by the previous example. That means that even if something is not considered violence today, it might be seen as a violent act in the future. For instance, everyone knows that earthquakes are not something that humans can control today, and therefore, they might not be considered violence. However, earthquakes will be taken as a violent action in the future if they will be controllable by any means of technology. Galtung also gives this example in his previously mentioned article (Galtung 1969, 171). We can argue that earthquakes are structural violence at the current time because they can be avoided to some significant level. The damage an earthquake may cause in Japan is far less than the same earthquake in a developing country. This means that there are tools and capacity to avoid or lessen the damage, but these tools are not used due to global unfairness. In addition to previously stated reasons for this unfairness, it can be caused by corruption restricting a country's capability compared to another or many other reasons.

The structural violence I consider in this thesis is the one that exists between groups of people with different religions, beliefs, race, and gender. Galtung sees this type of conflict between groups as the primary source of structural violence because that is the reason which leads to all the other issues which become more and more complicated. The conflict between different social classes, people with different political and religious views, and the gap between genders can be the main categories or groups of structural violence.

Following the first step of violence, comprehension, viewing and commenting on structural violence starts, which is the second level of the triangle. This commenting is called cultural 
violence. The members of a society and groups are the main actors who come into the scene. Cultural violence is the second step in violence triangle. Galtung $(1990,291)$ defines this type of violence as the following:

By 'cultural violence' we mean those aspects of culture, the symbolic sphere of our existence -exemplified by religion and ideology. Language and art, empirical science and formal science (logic, mathematics) - that can be used to justify or legitimize direct or structural violence.

The group members start to accept the violence, and sometimes they do not even see it wrong. Violence might even be seen as necessary and acceptable to a very high level. This is the second phase of the violence triangle, which takes structural violence into a new phase. Cultural violence is a mediator and transition stage in the introduced violence triangle as it connects structural to direct violence. This step is crucial to consider as it symbolizes a filter or barrier that can stop structural violence from transforming into direct violence by denying or refusing to give it a platform. If it stops structural violence, there will not be any violence conducted personally or directly, as there would be a barrier that does not let structural violence develop or proceed. This type of violence does not have a lesser level of danger - in fact, compared with structural violence, it could be said to have more because this is the stage that creates an environment in which violence can grow and develop. Violence will be significantly reduced and controlled if there are some obstacles, and culture can be one of them. When culture starts to accept violence, it helps in the progression. This makes cultural violence as dangerous as structural violence, if not more, as it can play a role in putting a limit on its development phases.

The third type of violence in the violence triangle theory is direct violence. Direct or personal violence is the direct involvement of an individual in violent action. This can be a verbal or physical action such as beating, killing, raping, and swearing. This type of violence typically has an influence that can be seen with the bare eyes. The symptoms of such violence appear physically or psychologically in the affected person, of which the behaviour shows the violent action. There could be blood, torn clothes, skin scratches, or any other visible signs for physical signs. It will be more challenging to identify the signs of psychological violence; they may 
include depression, becoming antisocial, avoiding being close to him/her, fear of going to the public, and many other signs which can be identified.

Following the exploration of the violence triangle, it is also essential to consider the connection between violence types. The theory itself gives the reader a feeling that it aims to explore the roots of violence to find a permanent solution. Each type of violence results from another type, and they cannot exist without each other. Cultural violence puts the structural one into a new phase and processes it to create direct violence. This is why the violence triangle is introduced, as it is a circular process that connects each type to the others very strongly.

The violence triangle concludes that direct violence is a result of structural and cultural violence. In other words, direct violence is the reinforcement or manifestation of other types of violence. It manifests the existence of violence in general and the other two types that remain invisible. It could be difficult to argue about the presence of structural and cultural violence, as there would not be any objective proof of the occurrence of violence. The best way to document violence is the direct violent action seen objectively by the people's eyes, which is used as evidence of other types of violence.

When manifestation is the topic, visibility and invisibility of violence are significant points to be discussed under documentation. In Galtung's theory, direct violence is the visible type, while structural and cultural violence is invisible. The visibility can always be considered as evidence to prove the existence of something hidden or invisible. Invisibility does not help much in arguments unless the effects are documented and proven that they exist. However, invisibility creates visibility; there is always something hidden behind the existence of something visible. Maurice Merleau-Ponty (Merleau-Ponty 1968, 247) says:

when I say that everything visible is invisible, that perception is imperception, that consciousness has a 'blind spot', that to see is always to see more than one sees-this must not be understood in the sense of a contradiction - it must not be imagined that I add to the visible... a nonvisible. - One has to understand that it is visibility itself that involves a nonvisibility. 
There are always nonvisible facts that make the visible possible. As argued in previous paragraphs, structural and cultural violence are leading to direct violence. The first two types are invisible, and the last type is the visible one. Whenever a visible issue is approached to solve it, the invisible causes behind that should be studied and explored to solve the roots' visible problem, not to re-emerge. A lasting solution needs studies to be carried out on the invisible causes, as the visibility, while anyone can see it, might not be dealt with efficiently unless the invisibility is looked at in parallel with the issue's visibility.

Violence cannot be excluded from the perception of blind spots. We, human beings, see the surface or what can be seen with the eyes when it comes to violence. Like everything else, the hidden part of violence is the basis of the commitment that starts the visible - direct violence. The blind spot of violence, according to the violence triangle, is structural and cultural violence. Bell Hooks (1998, 343) says:

If the current fascination with otherness is an authentic expression of our desire to see the world anew, then we must be willing to explore the cultural blindness of the many people who saw Wings of Desire and who did not see whiteness represented there as sign and symbol.

Thus, cultural violence should be considered a primary type of violence, as cultural blindness can be a major cause leading to direct violence happening and existing. If the culture rejects and resists structural violence, there might be a limit put, and no one might get hurt because of direct violence, as the causes of violence might be eradicated or abolished before it happens on a direct level.

The role of trauma in creating or maintaining violence remains vital; trauma can be a primary reason behind all the types of violence, regardless of the types introduced by Galtung. Kirthi Jayakumar (2019) argues, "unhealed and unacknowledged trauma creates room for both violent structures and cultures." Moreover, unhealed and unacknowledged trauma requires explicitly further attention, as the hidden reasons are less likely to be treatable than visible ones when they progress to the following more advanced stages. McGrattan $(2014,535)$ claims that the acts of violence and inequality continue until those types of trauma are seriously considered. The past should not be passed on; "demons of the past" have to be dealt with to create a better future after 
an ongoing conflict (Gibney et al. 2008, 1). Thus, it is the invisible level of violence that must be considered, but the unhealed trauma has a significant role and should be studied as it can be the main factor in creating invisible violence.

There are other significant modals and theories, besides the violence triangle, which I find essential to use in this thesis as they help understand violence and the causes behind it is existence. The extended parallel process model (EPPM) is a developed framework by Kim Witte that tries to explain the individuals' reactions in situations in which they face their fears (Witte 1992). According to this model, fear exists and leads to defensive and protective actions. Those actions are motivated by the existence of fear. There will be a process to control the fear, and the threat is evaluated and then dealt with based on the evaluation. There is an initial or starting phase that will be seen as a threat to the subjected individual, and the person responds accordingly to that initiated fear.

This model directly connects with violence, as the person who commits violence has motivation, acceptable or not. When someone is killed, most probably the killer had tried to protect or to defend him/herself in a situation when fear was felt. This is a reason which may lead to violence. A primary question that arises here is whether we should deal with the fear before the violence, as fear may lead to the latter. It is not only about physical defense or protection, but it can also be all about existence. A male person may continue committing violence against the opposite gender to keep his dominance and presence there since the beginning of the time, out of fear of crumbling foundation, leading to losing that dominance. The same thing can happen with a group that is the majority in a country. They may deprive a minority group of rights because they fear fearing losing their power and changing their majority status to a minority. Abolishing this kind of fear can be a primary method of stopping the violence. A similar conclusion is reached by the protection motivation theory (Rogers 1975). According to this theory, people commit violence when they sense fear and threat, followed by a protection reaction. Stopping or removing fear can limit violence if it is not ended entirely.

Significant quest theory explains the process of becoming an extremist and committing violence due to the situations someone faced (Kruglanski et al. 2018). It starts with a "triggering event" when an individual feels ashamed or dishonoured by others, which leads to the loss of 
significance. We all want to be valued by other people, and we become angry when we are devalued. The devaluation can be in social status, identity, and religion. Following that, the devalued person feels a need for closure or isolation. Then, the person starts to look for a network where the members share the same destinies or at least understand the individual's situation. Through these networks, s/he is now accepted and respected by a community. The final stage will be the extreme violence that the isolated individual commits.

As a result of this theory, we can see how important is it to make all the individuals of a society feel and know that they are included in society. The individual, who feels that they are an inclusive member of a larger group where s/he belongs, is less likely to commit violence and preferably use dialogue as an alternative to solve differences. There is a need to embrace everyone even when they make mistakes and help them return to society; all they do can be to get others' attention or be an act of revenge. Forming an inclusive society would decrease loss in society, and there will be a more harmonious life among all the members of the communities regardless of their differences.

To do this, we should look at the results and the problems found on the surface level. It is crucial to go deeper into the issues and highlight the reasons and causes of violence. The elaborated likelihood model is one of the models that explain central root processing by looking at central and peripheral paths (Petty and Cacioppo 1986). The first path describes how someone is influenced more by the appearance and visible aspects of an object that is mainly preferred or shown. The latter path is more about attention to the details and diagnosing the object considering all related aspects. This model can be applied to situations, and it demonstrates that it is much better to analyze a situation and examine details of the causes rather than just looking at the result and seeing the visible levels. It is very misleading, for example, to only mention a violent action without mentioning its causes from the less-visible roots. While this is exceptionally relevant in real life, this aspect should also be taken seriously in a fictional context while witnessing a narration. If a fictional context is meant to address an issue to the reader, then both the visible and the invisible aspects should be understood and seen.

The terminology of blaming the victim has long been used in society against victims of violence. In victim-blaming cases, the victim is held responsible for the entire or partial act committed 
against them. Most of the cases are related to sexual assaults and rape, of which women form the majority of the victims. The victim is often criticized for the outfit, adherence to alcohol or drugs, or mere negligence. The victim is blamed in these situations because it becomes easier to blame the victim than to understand the systematic misogyny and rooted patriarchy that has resulted in the plight. Stereotyping a gender becomes comparatively more effortless than the probe into the violence. William Ryan (1971, 196-322) describes victim-blaming as an ideology used to justify social injustice. The social injustice can be class division, but it can also be gender discrimination, which comes from the idea that males remain males who are allowed to rape; even if not, the act is seen as possible and expectable.

It is rape as a type of violence, but victims are blamed in almost all the other types of violence. Moreover, mainly in the Mediterranean and Eastern context, women are supposed to obey the husband's orders; when she becomes a victim of domestic violence or verbal abuse, she is told that she lacks communication with her husband and is blamed for this. When a minor group is discriminated against in a country, we often hear people ask why they do not reach an agreement or seek independence. In cases where they try to separate from an internationally recognized border, they are labelled as separatists. In the following paragraphs, I start talking about narratology a way to portray invisible violence.

When we read a narration, the meaning and the story's construction precedence the narration's factuality. Of course, this is true for fictional narration, while the facts remain the main elements of narration in a non-fictional text. This thesis concerns fictional context and the meaning establishment by fictional work, considering what is shown and represented and what is hidden or not happening. There are further definitions of narrative, for example: "one will define narrative without difficulty as the representation of an event or sequence of events" (Genette 1982, 127); "a narration is the symbolic presentation of a sequence of events" (Scholes 1981, 205); "narrative may be defined as the representation of real or fictive events and situations in a time sequence" (Prince 1982, 1); "narrative is the representation of at least two real or fictive events in a time sequence, neither of which presupposes or entails the other" (Prince 1982, 4); "What we get in a narrative text are not events as such, but signs, the representations of events" (Onega and Landa 1996, 5); "the representation of an event or a series of events, in other words, a series of actions represented fictionally or none fictionally" (Abbott 2008, 13). 
There have always been discussions about why fiction exists or why human beings need fiction as a form of communication rather than always communicating more instantly. According to the claim of Richard Walsh:

Not that fictionality should be equated simply with "fiction," as a category or genre of narrative: it is a communicative strategy, and as such it is apparent on some scale within many nonfictional narratives, in forms ranging from something like an ironic aside, through various forms of conjecture or imaginative supplementation, to full-blown counterfactual narrative examples. (Walsh 2007, 7)

Walsh sees the works of fictionality as a "communicative strategy." He separates such works from pure fictional works. This argument adds contextual value for such texts, as they appear more serious according to this claim. We do not deal with fictional works for pleasure but rather learn from them and know about the real situations they describe. They tell us about these situations using a different method and medium adapted, compared to non-fictional texts. Real situations are communicated to readers through these texts, and they connect us to real-life using a creative technique. The method is called fictionality and appears more engaging and attractive to the audience. A good explanation for Walsh's argument is from James Phelan $(2018,75)$, "fictionality is a way not of escaping from the actual world but of engaging with it distinctly." We do not have to escape from reality; the wise step is to engage and face it to enhance our learning. However, the effective method of engaging with non-fictional life is negotiable. In fictionality, the speakers are trying to portray a not-real event (Phelan 2018, 75), and the purpose of this is to attract and engage the audience and communicate to the reader more effectively. Elaborations of the details fictionalize the real situations; in other words, fictionalization is the outcome of an event's representation process. When it comes to the significant consequences of fictionality, Phelan states:

It allows us to recognize that fictionality is not primarily an escape from the actual world but rather an indirect way of engaging with it. The most common reason we shift from non fictive to fictive discourse is to get a better purchase on aspects of the actual. (Phelan 2018, 75) 
This statement is seen as a gripping status for something to present it better. Offering our thoughts and ideas is similar, if not the same, to any other objective product. The thoughts and ideas are subjective products produced by human minds. There will not be any argument about serving them or how they can be delivered the best. An author always constructs a story that s/he extracts from a combination of real and imaginative situations to form a change or impact on others' thoughts. If fictionalizing the incidents serves this purpose, then a better marketing method for the thoughts is acceptable. Phelan also argues,

It both highlights the utility of the fiction/non-fiction distinction and provides a fresh approach to "cross-border traffic." It opens the door to attention to the deployment of fictionality within global non-fiction and of non-fictionality within global fiction. (Phelan 2018, 75)

Both fiction and nonfiction aim to start communication, but a better communication form cannot be achieved through direct methods. The authors remove the borders, and the fictionality sneaks into non-fictionality. When fictionality is involved, the reader becomes engaged more in the issues explained through a different medium of communication by the author.

An author's text is the product of imagination and talent, but many other factors influence any writing formation. In other words, the produced text is the manifestation of the experiences that someone witnesses. Afterwards, the author transfers the experiences creatively to the audience in a literary form using figurative language and narrative techniques using narrators, the created fictional characters by the author. As a result, there is a story representing some real experiences that are fictionalized. Uri Margolin $(2007,68)$ states, "characters are abstract in the sense that they do not exist in real space and time, and are more like concepts in this regard." More specifically, characters are the imaginative figures created by the imagination of the author. Hence, they represent the imagination of the author, and the world aimed to be created. It is the story and fictional storytelling that identifies their roles in a created world.

Furthermore, it is in the interest of the modernist authors to present the world from the characters' points of view primarily through their moods, emotions, and beliefs rather than representing a realistic image of external phenomena (Jahn 2007, 94-95). Such an approach implemented by the writers gave the characters a significant role in the fictional contexts, and the 
narrators and other elements of the narratives as the characters started to influence the readers' comprehension and interpretations. Luc Herman and Bart Vervaeck (2007, 218) state that "narratives that seem plausible, trustworthy, and truthful bear the stamp of verisimilitude, or lifelikeness." Including a character or narrator's ideology makes a narrative look more like a trustworthy representation of real life.

For example, war is an incident that affects the writing and the writer's role and identity (McLoughlin, Feigel and Martin 2017, 1). Geoffrey Hartman argues that literature is a way of expressing memory resulting from a traumatic event (Hartman 1995, 542). The traumatic event causes violence followed by a memory; violence can also result in a traumatic event. Either way, the process ends with a concluding stage called memory, narrated by an author through narrator/s that the author creates. Anne Goarzin $(2011,2)$ claims, "trauma is thus ambivalent on the individual level, as an experience of excess that can only be manifested in the lack of a meaningful structure or form to express this extreme, unbearable moment the self goes through." Literature represents the traumatic events and violence through figurative language - there are no better and more communicative structures and mediums than literature for this purpose. However, the authors should be careful in representing such incidents, especially during the attempt to make the representation appear more real, and they should not forget to draw a line between the fictional and non-fictional incidents. However, the non-fictional is always fictionalized and there are literary elements that deviate from the realities and truth. The audience should consider these deviations, especially those who experienced similar traumatic events. The language of literature is a medium that allows trauma to be told and expressed to deal with the issues (Hartman 1995, 547). Whether the authors narrate about something or narrate the thing itself is an important consideration. According to Kate Hamburger $(1993,136)$, an author does not "narrate about persons and things, but rather he narrates these persons and things." Clarifying this claim further, the authors aim to produce a representation of reality rather than explaining or defining the events. There is direct knowledge transfer from reality to the reader rather than involving any indirect method. The author transfers the image of the thing itself in place of making an image of something. Debjani Ganguly argues that 'novel worlds do not reproduce sociological realities; they generate imaginative approximations of possible worlds 
through a dynamic reconfiguration of the space-times of the historical or contemporary real' (Ganguly 2016, 102).

In Hosseini's novels, Hosseini narrates the violence rather than narrating about the violence. This allows this thesis to analyze a fictional work using a nonliterary theory more comfortably. When the author's fictional works are compared to available knowledge, it becomes clear that factual incidents happened (or are currently happening) or are very similar to the fictionalized incidents. Hosseini states that he has been told, and he realized that there is a cinematic quality to his writings in the sense of image, scene, and place. He also identifies his tendency to finish his novels because Hollywood finishes its films (Mustich 2008). Hosseini hopes that the film adaptation of The Kite Runner "can help provide an emotional connection across cultural and political lines ... and he sees the film as a significant advance in how Hollywood portrays Muslims" (VOA 2009).

The narration modalities are based on the narrator's approach: knowledge or opinion. Conviction narrative theory (CNT) is a theory that allows the narrator not only to experience but to judge as well. According to Mikhail Bakhtin (in Tjupa 2014), "conviction" focuses on "a definite set of values ... Only one voice sounds in it ... It exists in the ready-made, stably differentiated and evaluated world." In this theory, the narrator evaluates and assesses the situations and decides on the characters' moral attitudes. CNT is a narrative model that primarily focuses on opinion in addition to narrating the knowledge. Bakhtin (in Tjupa 2014) names this "evaluative outsideness": that omniscience is not presupposed, but the narrator has a broader concept rather than being only a participant. In such narrations, reliability is questionable, and the reader sees the judgments of the narrator.

Theory of Mind is a recent narrative theory used to describe situations in which readers read the characters' minds or characters read each other's minds. Lisa Zunshine $(2006,6)$ claims that the Theory of Mind is humans' "ability to explain people's behaviour in terms of their thoughts, feelings, beliefs, and desires." According to this theory, characters, both fictional and nonfictional, interpret and analyze behaviours and speech to better comprehend situations or predict future actions. Their interpretations are subjective, as they are made according to various aspects, such as the interpreters' beliefs. Furthermore, we need such interpretations to go into fictional 
contexts deeper and relate them to the non-fictional world. Using the Theory of Mind, we can better understand the authors, narrators, and characters' approaches. This theory is one of the theories that I use to interpret the author's mind, narrator, and characters. It is necessary to use such a theory as this thesis mainly focuses on violence and the role of traumatic experiences. As a result, looking at the characters and the author's mental status will be a significant step during the exploration process to represent violence.

Monika Fludernik $(2009,2)$ argues that narrative is "based on cause-and-effect relationships that are applied to sequences of events." The events are the backbones of a narrative: narratives are organized based on the reasons that result in the formation of events or direct them into a dynamic story structure that involves putting some selected events into an order. Thus, narrativity depends on each individual to assess how dynamic the telling process is "highly narrative for you may not be highly narrative for me" (Prince 1982, 147). Phelan (2017, ix) has similar arguments, describing "somebody telling somebody else on some occasion and for some purposes that something happened." A narrative is not only a chain of events, but there should be characters, fictional or real, transferring knowledge to each other. The actual character can be directly or indirectly involved in the story by becoming a part of processing and interpreting the narrated events.

A narrative is a communication tool helping the reader to understand the world, and Paul Dawson (in Lambrou 2019, 10) states:

And so narrative is transformed by the cognitive revolution, from a noun to a verb. To narrativize is to make sense of the world, to narrativize is to emplot history, to narrativize is to invite empathy, to narrativize is to employ a 'natural' cognitive frame that will enable us to read any literary work as a narrative. It's what people do with narratives that makes them narrative, in the same way that what people do with artefacts constitutes popular culture. And in the same way that one's creativity guarantees individual selfhood, so does narrative: no longer a deliberate artful structure, but simply a way of thinking that guarantees our sense of identity as homo narrans.

The readers make some texts narratives by the way the narrations are dealt with or perceived. Narration helps people make sense of the world because people can see the world through 
fictional works in readers' position. According to Yanna Popova (2015, 494), narratives are "an aspect of social cognition" as some social structures are formed according to the understanding of any particular society. Thus, Edward Branigan (1992, 3) defines narrative as "a perceptual activity that organizes data into a special pattern which represents and explains experience" containing "cause-and effect chains of events" evaluating or judging the events. The "data" is the knowledge, information, and details of the narrator who gains this data through a complicated experience and transfers them to the audience in another complicated narratological structure. Non-fictional narratives also include the features of fictional narratives: (Fludernik 2009, 59; Ochs \& Capps 2001, 33) argue that all the forms of narratives with the ability of reliability are storytelling, making them fictional texts.

As mentioned earlier, narratives are a pleasurable pastime, but instead, they exist to communicate an issue to the reader. Herman $(2003,165)$ argues that narratives are transformative processes that offer "tool[s] for thinking" that lead to activities that help solve problems. The arrangements and constructive elements of a narrative are essential, but the context has the leading role in making the narration successful (Prince 1982, 147). The "data" of the narration extracted from the narrator's experience - which provides the narration context - is significant as it leads the reader to develop their thoughts and interpretations. The reader needs to imagine the real world in the fictional narration, but it is also essential to witness the non-actual world that helps the audience engage more as they find the narration forms more interesting (Ryan 2013, 734). Moreover, to narrate various issues such as violence, conflict, desire, and hope, the author must use methods for delivering are visible and effectual methods of story construction (Puckett 2016, 68).

One may argue that the central aim of narratives is to portray a representation to an actual account of the life and the real world. Fludernik (1996, 27) claims, "narrative is the only discourse that can portray consciousness." On the one hand, the narrator's consciousness is his/her unconsciousness to the others as the unconscious mind is unlikely to be accepted by the others if portrayed directly without fictionalizing. The unconscious stage described by Freud is not easy to draw an image of or represent. The narrative here can represent unconscious thought in a person's mind, as the conscious might make it difficult to let these unconscious thoughts become visible or known to others. 
On the other hand, consciousness can be part of the narrator, who is aware of the events. In this case, s/he may feel responsible for making them visible and noticed. The narrator is conscious of some sequences of events and finds it necessary to make others also become conscious of them. According to Richard Walsh $(2005,151)$, "the general point here is that all narrative, fictional and non-fictional, is artifice: narratives are constructs, and their meanings are internal to the system of narrative." The narratives are to be cleverly perceived by the reader and interpreted as they can be decisive. The systematic structures should be carefully considered when approaching the inner and hidden meaning of the narration. Thus, it is essential to balance considering and analyzing a narrative both as a factual and non-factual context. Hence, Jean-Marie Schaeffer $(2009,98)$ argues that confusion of factual and fictional narratives is unavoidable and might not be distinguishable, even though this can have undesired consequences.

Producing representations is the main, if not the only, narrations' task; therefore, most of the narrative features serve this purpose. Representation is cohesion "(or the possibility of producing a representation)" (Toolan 2009, 51). A chain of events is put in order by a narrator and combined into a coherent system; following that, they collectively represent a chain of incidents that the narrator finds essential to tell the audience. The coherence feature helps the reader make sense of the represented events as ordered either chronologically or by any other ordering pattern. Martin Kreiswirth says (in Puckett 2016, 3), "narrative has become a significant focus of inquiry in virtually all disciplinary formations, ranging from the fine arts, the local and natural sciences, to media and communication studies to popular therapy, medicine, and managerial studies." In the literary and non-literary fields, narratives represent a past, current, or future story. These narratives are used to represent all the experiences and knowledge gained through time with difficulty. The narrative contains facts about humans' lives nowadays and is also a method of dealing with various issues in different fields (Puckett 2016, 3). Narration is one of how humans make sense of their lives or the world. Marina Lambrou (2019: 8) argues that "narrativizing our past helps us make sense of our existence and sense of self as through the narrative mode." Although coherence is a way of letting a context make sense, narratives "often go beyond common sense," and the coherence might not be seen as the most effective method of making sense out of a narrated context (Toolan 2009, 44). Thus, coherence can be seen as one of 
several methods in the sense-making process, as humans need to make links between the incidents and events. The linking procedure eases the process of comprehension.

According to the poststructuralist criticism on fact and fiction, all narratives and representations are human constructions extracted from realities (Schaeffer 2009, 99). Human beings are the prominent figures in building construction of a story. There is no doubt that the "facts" in a narrative have many exaggerated and deceptive facts in the context, but they are still based on the facts. The meaning of the word "fact" may change from one person to another, one time to another, one space to another. Today's facts were not facts centuries ago, and the things that will be facts in the future are not facts in the present. According to its believers, defenders, and deniers, facts should be explored to see where, when, and how they lived. Exploring a fact in this way allows us to comment on factual and nonfactual status. Nevertheless, fictional narratives should be distinguished from non-fictional narratives as the fictional ones have special codes of working in all the cultural and social platforms (Walsh 2005, 152). Hence, it is worth sometimes treating fictional and non-fictional narratives interchangeably to make the meaning construction a narrator adopt more precise and more effective.

According to Kantian philosophy, time and space are two main elements that structure humans' experience (Ryan 2009, 420). In determining the importance of what happens and structuring a narrative, space, the characters, and narrators are significant elements. The basic requirements of a story are "the presence of a story and a story-teller" (Scholes, Phelan, \& Kellogg 1966, 4), including the characters as a story, cannot exist without characters: humans or non-humans. Humans can organize experiences and create narratives following a transitioning process, and the narrators or the authors have the primary role in this process in which language is used as an intellectual tool that human beings are responsible for possessing (Cobley 2014, 21-22). Thus, Fludernik (in Ryan 2009, 420) argues, "narrative is widely recognized as the discourse of human experience.” Additionally, according to Marie-Laure Ryan and Paul Werth, narratives are to be read and to engage with an alternative world with its characteristics and structure (Bridgeman 2007, 52). The idea of world creation in a narrative encourages the readers to take all the elements into account while reading and interpreting the text. Moreover, the setting, which includes time and space, becomes a significant element that the reader should not avoid, and it has to be fully considered to analyze the imaginary world with a more in-depth approach. 
As time, space, characters, and experience are involved in structuring a narrative, the value of factuality should be considered either in fictional or non-fictional narratives - the two leading theories of narratology help comprehend the narrative genre: contextualist and cognitive narratology. Seymour Chatman (in Meister 2009, 340) defines contextualist narratology as a focus on the structure of the narrated context, especially in terms of culture, history, themes, and ideology. Cognitive narratology is explained by David Herman (in Meister 2009, 340), who describes that it "focuses on the human intellectual and emotional processing of narratives." Thus, contextualist narratology focuses on more visible aspects of a narrative, while cognitive narratology concentrates on humans' intellect and emotions. Various fields may find either or both of these approaches to be helpful in analysis. In this research, I find both methods significant when considering how intellect and emotions are combined with a structural process of strory construction on specific incidents and representing violence's complicated issue.

One of the main features of any product is the creator. The author, fictional or non-fictional, is an intelligent creator of any text produced for a communication purpose (Schönert 2009, 1). The non-fictional author is indeed responsible for making the communication, but it is the "voice" that becomes a medium for communication. Here, the narrator/s and characters get are involved in structuring the communicative process (Schönert 2009, 2). It is essential to mention here that it is the author who creates the voice, and although maybe sometimes the voice is not controlled, most of the time, the author leads it on his or her desired path. However, the voice may sometimes proceed so that the author plans, but it is accepted when it cannot be controlled anymore. Moreover, the narration can detach the author/speaker from the writing/speaking itself, giving a self-reflective quality to the product (Bamberg 2009, 133). According to this claim, the voice is not led, but it leads itself. In this case, a narration's progress - especially a fictional one is not according to the author's will, sometimes even the narrator. Identical elements such as "gender, age, race, occupation, gangs, socio-economic status, ethnicity, class, nation-states, or regional territory" have prominent roles in the differentiation and integration processes of someone to the self, surrounding, and the text (Bamberg 2009, 132).

The product as a result of a narratological development can differ depending on the characters and circumstances involved. When a narrative is analyzed, all those different factors should be considered to comprehend it best. According to Michael Bamberg (2009: 138), there is an 
adjacent connection between life and narrative mentioned as "life as reflected" and "life as lived." There is a life everyone lives, and that same life is reflected on, which leads to the existence of a virtual life that is very different from the living one. The reflected life is communicated to the reader through a medium, mainly narration. Anne Bohnenkamp (in Schönert 2009,2 ) claims that the legitimacy of a work lies in the actual author, who is the "originator." However, the author gives a role to the other fictional characters, including the narrator. This fact cannot be avoided; assigning roles reduces the responsibility that can be problematic to an author to be counted for everything told and happened.

Time and space are other vital elements in narration. The transitions between events create a chain that collects all the events under one umbrella of the meaning-making process. Mike Bal $(2017,155)$ argues, "the word "transition" stresses that an event is a process, an alteration." It is the transition needed to make a whole picture visible and make sense to the audience. One event alone may not make meaning, while many events can make a picture complete and meaningful. To do so, transitions are needed to link all the events. In other words, to make all the events make one coherent meaning, they should be linked to each other.

The events are in different stages of narration. Aristotle and Bremond (Bal 2017, 160) divide the narratives into three stages: the possibility (or virtuality), the event (or realization), and the result (or conclusion) of the process. Everything starts with a desire when someone wants to achieve something. That is the first stage, possibility. Following that, the characters realize what to do to make that possibility occur and where they can have control. This is the event or realization. At the final phase, there is a conclusion of the desire. The conclusion can be either positive or negative. Those phases distribute the events into groups, and once they are linked together, they make sense and a proper meaning out of the narrative. The sense and meaning are delivered to the audience. This process is called "narrative cycle" and consists of improvements and developments of the characters, events, and other fictional features (Bal 2017, 163). The process and development require changes, mainly in the characters' status and time and space. It is the change that makes a process, and a process needs links and transitions to combine everything and make one coherent story. The time is also divided into the duration of "crisis" and "development" - the crisis is a short period, while development is longer and allows progress in the process ( $\mathrm{Bal} 2017,178)$. It is the time that decides not only on the duration of the events but 
sometimes on the space as well. Some kind of events happens at a particular time which may not exist in the same space at a different time. An example would be accusing a woman of being a witch and sentencing her to be executed in the USA in the past, which is unimaginable at present. Hence, at the same time some events can happen in a space while they may not happen in another space at the same time, like stoning a woman in a space for engaging in a sexual act outside of marriage in one space, but seeing the same act even unspeakable in another space.

Following a detailed narration and narratology account, the next part of this thesis explores the terms unnarration and disnarration. Gerald Prince is one of the key researchers in this field and explores those terms; thus, Robyn Warhol $(2005,221)$ argues that Prince has not defined "the unnarratable" while he identified "the nonnarratable" in his attempts of exploring "disnarration." The unnarratable is something that is beyond the capabilities of a narrator to narrate. For any reason, the non-narratable is something that the narrator does not find worth narrating. According to Warhol $(2005,222)$, there are significant dissimilarities between "cannot be narrated" and "is not worth narrating." This argument shows the significant differences between the two terms. Some events cannot be narrated due to fear or reasons related to society, politics, and religion. This is clear censoring of freedom as it suppresses things that might be told to unearth the problem in the hope of seeking a solution. While if they remain hidden, the problems will grow without even looking for a solution. Thus, when it comes to the non-narratable, the narrator decides that the incident and information are not significant enough to be conveyed. Here, the narrator becomes dominant and makes the decision instead of leaving the decision to the audience. Suppose the unnarratable is accepted due to the difficult circumstances of the narrator. In that case, the non-narratable should not be tolerated, as all the available knowledge should be transferred to the audience, and it is the audience should assess the transferred information if it is meant to drag the audience into the narration for engagement. Hence, this may lead to too long and disorganized narratives.

Prince $(2003,56-57)$ defines the narratable as "worthy of being told; that which is susceptible of or calls for narration." Regardless of definitions, the narrators have to transfer all the information and knowledge to the audience and leave the decision for them if they find it worthy or not. As Prince defines "narratable" like this, then the "unnarratable" should be the opposite of that and mean "unworthy of being told" (Warhol 2005, 222). Warhol $(2005,222)$ identifies two narrative 
strategies: disnarration meaning "telling what did not happen, in place of what did," and unnarration, meaning "what did happen cannot be retold in words, or explicitly indicating that what happened will not be narrated because narrating it would be impossible."

This thesis aims to explore the two terms unnarration and disnarration. Moreover, Prince (1988, 1), in his article The Disnarrated, defines "unnarratable" as:

that which, according to a given narrative, cannot be narrated or is not worth narrating either because it transgresses a law (social, authorial, generic, formal) or because it defies the powers of a particular narrator (or those of any narrator) or because it falls below the so-called threshold of narratability (it is not sufficiently unusual or problematic).

Then, unnarration is an act or reaction of the narrator towards the events that $\mathrm{s} / \mathrm{he}$ does not want to reveal to the audience due to various reasons. The reason may change from one narrator to another or according to space and time. For example, it is improbable for a narrator in a country like Afghanistan to narrate a sexual scene, while there are no obstacles for a narrator in a western country to do so. Similarly, but regarding space, centuries ago, it was not typical for narrators in western countries to narrate things openly like sex, while narrators in those countries today can do so. Thus, primary influences on unnarration are time and space, as well as the bravery of a narrator if things can be risked or not.

To better organize it, unnarration can be classified and divided. Warhol (2005, 222-27) categorizes the term in four parts: “(1) "needn't be told (the subnarratable)," (2) "can't be told (the supranarratable)," (3) "shouldn't be told (the antinarratable)," and (4) "wouldn't be told (the paranarratable)." The first one, "subnarratable," refers to some information that is seen as details. These details are not seen as necessary to tell, according to the narrator, as they are seen as extra, unimportant, or irrelevant knowledge. This is followed by "supranarratable," which classifies some events that cannot be narrated as they are too great to be narrated; in other words, they cannot be fully represented through words or any other visual methods. The third type is "antinarratable." In this type, the social barriers and taboos resist narration, as those issues are not accepted or permitted to be narrated. The final category is "paranarratable," which depends on a specific time's literary or narration rules. It expresses that something cannot be narrated due to literary or narration barriers. For example, in Victorian novels, a heroine either dies or 
marries, and there is no other possible ending, while there were many other possible endings to the real stories of women at that time.

Having built a structural understanding of unnarration, the following paragraphs will explore disnarration. Gerald Prince (1988) defines this term in his article "The Disnarrated." According to his definition, "disnarration" is what is not represented in fictional works and what is not happening in a narrative. In the following work, Prince (2003, 22) widens his explanation towards the definition of the term by saying, "the elements in a narrative that explicitly consider and refer to what does not take place ("X didn't happen"; "Y could have happened but didn't")." Disnarration focuses on what did not happen but could happen, and if it happened, the story might have progressed in a different direction. This type of narration is used to criticize history for considering the possible outcomes, mostly positive ones. Here the didacticism is more pronounced. It advises the reader what led to a particular conclusion and informs them that the same paths should not be followed again as they caused downbeat endings. Then, disnarration is vital in stories because, as argued by (Harding 2007, 264), "counterfactual scenarios are evocative not only because they illustrate attitudes, but because they often depict near, misses, lost opportunities, and foreclosed possibilities." Counter factuality is "a hypothetical alteration in a past sequence of events that changes the events in a factual sequence to create a different, counterfactual outcome" (Dannenberg 2008, 119). Thus, disnarration is a suitable narrative mode to explore a story to assess and evaluate the events' progress for the audience to follow or avoid similar steps in their own stories.

Disnarration is not hidden or difficult to look at in a narrative; according to Prince $(1988,2)$, it is possible to express it through narration, narrator, or character. However, a construction process is needed by using:

alethic expressions of impossibility or unrealized possibility, deontic expressions of observed prohibition, epistemic expressions of ignorance, ontologic expressions of nonexistence, purely imagined worlds, desired worlds, or intended worlds, unfulfilled expectations, unwarranted beliefs, failed attempts, crushed hopes, suppositions and false calculations, errors and lies, and so forth. 
Thus, disnarration is neither hidden nor very obvious and straightforward. It needs to be considered and studied through a detailed analysis of a text considering various factors in its construction. Through this mode of narration, Prince theorizes the importance of imagination as he:

directs our attention to the issue of how vital the hypothetical in fact is in its dynamic and contrastive interaction with events which are deemed to "really happen" in a narrative world, and he shows that such questions are not only ontologically complex but rhetorically significant in a variety of ways. (Dannenberg 2014, 307)

The most significant purpose of this narrative mode is to assess and evaluate. This may lead to a reader passing judgment on a text and the characters and narrator. What did not happen and what had to happen were the major narration processes and a narrative dynamic. The narrations should not be looked at only in what they represent and what events happen, but it is also essential to look at what could happen as an alternative event reshaping the story. This narration mode can also "create suspense by presenting possible and false solutions in contrast with the correct and inevitable one," and it can also "distract the audience" (Lambrou 2019, 22). The distraction is good, although not always, to engage the audience more in the possible actions and the details behind the scenes. In other words, disnarration decodes the narrative codes set by the narrator. The narrators can code a narration, and this can be interesting for the audience. They may see it as a puzzle, and they become a part of the solution by pointing out what did not happen and while it could happen for the benefit of a better result in the story.

In short, unnarration is when something happened, but it cannot be narrated in words or represented in any medium. This can be due to various reasons that are building barriers in the transition of the narrator's knowledge to the audience. In contrast, disnarration is something that could have happened but did not happen. Both narrative strategies are essential when investigating a narration, as they expose different invisible possibilities. This is especially the case when they allow readers to decode the narrator's codes to comprehend the story content better to be conveyed to the audience through different used narrative features.

Following mapping the theoretical background and approaches, I outline a theoretical framework to look at the representation of violence in Khaled Hosseini's selected novels to use and test 
various theories and approaches looking at the crisis of disnarratability. I will look at both the ways the phenomena are represented and how it is not represented. I focus primarily on the factors behind the creation of brutality. I aim to consider Johan Galtung's violence triangle mainly and look at how the theory's structural and cultural levels lead to direct violence in a fictional context. The theory has not been used previously in any literary works to the best of my knowledge, and this dissertation will be the first attempt.

I create the term literary violence triangle to see the theory's implementation in the fictional context. By implementing the literary violence triangle, I represent violence throughout Hosseini's novels through figurative language, narratological tools, and various other literary techniques. The literary violence triangle will analyze the violence-creation process in a fictional context, in addition to its use in non-fictional texts. The term is a new approach to interpreting the representation of violence in literary texts. I find new approaches to interpreting the representation of violence important to look at the representations on a different perspective especially in Hosseini's works as there are very limited critical studies on his literary works.

In addition to the literary violence triangle, I have explored the field of trauma. In the novels of Hosseini, there is always a trauma that starts the main incidents or critical events. I call that "major trauma" or "original trauma." The original trauma in The Kite Runner occurs when Amir witnesses Hassan's rape, he is traumatized and plans to get away from Hassan by any means possible. He plans a scenario showing that Hassan steals his watch, and as a result, Hassan and his father leave the house. Amir believes that this will allow him to get over the trauma, but he does not, and the trauma haunts him until the end of the story. The original trauma in $A$ Thousand Splendid Suns is the illegitimate status of Mariam, who becomes a traumatized victim, and her previous life draws her future. An act of child adoption in And the Mountains Echoed is also the major trauma on which the following story events are built on.

In Hosseini's novels, the incidents in childhood shape the life of an individual. In other words, one's future is based on his or her past, and life gradually develops according to childhood. During the early ages, trauma can lead to an undesirable life, and a character will not have a happy life. However, the endings can change, and a character can overcome the trauma by going back to face the old unsolved issues from childhood or merely narrating them. 
Childhood and unsolved of traumas are the starting point of Hosseini's novels, and they are the results of the violence triangle. Furthermore, narrative techniques have essential roles in mapping both the trauma and violence in Hosseini's novels. It is essential to consider what is shown and told by the novels' narrators and what is not told and what is not shown. These elements allow readers to interpret the novels in multiple ways. The reader can interpret the events differently if the narrators tell the readers about what is not happening. The choice made by the narrators when they select which knowledge to transfer to the reader and when they unnarrate some other information is also problematic, as this causes the interpretation to be biased. Here the reader cannot have the freedom or knowledge to decide on when it comes to the reception of the literary works to interpret the texts, but rather, the narrators instead manipulate them and lead the interpretations.

Following the previous discussions on trauma, violence, and narratology, this thesis contributes to the field by introducing the literary violence triangle concept. Violence has an invisible level, but there is another sub-level underneath the invisible violence - trauma. Trauma is the sub-level that causes violence. Violence causes trauma, but the main issue to consider is the reason behind the violence, and trauma comes first. Unaddressed trauma is the central issue in the process of violence creation (Jayakumar 2019). To address violence, first, the unearthed traumas can be explored to understand the reasons behind the violence, and this is important to portray the whole picture to see how violence functions.

Following the exploration of trauma studies, narratology has the leading role in elaborating this thesis to study unaddressed trauma and violence issues. To build on that, this thesis is also about the novels' hidden knowledge that the narrator does not narrate purposely or unconsciously. Testing the narratological methods of disnarration and unnaration on Hosseini's novels allows me to look at the representation of violence in-depth, including the unaddressed hidden traumas, which are the main reasons for the creation of represented violence in the fictional works.

I connect trauma, violence, and narratology and gather them together under the violence triangle's umbrella term. In the following chapters, I will test the term of the literary violence triangle in Hosseini's selected novels to see how violence is represented. I aim to fill the gap in the studies on Hosseini's works as there is a lack, especially looking at the representation of violence and the developed term here stands as an outstanding concept to test on the author's 
novels. As argued in the previous sections, there is a circular process of violence creation, and different reasons lead to each other. Violence causes trauma, but trauma also causes violence. The literary violence triangle helps to form a textual analysis to integrate all the mentioned comprehensive theories under one umbrella. This thesis will test them in the selected novels chosen as primary resources. Reading Hosseini's novels using this new term will allow us to see the invisible violence as a hidden part in the completion process of violence creation and the visible types of the phenomena. Testing the term will also allow analyzing the invisible violence as a manifestation form of visible violence.

As the violence triangle explained earlier, the theory divides violence into three types: structural, cultural, and direct. The theory has been a leading one to use in conflict resolution, peacebuilding, and other fields related to society, culture, and human behaviour. Here I chose the theory to test it in literary context with some other theories and approaches from narratology and trauma studies. Following the new term's formation, the literary violence triangle, I would like to see how the theory's typology is represented in the novels by Hosseini. The novels' analysis will show how those types are represented in the novels and how they are causing each other as they are in a nonfictional context. The violence triangle typology will be identified through a thorough textual analysis and looking at the literary elements used in constructing the stories.

The invisible types of violence in the theory are connected to unaddressed trauma, and this trauma comes at the beginning of the violence creation process. The represented visible violence is the result and manifestation of invisible violence, which is the outcome of unhealed trauma. There is a push to form various structures in conflict, and there is a validation process of the other members within the same structure or outsiders. At the end of the process, visible violence occurs, which could be stopped at some previous stages. I will test this typology of the theory in the selected primary sources of this thesis to identify them first and see how the representation of direct violence manifests the other two types. The terms of unnarration and disnarration will assist in looking at hidden information and the role of that knowledge in the representation of violence. I will partially explore the functions of untold information in the process of violence creation. The hidden information also affects the reception of the novels and significantly affects the interpretations. The stories and incidents would develop differently according to the information chosen to be untold by the narrators. There might be information that should be 
unearthed to the readers to let them have their individual and personal understanding of the novels' understanding.

The previous theories and terms discussed are connected and collected under the term, the literary violence triangle. The theories and approaches make the newly created term suitable for testing the novels to look at violence representation. As discussed earlier, the mentioned methods and theories from violence, narratology, and trauma studies are linked to each other through the created new term. In Hosseini's novels, it is necessary to look at the narrators' disguised knowledge and explore the characters' traumatic experiences and the narrators to have a clearer picture of the represented violence. The literary violence triangle is the connecting term among all the mentioned theories and approaches, which I test in the selected primary sources of this thesis to look at the representation of violence.

As a result, the literary violence triangle will offer a more extensive and deeper analysis for the broader discourse on narratology and trauma studies. Also, the typology of violence will help in a more thorough textual analysis. It will allow me to look at the violence precisely on a more detailed level, that is to say, on both visible and invisible levels looking at the information revealed and unrevealed by the narrators. As a result, the analysis will be precise and effective in examining the texts by testing the literary violence triangle's detailed theoretical approach. That is what I found a gap in the limited studies carried on the representation of violence in Hosseini's novels. Most of the limited studies of violence in Hosseini's novels were vague in their definition of violence. I will look at the types of violence represented on visible and invisible levels and the role of hidden knowledge in promoting the violence, and the role of the narrators in the process of violence representation. The other approaches and theories on violence representations would not let me undertake such deep analysis, while the literary violence triangle helps me explore the issue of violence profoundly and extensively in Hosseini's novels. As mentioned earlier, I will look at revealed and unrevealed knowledge by the narrators. I explore the hidden and untold narratological knowledge to test their role in promoting visible types of violence. 


\title{
3. Representing Direct Violence in A Thousand Splendid Suns
}

\author{
"Tariq tucked the gun into the waist of his denims. \\ Then he said a thing both lovely and terrible. "For you," he said. "I'd kill with it for you, Laila." \\ - Khaled Hosseini, A Thousand Splendid Suns
}

Analyzing violence in fictional texts is not a new perspective; this broad theme has been examined in various ways. However, there is a unique approach for analyzing the types of violence by using a non-literary theory about violence: Johan Galtung's violence triangle, an approach that has not yet been researched as far as I know. This paper aims to explore a specific literary text and see how violent issues can make sense if circumscribed by a non-literary device. The main aim is to examine how the narrative of a novel provides examples of Galtung's theory in literary practice-and if this theoretical frame can make readers aware of the importance of other types of violence at work.

Galtung introduces the concept of the violence triangle in which he defines three types that consequently follow each: the first type is called structural violence, followed by cultural violence and with the consecutive result of the first two types, the direct violence; a detailed description of the violence triangle is given in Galtung's articles on "Violence, Peace, and Peace Research" (1969) and "Cultural Violence" (1990). Galtung identifies structural violence as a conflict between two groups confronting each other on different matters, including race, religion, colour, and ethnicity. Cultural violence is explained in how members of the society are involved in observing the first type: they start to see violence as 'acceptable,' even not, they do not resist to stop it. The last type, direct violence, comes from the first two types, where individuals are involved directly against each other during aggressive acts of beating, hate-related actions, killing, raping, and hostile gazing.

By analyzing the violence triangle in the Afghan-American author Khaled Hosseini's work entitled A Thousand Splendid Suns (2007), I aim to draw attention to structural and cultural violence in promoting direct violence. By resisting and abolishing structural and cultural violence, direct violence can be halted or controlled to diminish its destructive results in many societies worldwide. 
Structural violence is the first type of Johan Galtung's violence triangle and represents the starting point of any violence, mainly seen and perceived between opposite ethnicities, genders, political groups, and religious doctrines. Galtung sees this type of violence usually between two groups of people rather than individuals in the following way: "Thus, when one husband beats his wife there is a clear case of personal violence, but when one million husbands keep one million wives in ignorance there is structural violence" $(1969,171)$. This type of violence occurs quite frequently in Hosseini's novel and provides the first step in perceiving the other two types of violence. The novel's characters' social mentality, especially regarding different genders, is the main aspect that makes this type of violence central in Khaled Hosseini's A Thousand Splendid Suns.

The first words of the novel are a clear sign of the existence of this structural violence; these concern the labelling of a child identified as harami [illegitimate]: "Mariam was five years old the first time she heard the word harami" (Hosseini 2007, 3). Mariam is the illegitimate child of a wealthy man, Jalil, and his servant, Nana. After the servant's pregnancy is revealed, to avoid a further scandal, Jalil's wife forces him to send pregnant Nana to live out of the town in a remote rural area. Later on, even Nana herself labels her own child illegitimate, especially when she gets mad at her. This stigmatization remains with Mariam till the end of her life: she is often insultingly called harami even at her husband's house.

The culture of legitimacy nowadays occurs, in particular in very religious and quite conservative societies. For example, children might be left stateless and unsupported due to the legal systems in several regions of North Africa and the Middle East (Fisher 2015,2). This is something that psychologically traumatizes individuals, and there is hardly anyone to protect such people from the insults of its mainstream community, as they are seen as a result of sinful and thus shameful event rejected by the ruling religion and its subsequent social and moral codes encoded in the belief of most of its members. There is no doubt that even within that community, there are still individuals that see the so-called 'illegitimate' people as legitimate human beings; they see these outcasts as having no share in the sins they were created in - if any. This stance, however, is argued differently by various religions and cultures over the world. Regarding the Afghan context, a report of World Child UK states that "Afghan life and culture very much revolve around families and clans. The laws and moral standards are based on these blood ties much 
more than on the state and the "rule of law' like in countries such as the UK" (Poyesh et al. 2015, 22). And in such a context, the governance rules are seen much less than the commonly accepted practices of the society.

In Hosseini's novel, Mariam thinks that this discriminatory label was only a product of Nana's imagination when she first goes to Herat. This is how the novel describes this perception:

Nana was wrong about Herat too. No one pointed. No one laughed. Mariam walked along noisy, crowded, cypress lined boulevards, amid a steady stream of pedestrians, bicycle riders, and mule drawn garis, and no one threw a rock at her. No one called her a harami. Hardly anyone even looked at her. She was, unexpectedly, marvelously, an ordinary person here. (Hosseini 2007, 28)

Mariam is still a child and cannot correctly observe her surroundings to see what is going on around her consciously; this is the first time she arrives in a crowded place. Her first thoughts about others are pretty misleading, and it will take her a long time to recognize that what Nana said is true: others will look down on her once they know her identity and the facts about her life. Indeed, most of the individuals described in Hosseini's novel are like in Nana's description, and they accuse the child of being an illegitimate human being. This gives them the right to exclude Mariam from their closed, legitimate community to eradicate 'bad' individuals or false commitments. She will not be adopted but instead sent away. This exclusion event complies with some adoption laws in the region since it is illegal to adopt a child in Middle Eastern and other countries with laws based on the Islamic Shari'a Law (See the Joint Council on International Children's Services-Afghanistan \& Iraq in Richards 2013, 404). Due to these laws, parents from Western countries have no reliable statistics of adopted children in Iraq and Afghanistan. Overall, these countries' governing laws and religious beliefs have a significant role in shaping a love-child's future, as they do in Hosseini's novel.

When Mariam goes to live in her father's house after Nana's death, her illegitimate status becomes more problematic. One of Jalil's daughters accuses her of lying when she tells Mariam that "[M]y mother says you're not really my sister like you say you are" (Hosseini 2007, 39). The marginalization of Mariam becomes more and more pregnant. Although all children are siblings in that house, the mothers' marital status decides on the children's status; this, in Mariam's case, 
structurally violates her right to that family. Later on, after she is given into an arranged marriage, this violated right seems to fade away. Rasheed, Mariam's husband, clarifies that he can look at her with different eyes, provided she is well-hidden from the eyes of the outside world. He says:

But I'm a different breed of man, Mariam. Where I come from, one wrong look, one improper word, and blood is spilled. Where I come from, a woman's face is her husband's business only. I want you to remember that. Do you understand? (63)

At first glance, what makes Rasheed different from other men is the way he thinks-and his beliefs. Such beliefs are not necessarily religious (as he is not), but these counts more on an individual basis under the influence of various ideologies at work for the moment in that given community. The novel also has an example of a more integrating character, Rasheed's neighbor, Babi, who is a teacher and who is very open-minded - as well as some others living in Kabul then.

The ethnic doctrine leading to conflicts is a significantly provocative element in structural violence in general. Hosseini's novel abounds in the description of such doctrines when describing the Pashtuns as the majority in Afghanistan with other minority groups, such as Hazaras and Tajiks in the words of Babi, who said that

there were tensions between their people the Tajiks, who were a minority, and Tariq's people, the Pashtuns, who were the largest ethnic group in Afghanistan. Tajiks have always felt slighted, Babi had said. Pashtun kings ruled this country for almost two hundred and fifty years, Laila, and Tajiks for all of nine months, back in 1929. (117)

For Babi, all this is nonsense, as he argues, believing that they are all "Afghanis," while any separation into ethnicities is merely separation from all their fellow humans on the planet. His thoughts are far more liberal than most who lived in the same country as him as they promoted human-made differences, increasing the tension among various groups. In the novel, the Tadjikborn Laila, Mariam's young neighbor, does not feel any difference when she is at Tariq's Pashtun home, and such a topic never comes up although they are from different ethnical backgrounds. However, this is different on a grand scale. In neighboring Pakistan, the situation is 
similarly tensioned as different religious communities noticeably become antagonized (Riaz and Khan 2015, 345). This particular geographical area has always struggled with the conflict between various religious and ethnic groups, and this has been the main reason for the structural violence so far in the region that is mirrored in the novel. The brutality of structural violence reaches its peak as the two main ethnic groups start reacting violently and with utmost aggression to the crimes done to them by the other:

Laila heard that Pashtun militiamen were attacking Hazara households, breaking in and shooting entire families, execution style, and that Hazaras were retaliating by abducting Pashtun civilians, raping Pashtun girls, shelling Pashtun neighborhoods, and killing indiscriminately. Every day, bodies were found tied to trees, sometimes burned beyond recognition. Often, they'd been shot in the head, had had their eyes gouged out, their tongues cut out. (Hosseini 2007, 159)

This is the most brutal point in the novel where Pashtuns and Hazaras arrive due to their structural violence. At the time of the civil war in Afghanistan between 1992 and 1996, rape and gang rape were systematically used against the other ethnic group's women as a weapon (Ahmad 2014, 15). Due to its consequences, Baba would rather have a communist ruling system; that is why in the novel, "Laila could still remember Babi saying of those years of communist rule, It's a good time to be a woman in Afghanistan" (Hosseini 2007, 232). The structural divisions were already decided; they are taken as acceptable or not, according to different interpretations of various groups and Afghan society individuals. However, the differentiation between various groups is always an excuse to raise the tension among the individuals in each community. This is exemplified in the novel when "Rasheed had called the customer a monkey-faced Uzbek. A gun had been brandished. A skewer pointed in return." (271). The characters are all culturally traumatized that drags them into a social division on a structural level. Jeffrey Alexander states that cultural trauma "occurs when members of a collectivity feel they have been subjected to a horrendous event that leaves indelible marks upon their group consciousness, marking their memories forever and changing their future identity in fundamental and irrevocable ways." (Alexander 2004, 1). The religious division on a social level divides Hazaras and Pashtuns that leads to a cultural traumatization of all the Afghanis. Traumatization has the leading role in creating the individuals' identity and forming future social, cultural, and individual 
identifications.

Gender differences are also important issues in the novel, leading to the creation of structural violence. There are many scenes clearly showing discrimination between genders of children or adults. In this context, Rasheed's attitudes towards both his children, Aziza and Zalmai, are utterly discriminative in his behavior at home:

Aziza pushed the TV's power button. Rasheed scowled, snatched her wrist and set it on the table, not gently at all. "This is Zalmai's TV," he said. (Hosseini 2007, 265)

Rasheed is in doubt about Aziza's father; he firmly believes that he is not the biological father of the child-and that is true as she is from Tariq, Laila's love, whom she met before getting married to Rasheed. Even though Aziza's bastard identity is not proven (since nobody confessed it yet), Rasheed still treats his children differently-as he always wanted to have a son, not a daughter, and so his son has more rights in the house and outside of it. Generally speaking, Afghanistan is a more gender unequal country than many others around the world (Lough et al. 2012, 2). Thus the unequal opportunities for Aziza and Zalmai are made pregnant in Hosseini's text to present a close-to-authentic picture of the world in the characters inhabit. As a result of the war and the ongoing conflicts, starvation is a daily issue in the world of the novel, and many families give their children away to orphanages as they cannot provide food at all. Accordingly, Laila and Mariam decide to place Aziza in an orphanage, as they see this as a better solution than forcing her to beg on the streets-as suggested by greedy Rasheed. There is not much they want for the only girl, Aziza, just essential nutrition to survive. They explain it thoroughly: "Here, you won't go hungry. They have rice and bread and water, and maybe even fruit." (Hosseini 2007, 281). The fruit is seen as a luxurious food item, while in many other countries, such nutrition is a fundamental right for each citizen. At this point, this is clear evidence of structural violence, as there are people who can access food easier in other parts of the world, even across the borders of Afghanistan. When there is an unfair system in distributing the food among human beings with some people starving due to siege, war, conflict, or any other reason, there is, as Galtung argues, the existence of structural violence (Galtung 1969, 174).

When the Taliban takes control over Afghanistan, the people of the country face poverty and starvation, and many other problems. The main issue is gender discrimination as women cannot 
go out without a legal male companion, with those who lose their family and husbands being affected the most, as they are not allowed to go out of their homes alone to make a living. When Mariam is obliged to give and put Aziza in an orphanage due to not being able to afford to feed her child (she lies to the head, stating that she is a widow and has lost her husband), the head of the orphanage tells her:

It isn't your fault. Do you hear me? Not you. It's those savages, those wahshis, who are to blame. They bring shame on me as a Pashtun. They've disgraced the name of my people. And you're not alone, hamshira We get mothers like you all the time all the time mothers who come here who can't feed their children because the Taliban won't let them go out and make a living. (Hosseini 2007, 283)

Here are religious radicals, which enforce such rules, but they are Pashtuns, and many of those in the same ethnicity feel ashamed due to their commitments. The Taliban's followers interpret Islam, but not in the same way as it is interpreted by many other Muslims in Afghanistan, as well as by many others in various Muslim majority countries. During the punishment of Mariam, the execut or says:

"I wonder," the young Talib said. "God has made us differently, you women and us men. Our brains are different. You are not able to think like we can. Western doctors and their science have proven this. This is why we require only one male witness but two female ones." (324)

He does not see a woman as even semi-equal to a man; the executor starts to reference the Westerners, whom he opposes in almost everything. Excuses are being made not only in the name of the religion, but science is used to support and prove his claim. The man interprets the religion in such a way that he makes all the decisions and punishments absolute, and they are all carried in the name of God: "What frightens me, hamshira, is the day God summons me before Him and asks, Why did you not do as I said, Mullah? Why did you not obey my laws?" (325). The acceptance of Sharia Law in one way or another by all political groups may have had a significant influence on shaping the common belief towards human rights; Sharia Law is formulated differently based on rural areas and more modern and developed areas (Barfield 2012, 48). 
The structural violence continues even at the very end of the story. There are ongoing conflicts between people, even those with the same religious background and doctrine. Ahmad Shah Massoud, an Afghani politician, and commander is assassinated as he is against many armed groups' religious interpretations, including the Taliban. He is a Sunni Muslim, just like those that assassinated him, but they have different religious interpretations. Al Qaida terrorists assassinated him and

[T]hey say he gave an interview to a pair of journalists who claimed they were Belgians originally from Morocco. As they're talking, a bomb hidden in the video camera goes off. Kills Massoud and one of the journalists. They shoot the other one as he tries to run. They're saying now the journalists were probably Al Qaeda men. (Hosseini 2007, 339)

Massoud is a real character mentioned in a fictional text. The Afghani people love him that even his assassination date is now a national public holiday in the country. Different interpretations of a specific belief can turn into structural violence if they are not handled logically and calm. If the interpreters do not control their attitudes and limit their extreme thoughts, opposing thoughts and ideas can quickly start structural violence. Abdul Majid Samim argues by saying that

[W]e can divide the understanding of Islam in Afghanistan into two categories. One is the rural or traditional or primitive interpretation of Islam which is almost based entirely on our customs and traditions. Second is the urban which tries to find a more modern interpretation of Islam. Due to the stronger influence and dominance of primitive interpretation of Islam, we are not able to open our doors to science and technology of the modern world (Barfield 2011, 180).

Those contrasting understandings towards the same religion have always been a reason for possible conflicts, leading to structural violence. Due to the lack of a modern legal system organizing each individual's certain rights and specific groups of the community, dominations start to exist, and minorities, or the vulnerable groups, are oppressed by the superiors. Different thoughts are not accepted, and people start to be less tolerant - the attitude of the Taliban follower towards Mariam and the assassination of Massoud in the novel can be clear evidence supporting this claim.

Galtung describes this type of violence as a mediator or transition bridge from the first type, 
structural, to direct violence. This type of violence somehow legitimizes the first type and prepares an acceptable route, changing it to direct violence. He defines cultural violence as

those aspects of culture, the symbolic sphere of our existence - exemplified by religion and ideology, language and art, empirical science and formal science (logic, mathematics) - that can be used to justify or legitimize direct or structural violence. (Galtung 1990, 291)

Cultural violence is also a very frequently seen type in the novel, and it can be argued that it is a mediator or transition point in transferring the structural violence into the direct. The first type of violence can be stopped and resolved through this step if dealt with properly. Nevertheless, when violence is accepted or seen as normal, the last stage becomes an increasing possibility, and individuals get seriously harmed.

In the context of the novel, when Nana becomes pregnant by Jalil, as a servant, she becomes unlikable and is left with no support - even her father leaves her and disappears. Jalil says that she forced herself on him, and he is innocent. Nobody in the community around her tries to solve the issue fairly or support her. Nana stays at the house until her belly begins to swell and

[W] hen that happened, Nana said, the collective gasp of Jalil's family sucked the air out of Herat. His in-laws swore blood would flow. The wives demanded that he throw her out. Nana's own father, who was a lowly stone carver in the nearby village of Gul Daman, disowned her. Disgraced, he packed his things and boarded a bus to Bran, never to be seen or heard from again. (Hosseini 2007, 6)

Nana starts to disbelieve everything, and she becomes sure about the status of women in the society in which she lives, saying to "[L]earn this now and learn it well, my daughter: Like a compass needle that points north, a man's accusing finger always finds a woman. Always. You remember that, Mariam." (7). She believes that the man is always right and that nothing can be done towards the rights of a woman; Mariam remains accustomed to this reality until her execution at the end of the story. When Mariam sees her father, she is not allowed inside the house, although she has the right to see her biological father in his house. There is no one there to state that reality for her or support her; even the driver chooses to be silent while seeing that there is something unfair going on. The driver sighs and, as the novel says, looks at her with "gentle reproach." (31). 
Mariam is only 15 years old when she is pushed into a forced marriage by everyone in her surroundings, and the ceremony is conducted by a Mullah - a preacher in Islamic religion:

"And do you, Mariam jan, accept this man as your husband?"

Mariam stayed quiet. Throats were cleared.

"She does," a female voice said from down the table.

"Actually," the mullah said, "she herself has to answer. And she should wait until I ask three times. The point is, he's seeking her, not the other way around." (48)

Despite Jalil's wives not caring much for anything, Marian leaves and chooses to live far away from them. The Mullah sees this ceremony as his duty and finds it a religious and social norm - they all accept the marriage of a child with a man of almost three times her age. It was only with the introduction of the Afghan Constitution, the "2004 Constitution," which was said to be a "welldeveloped document," that many rights were legally allocated to female Afghan citizens (Ahmadi 2015 , 314). Post-2004 can be considered in a positive light, that is, the time in which the Communist rule lost power and Islamic radicals started to rule the country. In the novel, all of the women's issues that are revealed occur during the 2004 pre-constitution era, which demonstrates the extent to which women lived with no reasonable or supportive rules and laws to protect her. Thus, though not a radical upheaval, the post constitution era still shows positive changes compared to the old times, which gives some hope in terms of women's rights improvements.

In some instances, the wars in the novel are seen as holy actions - for example, a mother can be proud of her martyred sons while being fully aware that the war or conflict in they were which may be complete nonsense. Nana praises the talents of her passed away sons, as they both had the potential to be a leader and an architect respectively, however, she must accept that: "now they're both shaheed, my boys, both martyrs." (Hosseini 2007, 128). Nana was initially in favor of the ideological conflict that led to this deadly war, ultimately losing her sons. However, she still finds ways to support the cause, rather than being wholly against conflicts that will continue to cost many more lives. 
In another case, Laila hears some distressing news, and it seems the family no other choice but to escape. As the following excerpt shows, Nana goes a step further, stating that the brutality in itself is not forever and that she accepts the situation in its temporality:

Laila heard that Pashtun militiamen were attacking Hazara households, breaking in and shooting entire families, execution style, and that Hazaras were retaliating by abducting Pashtun civilians, raping Pashtun girls, shelling Pashtun neighborhoods, and killing indiscriminately. Every day, bodies were found tied to trees, sometimes burned beyond recognition. Often, they'd been shot in the head, had had their eyes gouged out, their tongues cut out.

Babi tried again to convince Mammy to leave Kabul.

"They'll work it out," Mammy said. "This fighting is temporary. They'll sit down and figure something out."

"Fariba, all these people know is war," said Babi. "They learned to walk with a milk bottle in one hand and a gun in the other." (159)

Throughout the novel, Laila remains aware of what is happening around her, as can be seen in this passage:

Laila knew that somewhere in the city someone had just died, and that a pall of black smoke was hovering over some building that had collapsed in a puffing mass of dust. There would be bodies to step around in the morning. Some would be collected. Others not. Then Kabul's dogs, who had developed a taste for human meat, would feast. (169)

The brutality is at its peak when the reader discovers that dead human bodies are left as food for street dogs; this shows that war and killings have become normalized to the point that people cannot even bury their dead. The ongoing violence has become impossible to stop, and especially for Leila, it becomes difficult to continue putting up a fight as despite being aware of what is going on, she is powerless against the terrible reality of the situation. It is the same for Babi, who states that people involved are used to guns, therefore that nothing can be done apart from fleeing the country's factual situation. On the other hand, Fariba remains hopeful that the 
conflicted parties may reach an agreement in the future - in this case, hope itself can be seen as resistance towards cultural violence. Though there are a few instances of resistance towards violence, they remain limited and not necessarily influential.

Cultural violence does not occur uninterruptedly in the novel, that is to say, that this mediator is seen more often than it is directly practiced. On numerous occasions, resistance is at least attempted - for example, in the following scene, when Laila tries to stop Rasheed from beating Mariam:

"I should have known that you'd corrupt her," Rasheed spat at Mariam. He swung the belt, testing it against his own thigh. The buckle jingled loudly.

"Stop it, bas" the girl said. "Rasheed, you can't do this." "Go back to the room."

Mariam backpedaled again. "No!

Don't do this!"

Now! (216)

Laila knows that she does not have enough power to stop her husband from beating his first wife, but she is courageous enough to try at least to stop him. It could be said that these small acts of resistance are all that is needed in order to make cultural violence disappear, and therefore to help in abolishing direct violence. Mariam and Laila run away from home, but a police officer catches them in a bus station. The officer insists on sending them back home, arguing that he simply enforces the law. They tell him that they could find themselves in danger with their husband: "As a matter of policy, we do not interfere with private family matters, hamshira" (238) The women respond to his statement with the following: "Of course you don't. When it benefits the man. And isn't this a 'private family matter,' as you say? Isn't it?" (238). As there are no laws to support the women against a husband that denies them their basic human and women's rights, they find themselves with no one to help them at all.

One last case of cultural violence that can be examined in the novel is the passage in which Mariam is executed in front of a crowd in a stadium, a punishment that she receives for 
murdering her husband. Though most spectators may have been forced to be present, this may also not be true for many attendees. In the excerpt, Mariam imagines the shaking heads of the audience, which can be interpreted in two ways: either that the audience does agree with the punishment, or that they disagree with the crime itself (that is to say, that a wife should not have committed said crime against her husband):

Thousands of eyes bore down on her. In the crowded bleachers, necks were craned for the benefit of a better view. Tongues clucked. A murmuring sound rippled through the stadium when Mariam was helped down from the truck. Mariam imagined heads shaking when the loudspeaker announced her crime. But she did not look up to see whether they were shaking with disapproval or charity, with reproach or pity. Mariam blinded herself to them all. (328)

Direct violence can be found in the last stage of Galtung's violence triangle, after having been built step-by-step by the first two types. This type of violence is identified as "direct violence where means of realization are not withheld, but directly destroyed. Thus, when a war is fought, there is direct violence since killing or hurting a person certainly puts his "actual somatic realization" below his "potential somatic realization" (Galtung 1969, 169). Here, violence is visibly identified through various signs such as blood, torn clothes, and wounds; thus, direct violence becomes the physical manifestation of the other two types of violence. As structural and cultural violence are the main factors in promoting or leading to the last step of direct violence, it can be stopped and abolished if there is no base for it to grow.

At the very beginning of the story, Nana starts to psychologically berate Mariam, which can be traumatic for a child when coming from someone that they love. It could be argued that Nana attempts to prepare Mariam for the reality that she will later face, however as she is just a child and needs the love of a father, this excuse can be seen as invalid. Nana always talks badly of Jalil when he leaves, which Mariam cannot say anything about despite it upsetting her. An example of the way Nana speaks of Jalil can be seen in the following passage:

"What rich lies!" Nana said after Jalil left. "Rich man telling rich lies. He never took you to any tree. And don't let him charm you. He betrayed us, your beloved father. He 
cast us out. He cast us out of his big fancy house like we were nothing to him. He did it happily." (Hosseini 2007, 5)

In this case, surely no child would like such words to be used for his/her father, as it can lead to the same type of psychological violence that was apparent in the way that her mother treated Mariam. At one point, Jalil gives his daughter a present, and Nana continues with her verbal abuse by stating: "Nomad jewelry," she said. "I've seen them make it. They melt the coins people throw at them and make jewelry. Let's see him bring you gold next time, your precious father. Let's see him."” (22). Nana aims to distress Mariam or even scare her, she does this by continuing: "I'll die if you go. The jinn will come, and I'll have one of my fits. You'll see, I'll swallow my tongue and die. Don't leave me, Mariam jo. Please stay. I'll die if you go.” (26). Nana clearly threatens the small child not to leave her mother and, consequently, not go to her father. Everything that happens to Mariam can be traced back to the psychological abuse inflicted upon her by Nana, Jalil, and even by society once she falls pregnant with an illegitimate child.

Another form of direct violence is sexual violence, which occurs when one of the partners does not consent to the act. At fifteen years old, Mariam can be considered a child, while Rasheed is three times her age. Today, the law of Elimination of Violence Against Women, which was decreed in 2009 in Afghanistan, states that marriage before the legal age, rape, beatings, and other brutal acts are legitimate forms of violence, and therefore punishable (Wimpelmann 2015, 102). However, as there was no such law in the past, in a non-fictional context, men comparable to Rasheed's character had more freedom in how they could act towards women, especially during the Taliban administration. In the novel, Mariam and Jalil's first sexual encounter reveals how Mariam is scared of what is about to happen. This leads the reader to realize that though the couple is legally married, that is to say, that their religious marriage is considered legal according to the country's rules and norms, the sexual encounter between them is non-consensual. Her uncertainty concerning sexual affairs, as well as her fear, is portrayed through the fact that she is shivering, as well as through the words that she utters:

Mariam began shivering. His hand crept lower still, lower, his fingernails catching in the cotton of her blouse. 
"I can't," she croaked, looking at his moonlit profile, his thick shoulders and broad chest, the tufts of gray hair protruding from his open collar. (Hosseini 2007, 69)

Though the legal age for marriage is 18 for boys and 16 for girls, this law is ignored in many parts of Afghanistan, especially in rural areas: Save the Children estimate that $48 \%$ of marriages involve children under age (Watchlist on Children and Armed Conflict 2010, 29). This is an incredibly high percentage, and unfortunately, it seems that girls make up the majority of this portion. Though fictional, Mariam is one of these many girls forced to marry a much older man while she is only fifteen years old.

In one occurrence in the novel, Rasheed does not like the rice that Mariam has cooked for him, claiming that it is not well boiled. When Mariam insists that there is nothing wrong with the rice, he forces her to chew pebbles: "He snatched her hand, opened it, and dropped a handful of pebbles into it." (Hosseini 2007, 94) and the result: "Then he was gone, leaving Mariam to spit out pebbles, blood, and the fragments of two broken molars." (94). Direct violence here becomes brutal, a form of torture even, which Rasheed justifies with trivial excuses. However, most of the direct violence towards Mariam throughout the novel is psychological. Since her childhood, forms of psychological violence and abuse have been inflicted upon her, which Rasheed simply builds upon. To justify his behavior and find the courage to carry out these acts, he conceptualizes her as nothing more than an illegitimate child with no family ties, as someone that is completely alone in life. This behavior is not exclusively reserved for Mariam, though, as when Rasheed marries a much younger girl Laila, he also berates her verbally by making comparisons and discriminating against his older wife:

We are city people, you and I, but she is dehati. A village girl. Not even a village girl. No. She grew up in a kolba made of mud outside the village. Her father put her there. Have you told her, Mariam, have you told her that you are a harami? ... I'll say it this way: If she were a car, she would be a Volga." (199)

By comparing the women to car brands in this instance, they are reduced to a simple commodity; this comparison continues in the following passage when he refuses to let Laila out of the house, ordering Mariam to do whatever she asks her: "Well, one does not drive a Volga and a Benz in the same manner. That would be foolish, wouldn't it?" (200). Unfortunately, though Mariam's 
psychological distress is understandable given the conditions and insults she must endure, her case is not an isolated one, as many women are not actively engaged in Afghan society. Their lack of freedom indeed constitutes the main reason, as women are not only separated from women, but they are also separated from the community (Sehin, Coryell, and Stewart 2017, 96).

Violence also arises between Mariam and Laila, particularly in the form of verbal violence. There is one specific instance in the novel in which they fight, which can also be considered the only moment in which there is a form of direct violence between them. After this passage depicting their fight, however, the women become close friends until the end of the novel:

"And it's possible you hid it somewhere, to aggravate me." "You're a sad, miserable woman," Laila said.

Mariam flinched, then recovered, pursed her lips. "And you're a whore. A whore and a dozd. A thieving whore, that's what you are!" (Hosseini 2007, 209)

This can be seen as the most straightforward and least harmful form of violence in the novel, as it seems to be nothing more than an ordinary fight that could happen between two people in daily life. This is also supported by the idea that compared to all of the other forms of ongoing violence and brutal scenes throughout the novel, the reader may not even consider it violence at all.

The peak of direct violence within the family is reached when both wives are caught after a failed escape plan. After they are taken back home by police car, they are alone in the house with Rasheed, and as he had always threatened, there would be no one and no law to stop him from giving his wives a lesson:

At the top of the stairs, Laila turned to him.

"She didn't want to do it," she said. "I made her do it. She didn't want to go."

Laila didn't see the punch coming. One moment she was talking and the next she was on all fours, wide eyed and red faced, trying to draw a breath. It was as if a car had hit 
her at full speed, in the tender place between the lower tip of the breastbone and the belly button. She realized she had dropped Aziza, that Aziza was screaming. (239)

Rasheed cares about no one and listens to no one to the point that he does not even consider the small child that could get hurt because of his violent actions. Here he even starts to act violently towards his beloved young wife; however, it is worth mentioning that Mariam receives most of the beating, as usual. Rasheed wants to send Aziza out to beg as he is making enough for a living, but Laila disagrees: "The slap made a loud smacking sound, the palm of his thick fingered hand connecting squarely with the meat of Laila's cheek. It made her head whip around ...Then Laila punched him." (266). As they find no other solution, both Laila and Mariam start to consider using violence in order to protect themselves and their children. Rasheed finds more and more excuses all the time to behave violently, for example, when he loses his shop after a fire, as can be seen in this passage:

After the fire, Rasheed was home almost every day. He slapped Aziza. He kicked Mariam. He threw things. He found fault with Laila, the way she smelled, the way she dressed, the way she combed her hair, her yellowing teeth.

"What's happened to you?" he said. "I married a pary, and now I'm saddled with a hag. You're turning into Mariam." (271)

He commits all types of direct violence: physical, psychological, even child abuse. As there is no law to stop him, the women can only endure his fits as they were taught to do so, much like Nana taught Mariam from a young age. In Afghanistan, domestic violence has always been a significant issue, and there are still no well-structured solutions to deal with it (Gibbs et al. 2018, 11-12).

It becomes clear throughout the novel that no one and nothing can escape from direct violence, as its basis has been paved for a long time. This is shown in the following passage, in which even dead bodies are not exempt from brutal acts committed by various ideological groups, often by those that had opposed their actions when they were alive.

"The Taliban went to the grave of Tariq's favorite singer, Ahmad Zahir, and fired bullets into it." 
"He's been dead for almost twenty years," Laila said to Mariam. "Isn't dying once enough?" (Hosseini 2007, 251)

We learn from the narrator that the Taliban prohibits all types of musical instruments as well. Their violence transcends death even, as they set fire to the grave of somebody who had committed an act they had disagreed with, even though it occurred when the person was alive. This reveals a thought process that can seem illogical and unthinkable to the reader but clear to the perpetrator of the said violent act.

Sometimes, however, it must be considered that people use violence to survive and get what they need to make a living as they have no other choice. For example, in the novel, when Tariq is a refugee in a refugee camp, his mother becomes seriously ill, and he is left with no option:

That same winter, Tariq had cornered a kid.

"Twelve, maybe thirteen years old," he said evenly. "I held a shard of glass to his throat and took his blanket from him. I gave it to my mother." (299)

In this particular case, the use of violence makes the reader think twice and directs many questions to him/herself about the reasons which make Tariq act in such a way - it can be even argued that this might not be violence due to the circumstances, however, the nature of the act remains clear. The reader cannot easily judge Tariq's decision as he is left with no solution if he wants his sick mother to survive the cold winter. It is crucial to consider the brutal nature of war and refugee life as factors here, as they lead to the point at which words start to be meaningless. Tariq's narration here also reveals that he has post-traumatic stress disorder (PTSD), which he developed due to his traumatic experiences. As he narrates his memories, he is torn: though he believes that he had no other choice, he still knows that cornering somebody and taking their property by force was wrong. Tariq may be a fictional character, but he is representative of a real issue, as, in real life, a significant number of children in conflicted or war zoned countries face PTSD (Catani, Schauer, and Neuner 2008, 166).

Mariam murdering Rasheed can be seen as the last significant example of direct violence to be examined in the novel. Rasheed finally finds out that Tariq has returned and that Aziza is indeed his child - a fact that, although he had always had his suspicions, Laila had hidden from him. In 
the following passage, Rasheed starts to beat Laila, and as usual, there is no law or any other means to stop him - except one person:

In the toolshed, Mariam grabbed the shovel.

... Mariam saw that she was no longer struggling. He's going to kill her, she thought. He really means to. And Mariam could not, would not, allow that to happen. He'd taken so much from her in twenty seven years of marriage. She would not watch him take Laila too. (Hosseini 2007, 310)

Here, Mariam uses violence to stop another violent act: she is left with no choice but to stop Rasheed by any means possible. To stop him and, in turn, abolish the source of brutality in the household, she must carry out a violent act herself. This situation echoes that of Tariq's, in which his morally questionable actions were actually to save his mother. The reader is therefore faced with a position that can be difficult to accept or reject. In identifying with Tariq or Mariam, the readers themselves become involved in cultural violence, forced to contemplate a complicated situation in which a clear cut decision is almost impossible.

The violence triangle is present in narrative details in Khaled Hosseini's A Thousand Splendid Suns, and its points are smartly connected, adding stress to each other. Direct violence manifests the first two types: structural and cultural violence and comes into existence only after the other two types. This happens the same way in the novel as well. Direct violence can be stopped and controlled and made less influential if we can deal with the other two forms that occur invisibly.

Rasheed's mistreatment of Mariam is facilitated by the fact that he considered her as an illegitimate human being and that no laws or people were around to support her. From her childhood, she is psychologically conditioned through the presence of structural violence to submit herself to future acts, such as being beaten by her husband - which is a case of direct violence. Cultural violence can also play a significant role in preventing direct violence, but only if members of society resist the structural violence. A case in point would be if Jalil, his wives, or the Mullah had tried to stop an underage girl from getting married to a man three times her age. When structural violence prevails, followed by the invisible steps of cultural violence, the 
visible manifestation of direct violence becomes a greater possibility and even expected to a certain extent.

As this novel has shown, fictional works test within a narrative environment and well demonstrate theories that are mostly adapted in nonfictional contexts. The reader can see more directly and explicitly how violence theory and its consequences work in various fictional situations, which may be used in an educational context to raise awareness of the negative outcomes of violence and how to treat and deal with it. Analyzing this fictional work by adapting a theory in the field of conflict and peace would lead to a generally clearer understanding of the meaning creation process of the fictional work and help the reader better comprehend the novel. 


\title{
4. Traumatic Experiences and the Narration of Violence in The Kite Runner
}

\author{
"Some stories don't need telling." \\ - Khaled Hosseini, The Kite Runner
}

"There are a lot of children in Afghanistan, but little childhood."

- Khaled Hosseini, The Kite Runner

The onset of obvious ethnic hierarchy in Afghanistan, violence is a central theme represented in Khaled Hosseini's The Kite Runner. As Hosseini mentioned, the concern related to violence is peripheral, but it is rooted in its social, political, and economic spheres. The represented violence manifests the novel's other hidden issues, either "unnarrated" or "disnarrated." There is a significant amount of hidden knowledge, and the narrator shows what happens and what does not happen in the narrative. A key element causing violence is the traumatic experiences of the narrator. Amir's bildungsroman creates a sense of belongingness; the past continues haunting him until the end of the story, which is evident from his explanation of the sight of the terrible incident he narrates as, "just watched everything, paralyzed" (Hosseini 2003, 69). The story itself presents a healing method from trauma by talking and sharing the stories with the close and beloved ones; Soraya, Amir's wife, is an example who narrates her story to her husband as well as listening to his stories, and this leads to a healing process from their long continuing traumatic experiences.

Personal traumas are influencing the development of the narrative, but collective trauma affects the characters and events. Sarah O'Brien $(2018,4)$ claims that Hosseini deploys “Afghanistan's national trauma" by using the character of Hassan framing his "rape and its resultant trauma as an allegory for the turmoil engulfing Afghanistan following a coup in 1973 which toppled the monarchy and precipitated decades of political uncertainty, starting with a communist takeover and the invasion of Russian forces in 1979." Both Hassan and Amir's traumatic experiences and the other characters, which are the results of war, sectarian and religious conflicts, show the collective trauma that none of the Afghanis could avoid. The traumas do not remain harmless; they progress into invisible violent actions, transforming into the visible ones of which 
abolishing becomes unimaginable. According to David Jefferess $(2009,390)$, "there has been diverse approaches to interpreting the novel - as ethnography, coming-of-age narrative, and/or morality tale" and "the text's apparent humanizing function reflects current theories of a cosmopolitan ethics." The novel can be received as a semi-reliable text for the readers to understand the history of Afghanistan and the structural establishment of social, cultural, and religious aspects of the country. Nevertheless, the novel is undoubtedly a fictionalized story, and it should be treated this way, but it can be rather a unique and significant resource to the reader understanding the situation and social structure in Afghanistan.

Amir and Hassan become the main characters of the narrative whose actions influence the developments of their lives. Amir indeed continues struggling even when he is mature with the guilt of not preventing Hassan's rape by Assef, but he "uses storytelling as a healing tool" to recover from the pain of the guilt from his childhood (Nayebpour 2018, 53). Amir realizes that it is a curse that he has to carry throughout his life despite his achievements and distanced geography. However, Hassan becomes a mediator symbolizing the narrator's root issues with his father as he builds the jealousy feeling towards the sympathy of his father to Hassan (Lee 2012, 327). Thus, Amir's storytelling helps him and all the other characters "make sense of themselves, one another, and the world" (Herman 2009, 54). The sense-making process is a critical element of healing from traumatic experience as the characters start to know the reasons behind things that have happened, which may reduce the possible violent actions after that. According to the argument of Ansgar Nünning and Roy Sommer $(2011,220)$, the act of storytelling by Amir is seen "as an important means of characterization, and helps characters to overcome traumatic experiences." If a traumatic experience may cause violent action and suffering, storytelling can help prevent harm to the self and other individuals. Amir's life from thereon has been tormented by guilt and realization. However, it further alienated him from the surroundings, people and Hassan whom he considered near. He yearningly looks around for confidant and hope but ends up seeing "signs of his loyalty, his goddamn unwavering loyalty" (Hosseini 2003, 83). In Trauma theory, the excessive result of Trauma happens when the individual is unable to voice out or narrate the incident to others. Amir is devoid of voice and agency here. He lacks control over himself and his mind. 
This novel's narrative style helps the characters shape their past, in other words, to "create the past" (Norrick 2007, 139). The narrator looks back in the past and suffers from all the issues which were the main traumatic events in his life; narrating the life of the narrator is "at once a product and agent of history; the site of experience, memory, storytelling and aesthetic judgment; an agent of knowing as much as of action" (Biehl, Good \& Kleinman 2007, 14). As the narration becomes an inclusive product, the narrator and the characters can use it as a healing tool to heal their traumatic experiences, which caused violence and made everyone suffer. There are depicted scenes that denote the actual occurrence, while others could have happened or did not occur. It is essential to see what had happened, what did not, and the ones that would occur to explore the results.

Literature is not only for our leisure time to please our desires but also for understanding the texts' obvious and hidden meaning. It is also to explore the hidden codes within the used language to analyze the bigger picture related to the reader's life, or the world s/he lives in. Edward Said argues:

Whatever I've done politically has been entirely dependant on the ability to read critically, to be able to understand the uses to which language can be put. And here I mean to refer to the truly vast range of possibilities that language has. I think the only place you can get a sense of this range, and a feeling for these possibilities, is through the study of literature. Because that's what literature in a sense is about. Writing is not only about describing the world, and writing about it realistically, and reporting it [...] (Higgins 2001, 154)

Likewise, literature should be read to be understood and comprehended as a simple text and critically to explore a more in-depth understanding. Besides considering the use of language and the variety of vocabularies, narratological methods have a vital role in critical reading. Therefore it is not enough to see what the narrator represents and what is inherently represented in narration, but the reader has to look for veiled and analyze the reasons for gaps and silences in the text. From the beginning of Marxist criticism, a text has been regarded as a product of social structure. Thus, it becomes impossible to separate it from the social, political, and ideological baggage it accompanies. If we mean to look at a text critically and look for a theme like violence 
to see how it is represented, this is a proper way of doing that as seeing only the represented violence in a text may not be of our intention as much as the reasons behind the root cause of those violent acts. All these provide a form of dialogue, and the text is a healing tool for the narrator and characters, but the reader may find it a medium in solution-seeking for the self.

There are various types of violence represented in The Kite Runner, and this chapter will mainly focus on structural, cultural, and direct violence. Unlike the following chapters, all the types of violence will be explored chronologically from the book rather than categorizing them into three different sections according to the violence triangle. The narrator, Amir, starts his novel describing Hassan with evident and apparent references to structural violence, "his almost perfectly round face, a face like a Chinese doll chiseled from hardwood: his flat, broad nose and slanting" (Hosseini 2003, 3). The narrator attempts to give Hassan a pleasant description and image while unaware that those descriptions violate his humanistic identity. Additionally, many words are used to mock Hazara people like Hassan, located in Afghanistan's specific geography, which could be read later in the novel. Being aware of the marginalization and systemic subjugation of the minority community, the narrator still portrays Hassan's image, which is limited to his appearance and discriminates against the latter based on appearance, caste, and creed. "Chinese doll" is used as a metaphor symbolizing an unimaginable beautiful object identifying a human as it is common to refer to the beauty of someone to a doll to exaggerate the pleasance of appearance. Moreover, using the word "Chinese" is an issue here itself as Hazaras in Afghanistan are considered immigrants outside the country, mainly from China, as they have similar facial features.

Amir sees Hassan as an outsider as well but in a beautiful way, or someone with a pleasing appearance from another geographical region; to the narrator, he is still coming beyond the borders but is pleasant and welcoming due to his appearance. Hassan's "flat, broad nose" becomes another important element mentioned as an excellent symbol to recognize him while he/other Hazaras are mocked by having such a shaped organ. The narrator makes this division and identifies people from such an ethnicity, and maybe he legitimizes them by picturing their appearance to identify them but eventually, this becomes a discriminatory form. On the other hand, the narrator may have portrayed them to stand against all the norms and other characters who mocked Hazaras with those outstanding features. He starts the narration like an activist 
supporting and backing the Hazaras through a symbolized character representing all the Hazaras. The second argument remains stronger as the narrator is seeking healing from his traumatic experiences and the guilt against his old friend, Hassan. While illustrating the community's physical features, the narrator has failed to analyze the character's personality, who is very close to him. A Hazara male character's physicality dominates the narrator's descriptions as he aims to stand against all the negative descriptions made by the Pashtun characters to show that what is known and told to be ugly is indeed beautiful and outstanding. Amir disnarrates Hassan's personality as for him the appearance comes first; the narrator may have tried to deconstruct the established perceptions of the majority community towards the latter; the Pashtuns towards the Hazaras. The disnarrated information is essential in formulating the story, and it is necessary in developing the events in the story (Prince 1982, 147). Thus, the narrator should focus on Hassan's personality, not only prioritizing his appearance.

The narrator fails to process the traumatic event and years for his father's attention, which becomes the major obstacle for him. Most of the time, Amir, who remains in solitude, exhibits jealousy, which pressurizes him too long for his father's complete attention. Moreover, as a child, he needed his father's attention and wanted to spend time with him. Nevertheless, his father, Baba, seems not that keen to take full parental responsibilities for various reasons. A primary reason is that his beloved wife died giving birth to Amir, which leaves Baba in deep pain. Although he does not state that Amir is the reason for the death, Amir senses this and believes in it. Another reason is Amir's characteristics, which do not meet Baba's expectation, while Hassan is more the one whom Baba may imagine as a preferred son. Amir states:

Sometimes I asked Baba if I could sit with them, but Baba would stand in the doorway. "Go on, now," he'd say. "This is grown-ups' time. Why don't you go read one of those books of yours?" He'd close the door, leave me to wonder why it was always grown-ups' time with him. I'd sit by the door, knees drawn to my chest. Sometimes I sat there for an hour, sometimes two, listening to their laughter, their chatter. (Hosseini 2003, 4-5)

The narrator clearly states that Baba has time for everything except him. Baba underestimates Amir's needs as a child who should be cared for and communicated. The deep sense of alienation and longing for care makes Amir grow hate towards anyone who receives Baba's 
attention, especially Hassan. Baba always has an excuse to ignore Amir, and "grown-ups' time" is a good excuse metaphorizing Baba's neglecting and ignorance characteristic. The phrase "go now" shows the silenced, the bitter truth that there exists no healthy relationship between a father and his son. Amir's basic needs remain unachieved; the attention and warmth of a parent. It lacks throughout the relationship, and Amir is aware that there is a barrier for that; he concludes that Hassan is the barrier while considering all the other possible reasons that seemed unimportant. This direct violence from a father towards his son leads to the creation of traumatic memories in Amir's mind, and this will negatively assist his already established hatred and jealously, more precisely, towards Hassan.

Facial and physical description as a form of structural violence is standard in the narration. Ali's wife is described (Hosseini 2003, 7), "Like Ali, she was a Shi'a Muslim and an ethnic Hazara [...] brilliant green eyes and impish face had, rumor has it, tempted men into countless sin." Her description cannot be categorized as structural violence alone, but her femininity and beauty are represented to form structural violence. Sanaubar is accused of "tempting" the other men into sin, and men get away with no accusation. If there is a sin, then all the involved parties are responsible for what has been done. Thus, the narrator discriminates against the genders here and writes nothing about the male characters' role in this situation. He unnarrates their role in those fairs and relationships, which is done to drag the reader into the debates of this issue as in the Afghan community, a beautiful uncovered woman is responsible for sexual attraction. This leads to direct violent incidents following the words of a soldier to Hassan (Hosseini 2003, 7), "I knew your mother, did you know that? I knew her real good. I took her from behind by that creek over there." A child who barely understands sexuality is being tormented by the words of the soldier. He is a believer who would have placed at most importance on the women's honour and pride, or more at least his mother. The soldier represents the wider community, not just Afghan, but any other community rooted in systemic misogyny and patriarchy. Furthermore, this scene manifests the other soldiers' silence around him who commit cultural violence by watching only without preventing structural and direct violence. The narrator shows this through disnarration as the reader can see what is not happening "What a tight little sugary cunt she had!", the soldier was saying, shaking hands with the others, grinning" (Hosseini 2003, 7). 
Nevertheless, the narrator chooses to be silent as he does in the following scenes. Silence in fiction portrays the inequalities, interactions, and hidden beliefs and ideologies of any society. We conceptualize silence, and empathy plays a significant role in how writers portray these themes' intersections. However, he was only a child at this stage, and it is not very proper to criticize him. He now narrates the past stories to show us what happened and what did not happen. Ali is a figure who represents the less privileged Hazaras in Afghanistan and the disabled and people with special needs: Ali has a disability of limping. He is chased on the streets by the children, "Hey, Babalu, who did you eat today?" (Hosseini 2003, 8). Babalu, boogeyman, is the Persian word used to metaphorize a man who is scared of his appearance and fear that this man might harm them. The depiction is not merely categorizing people into healthy and unhealthy sects, and it is instead structural violence towards the power distribution among the people. The children would not be able to do this to Baba if he had the same health condition and appearance as more powerful ethnically and financially than Ali.

The nose's shape becomes a symbol of oppression here again, and it symbolizes the less powerful people, "flat-nosed Babalu" (Hosseini 2003, 7). The narrator becomes a witness confirming the discrimination towards the Hazaras, and he informs the reader that he has been reading about the long ongoing issue. Amir notifies the reader about what happened in the past, and he mentions it as "unspeakable violence" (Hosseini 2003, 9) to show the severity of the acts Pashtuns undertake. "Afghanistan's national trauma" is represented through the references of the incidents that happened in the past (O'Brien 2018,4). When he attempts to further investigate information from the book, he is surprised by his teacher, who commits cultural violence stating, "that's the one thing Shi'a people do well" (Hosseini 2003, 9) to deny the books presented information that Pashtuns has never oppressed the Hazaras. The narrator shows the reader that the entire system has collapsed, mainly the educational sector, and cannot help the less privileged people seek their human and citizen rights. The collapse is shown through an ironic speech of a teacher who denies the books' information that indirectly rejects ethnicity's suffering with minority status. The teacher could criticize the book, the author, or the information, but he chooses to generalize his statement and make it inclusive to all Shi'a people to claim that they have been misled and have not been oppressed by the Pashtuns. 
Hassan's characterization illustrates the suffering Hazara oppressed by Pashtuns, more importantly, represents unlucky human suffering most of the time. He not only faces violence from people of different ethnicities and beliefs, but his mother does not even desire him. Sanaubar rejects Hassan when she gives him birth "Now you have your own idiot child to do all your smiling for you!" She had refused even to hold Hassan, and just five days later, she was gone" (Hosseini 2003, 10). The narrator unnarrates the mother's situation and details, even at the end of the narration when she returns. This is an "antinarratable" mode of narration as the narrator avoids narrating a woman who has acted against the social codes as she had an illegitimate relationship. Following that, she runs away with a gipsy group following giving birth to her son. Sanaubar remains a minor character in the story; she is neither supported nor criticized. She is one of those females being victims of double marginalization due to her gender and ethnicity. Here, she is misrepresented while denying her child, which is not a mother's right image. The author conveniently ignores the plight of a woman character whose trauma would have been undeniably massive.

Meanwhile, the narrator leaves all the reader's thoughts to imagine her while she is a victim herself. She is a woman who is recognized with no power in the community, and she roles a submissive person. Sanaubar is not consulted for anything that happens in her life; she is rather only seen as a tool to serve, give birth and meet the sexual desires of the male characters. The narrator cannot escape from his social and cultural background by ignoring this female's details to let the reader have a proper image of her. This example contradicts Herman's argument as Sanaubar is a character who has not been given enough space and opportunity to express herself. The females' restricted representation leaves doubts for the readers, in Hosseini's case being mostly western, to reinstate the idea of Muslim females as religiously oppressed. The reader may rather criticize her as an ignorant mother for not holding her child even once, but various reasons are traumatizing her to deny all the imagined, and expected behaviors from a human, especially the behaviors a mother is expected to have. Sanaubar does towards her child direct violence by avoiding him not knowing the future while a mother has to be with her child regardless of the unwanted circumstances. In silencing her part of the story, the narrator aligns himself with the patriarchy perpetrators, the powerful and unjust. As a result, the reader, who cannot read 
between the lines and question the gap, will wrongfully blame a victim while she herself is the victim of the various structures and the characters.

Corruption is always a familiar act in developing countries, and it is represented in Hosseini's novels as dangerous and necessary for good deeds. Whenever goodwill is aimed at, some corruption may assist even a charity project "mustaches needed oiling" (Hosseini 2003, 13). Here, this phrase is used as a metaphor to divide people into two groups; the one who receives the bribe and offers it. The division itself is a clear act of structural violence as the entire process is based on an unfair, illegal process. Bribing as an act of structural violence leads to unfair division and gain among the community's individuals and improperly develops a system functioning. Starting bribery is a point, but continuing that and staying silent against it is cultural violence. Rahim Khan confesses the bribery and states that Baba has no other way to build an orphanage.

Baba is a secular character who is always against religious people because they control society and dominate each individual's thoughts. It is not apparent when he tells Amir, "Piss on the beards of all those self-righteous monkeys" (16). The word "beards" here symbolizes a group of people practicing a certain religious sectarian, and Baba is against their ideologies as they categorize everyone into two groups, religious and secular- the latter always immoral and sinful. Baba commits structural violence against them by using offensive words towards them, especially in front of his only child. On the other hand, his inappropriate words predict the unpleasant future by those people he mentions, "God help us all if Afghanistan ever falls into their hands" (16). This is one of the narrative scenes as an example that can be analyzed according to the previously explained extended parallel process model and protection motivation theory (Witte 1992; Rogers 1975); they are both methods defining violence as an act of fear. Towards the end of the novel, the reader sees that Afghanistan is controlled by the Taliban, mentioned by Baba as "self-righteous monkeys." Baba is fearful that they will rule the country in an abominable manner if they come to power, and this fear pushes him to be violent against them and use some words that discriminate against someone's human rights and dignity. It is practically impossible to legitimate such acts of violence as a subsequent act of fear as the fear itself might not be legitimate. When the future is shaped by those "self-righteous" people and the scene is visible, it is not easy not to justify Baba's violent action due to his fear, which has the 
absolute right to be feared. Thus, he cannot do anything to stop them from taking further actions and expansion until taking down the country into their autocratic power. In the absence of commonly agreed rules and laws, such situations are highly expected, and the task of differentiating right and wrong becomes even more difficult. Hence, the decision seems easy for Baba, while the narrator has no role here, and he only laughs at the funny thoughts imagining his father urinating on the beards. Moreover, Baba is not a perfect character, or in other words, he violates his responsibilities towards his child, and Amir's fear makes him hate even the orphan children, which is rooted in his fear of not receiving his father's affection properly, "I already hated all the kids he was building orphanage for" (Hosseini 2003, 17).

Baba himself is a victim of the past traumas and had faced many difficulties leaving a deep wound in his psychology to an extent he may even not talk about or seek healing. Baba's weak point keeps all his past and current problems to himself rather than talking about them. Amir as a narrator, instead narrates them to the reader, helping himself overcome his guilt, and it is Rahim Khan tells Amir that a thief killed his father, and then the townspeople caught him and hanged him. This is why Baba thinks that stealing is the most sinful act a man may commit ever, as he always thought his father was stolen from him. He has been traumatized by and grown up with this incident leading him to sprout hate inside towards a negative commitment and seeing it as the most severe issue. The narrator shows how this incident would inspire him in the future when he wants to create a scenario to send Hassan away from their home. A traumatic experience is transferred from one person to another; hence, it should be dealt with if the next generations aim to be raised properly. Its Baba's masculine characteristics built by the social and cultural norms making him a man with some usual specific features who may think that "real men didn't read poetry--and God forbid they should ever write it! Real men--real boys--played soccer just as Baba had when he had been young" (Hosseini 2003, 19). The categorization of real and unreal men violates personal interests and hobbies, leading to structural violence to make people do what they do not want and behave according to someone else's wishes. The narrator represents how Baba is a part of the community and follows most of the agreed codes, although he criticizes others who are religious. He as well discriminates and has expectations towards others despite their dislike. Through various narrative techniques using the stereotypes Baba owns, the reader can see the human domination in the absence of proper agreed common knowledge and codes 
that anyone can hegemonize the life and think of others. The narrator criticizes this by showing us, and he offers a more acceptable attitude towards greater individual freedom.

Amir is aware that traumas are never healed to an absolute level, and the history cannot be changed, "history isn't easy to overcome. Neither is religion. In the end, I was a Pashtun, and he was a Hazara, I was Sunni, and he was Shi'a, and nothing was ever going to change that. Nothing" (Hosseini 2003, 24). Besides being aware of the long-lasting traumas, he still uses storytelling, even partially, as a method to heal from his past traumas (Nayebpour 2018, 53). The narrator reaffirms the structural violence, but he becomes a part of the act through the cultural violence by accepting the situation as a fact; no one can change that. Sunni and Shi'a become the symbols projecting the extreme ongoing violence among the people of the same country. Religious dispute and sect-based differences of the Pashtuns and Hazaras are a primary reason for the conflict, which transformed into new interpretations involving facial and physical discriminations. This shows that the historical traumas and incidents last longer than expected, and they are passed to the next generation, which cannot be dealt with efficiently. The next generations can do as a former step to accept what has they have inherited from the past, which becomes an act of cultural violence as something should be done to correct past mistakes. Likewise, the narrator represents a shared sense of acceptance towards the things that are difficult to be changed and the narrator himself becomes a figure representing cultural violence as he believes history and religion are concrete elements in the life of the characters and cannot be changed or resisted. Amir has a choice to teach Hassan how to read and write, but he makes no attempt to change the imposed structural violence, "a voice, cold and dark, suddenly whispered in my ear, what does he know, that illiterate Hazara? He'll never be anything but a cook. How dare he criticize you?" (Hosseini 2003, 32). "Illiterate" is a metaphor describing Hassan as a Hazara, and if a character owns that feature, not educated, s/he should not be allowed to criticize. Criticism is a right that brings equal rights to all humans, regardless of gender, race, identity, and religion. This term's usage and prohibiting it from someone is evidence of existing unequal rights, which manifests structural violence. The narrator has jealousy towards Hassan regarding sharing Baba. However, it is also the cultural and social codes tempting him sometimes to discriminate a Hazara as he sees himself as a superior human due to his education Pashtun identity, although it is less considered. Amir is only a child; it can 
be difficult for him to comprehend complicated identical features, but being educated is easy and comprehendible to isolate himself from Hassan as a Hazara and an illiterate person with no formal schooling education.

Assef is the character representing the oppressor group of Afghanistan, especially the majority of Pashtuns against Hazaras. Although he is half German from his maternal side, his blue eyes are a clear symbol of his outstanding feature in the community, and he still considers himself a real citizen of the country as a Pashtun. He keeps this claim that Pashtuns are the only owners of Afghanistan:

Afghanistan is the land of Pashtuns. It always has been, always will be. We are the true Afghans, the pure Afghans, not this Flat-Nose here. His people pollute our homeland, our watan. They dirty our blood." He made a sweeping, grandiose gesture with his hands. “Afghanistan for Pashtuns, I say. That's my vision." (38)

He signals an endless conflict in the future, starting from the past to the present, and will continue for future generations. The purity of citizens is argued to divide people and those who own the land while the others are only outsiders. The use of Persian words in the narrative makes strong emotional connections to the readers, and her patriotic feelings of Assef is revealed through the use of "watan," homeland, and the seriousness of the character becomes more evident to the reader. "Flat-Nose" remains the distinguished birth sign to identify the Hazaras, and they are mocked and insulted using this term instead of being identified. Assef further argues that he quotes Nazi Leader Adolf Hitler "Too late for Hitler," he said. "But not for us" (Hosseini 2003, 38). The claim of becoming better than Hitler shows his seriousness about the topic. The narrator here disnarrates his mother and the way Assef has been raised. The reader is not told about his mother directly, but through the thoughts of her son, the reader can realize that his mother blames the leader of her country that he could not accomplish a task which she desired, and she would teach this to her son to make the necessary comparisons between the two countries, Germany and Afghanistan. Assef does not show his seriousness only through quoting others and his words, but he willingly states that he wants to make the decision-makers do what he believes in, "I'll ask the president to do what the king didn't have the quwat to do. To rid Afghanistan of all the dirty, kasseef Hazaras" (Hosseini 2003, 38). According to him, the king 
was weak to do what was supposed to be done; the act of asking the president manifests Assef's power and prepares the reader for a deeper conflict towards the climax and falling action of the narration towards the denouement. This speech is a piece of evidence showing that the new president shares a similar ideology with Assef, and this gives the character the confidence to state that he will tell him about his visions even though if the narrator does not tell the reader through unnarration about the vision of the new president.

Direct violence, primarily psychological, becomes very brutal in the narration, but through the model of disnarration, the reader is shown what does not happen. One purpose of that is to prevent the reader from feeling sympathetic excessively, but also sometimes, what is not happening is a part of testing the loyalty of the characters towards each other. When Hassan informs Amir that he would do whatever he may ask and Amir responds, "Really? You'd do that?" (Hosseini 2003, 50). The loyalty of Hassan is attempted to be tested by Amir by asking him if he would eat mud in case of asking him, and he is surprised by the answer that he would do it so if he receives such a request from Amir. The narrator's question shows the reader what is not intended to happen while it is just a reaffirmation statement, and this statement assures the reader that the narrator would not ask him to do such a brutal act. Hence, disnarration here is a violent act itself as imagining such a thing is violence as it shows the inequality in sharing the power between the individuals. It is worth mentioning that the power is distributed based on owning social position or financial means, but Hassan does everything for Amir as an act of respect and pure love as he has no fear against Assef, who seems to be even more powerful than Amir. Hassan is a mirror to Amir's personality, symbolizing some of the issues and disorders in his personality and behaviors (Lee 2012, 327).

Running the kite as competition turns to violent action, especially when Amir's ambition to win grows to attract his father's intention. Baba's lack of attention towards his son is one of the central and original issues leading to more significant problems that result in severe violent acts. Amir aims to win the kite running tournament because he wants to "show him once and for all that his son was worthy" (Hosseini 2003, 52). The feeling of worthlessness in his father's eyes pushes Amir to do everything to get fatherly attention, which will make him make the wrong decisions. As competition and attempt to get his father's attention, he is not aware of others' pain who may feel due to that. Hassan is willing to do anything for Amir, and when he sees his desire 
and passion for winning the tournament, he forgets about all the pains and the price he should pay to make him win, "his hands already bloodied by the string" (60). The narrator represents a different form of violence committed against self due to the ambition of someone of whom a character submits to his/her wills. It is common to leave a string when pain is involved, but if it is a matter of urgency and significance, a character may tolerate all the pain and not abandon it. This is what happens to Hassan as he forgets about himself, knowing all capabilities; he even ignores the blood, which is a sign of violence. Even Amir sees the blood and chooses to remain silent against that violence that Hassan commits against himself to please him. The narrator here shows the kite running as an extreme and violent activity rather than a tournament as it becomes the reason for pain for some characters. How the author narrates the incident is a disnarration technique indirectly stating that he does not stop the violence as he can only think about winning to impress his father while he observes the entire situation seeing Hassan's bloody hands.

The represented direct violence is not the result of the structural violence, but instead the direct outcome of the cultural violence as most of the time, many characters rather accept or ignore what happens around them. There are very few incidents in which some characters try to prevent direct violence, retaliate, or are against the entire process to make violence. Hassan is chased by Assef now, and he tries to take revenge from him due to the previously discussed structural differences, which will lead to direct violence. Hence other characters can prevent it, but they all remain ignorant, for example, an old man Amir asks if he has seen Hassan, and he replies while he knows that he was chased, "Of course, they've probably caught him by now" (Hosseini 2003, 66) and he states, "Lucky Hazara, having such a concerned master. His father should get on his knees, sweep the dust at your feet with his eyelashes" (66). It is usual for the older man if Pashtuns chase a Hazara boy, and the violent action is not prevented as he believes that he is not worth being concerned about. When there is a concern, especially from a master, the Hazaras should see it for granted. More about the man's identity is narrated while he tells Amir, "you're making me late for namaz" (66). The act of praying shows the religious identity of the man, and according to his religion, he is taught to help people in need and the weak, but the national identity creating hate towards Hazaras overcomes the religious identity. It is not the man only, but everyone, including the narrator, remains observant, "Wali was standing on one side, Kamal on the other, and in the middle, Assef' (67). Wali and Kamal represent the other Pashtun 
individuals in the community who accept what influential people like Assef tell them and do not attempt to prevent direct violence. They act as a mediator in transforming the violence from the structural stage into the direct one. This is the act that traumatizes the narrator the most, and his silence remains his main enemy forever. If the silence traumatizes him, then breaking that silence is a healing method to overcome his guilt; moreover, writing narrations becomes the medium to help him overcome his psychological issues.

All the previously discussed violent acts, especially structural violence, are the causes of the narration's major traumatic incident. Hassan's rape will be the original trauma to the narrator, who cannot overcome until the far future when he can get healed to some extent. The rape scene is not a sudden incident, but this scene becomes unavoidable after a chain of events. Assef now has Hassan alone and weak, "A loyal Hazara. Loyal as a dog" (68). Being Hazara is a problem for the minority in the community, but being loyal is more problematic as he is targeted as a traitor as such people commit treason against the Hazaras and the Pashtuns. Being loyal means submission to the Pashtuns, and this means an end to the ongoing conflict. Furthermore, there should not be any loyalty, and the conflict must let people like Assef stay in power. A dog is an inhuman metaphor represented to show the value of Hazaras as Pashtuns dehumanize them. As stated before, the narrative style helps the characters create their past (Norrick 2007, 139).

As previously mentioned, all Pashtuns are involved in cultural violence, although the narrator tries to exclude himself, "I opened my mouth, almost said something. Almost. The rest of my life might have turned out differently if I had. But I didn't. I just watched. Paralyzed" (Hosseini 2003, 69). Those are the words used to disnarrate the violence prevention did not occur while the narrator himself confirms that everything would be different if he only talked. However, he instead "bit on my fist. Shut my eyes" (69). Amir unnarrates the same scene and rape by closing his eyes, and this is an antinarratable act as it goes against all the Afghan social and cultural norms. In the country, the rape of a woman can be explainable, while the rape of a male character is unimaginable and unspeakable.

On the one hand, it is a clear gender violation towards the characters, while the women characters are more publicized. On the other hand, sex outside the marriage structure itself is taboo in the country, and this is more arguable that the narrator unnarrates the details of the 
scene, fearing the reader's reception. Hence, Amir himself is in the USA, and he writes mainly for the American citizens, but it seems he still carries the social and cultural codes he has been brought up with within the Afghan community in the diaspora.

Moreover, Amir is a Pashtun, and he may limit the sympathy of the reader towards Hassan as his past traumatic experience may still keep this jealousy, and he may try to protect himself from the reader's anger. Without the existence of unnarration and disnarration here, the reader may have a very different view and reception towards the rape of a child by a teenager. Despite all of these, Amir is only a child-like Hassan, when this incident happens, but he is an adult when the narration is narrated. Thus, his narration can be criticized so that he tries to hide details from the reader, and this is direct violence committed against Hassan that the reader cannot observe the same pain he witnessed.

The narrator conflicts with himself, and his unconsciousness tells him something different from his conscious mind. The signals are received to his conscious that "he was just a Hazara, wasn't he?" (Hosseini 2003, 73). His depth thoughts and teachings direct him to ignore a Hazara as he is not worth protecting or defending. The narrator disnarrates the entire rape scene through a question he directs to Hassan, "where were you? I looked for you" (73). This statement shows an outright lie, but it also represents an absolute ignorant system towards Hazaras. It is shown that they are not discriminated against, but the Hazaras who do not belong to Afghanistan are considered invisible; Pashtuns are always unaware of them and do not see their struggles. Along all that happens, the narrator does all these while he is only a child, and he cannot realize what is right and what is wrong. The only thing Amir needs is attention from his father, and finally, he gets that, but Hassan has to pay the entire price for that, "I buried my face in the warmth of his chest and wept. Baba held me close to him, rocking me back and forth. In his arms, I forgot what I'd done. And that was good" (Hosseini 2003, 74). Indeed, he forgets all the past undesired deeds following achieving the desired result, and the narrator disnarrates the indirect involvement of Baba in the violence against Hassan. Maybe it is not the duty and task of a child to understand the structure of the violence, but it is Baba's responsibility as an adult to know his obligations as a father towards his son to give him enough care and love. Amir concludes the rape scene with a warm hug from his father, explaining the entire story since he struggled, regardless of all the other represented violence in the narration. 
Cultural violence becomes dangerous when it continues through time, and the individuals remain silent towards direct and structural violence. The danger is in the repetition, and the same issues may occur as there are not prevented and solved from the roots. The narration is structured in a way that shows the reader that the continuation and developments are dangerous. Assef, who will be a Taliban leader committing many crimes, including stoning a couple in front of thousands' eyes, is the same person. He is not stopped as a child when he commits a crime against others, and he then becomes an adult when no one desires to see him. Ali asks Amir if he knows anything about Hassan's situation as he sees him returning home with blood on his clothes, but Amir's responds, "how should I know?" (Hosseini 2003, 76). The narrator mainly represents the realities, and most of the time, he does not try to defend himself. Here, the reader can take the narrated stories as reliable as they could easily omit those details to portray himself as a better character. Nevertheless, the reader can assure his ignorance as an act of cultural violence while remaining silent. It seems Amir's only aim is to have his father solely for himself, and the ultimate aim would be sending Hassan away. Baba is one of the rare characters in the narration who mainly does not become a part of the cultural violence. Baba states that "Hassan and Amir ran it together" when he tells his relatives about the kite running tournament. Thus, Amir is more jealous, as he does not want anyone else to share his success. The narrator admits that he has seen the rape scene and told no one, "I watched Hassan get raped" (80). Thus, he did not close his eyes, and he chooses to remain ignorant to become a part of the cultural violence. Hence, he only admits this to himself, and he is aware of hiding something crucial. The hiding act becomes a more traumatic situation for him in addition to watching the rape scene.

The narrator's trauma grows only by facing Hassan's silence as he does not resist or react while he is aware of what the former has done. Amir could have felt relieved if Hassan reacts as he hits him and asks him, "hit me back! [...] get up! Hit me!" (Hosseini 2003, 86). In response, Hassan hits himself with a pomegranate, which puts Amir in a more profound sadness while he sees Hassan's loyalty and becomes hopeless about receiving anything negative as a response towards his evil deeds causing endless trauma. Hassan's self-hitting by a pomegranate is disnarration showing the reader that he will not react no matter what Amir does. The narrator uses this narrative method to assure the reader about Hassan's loyalty towards his master, Amir. 
Disnarration in The Kite Runner shows what does not happen, but it is also a matter of relief and escape from severe psychological pain. During Amir's birthday, there are fireworks, and that is the time when Hassan serves the guests, including Assef; as an effect of the firework, the lightening go bright and dark, and a statement by the narrator draws the readers' intention, "then, mercifully, darkness" (93). The use of the darkness is a disnarration act that helps the narrator go blind, both physical and metaphorical. He is aware that the darkness is the only way to partially get relief from all the pain he has as he can do nothing else. It is difficult for him to see the person who has saved him is serving someone he is hurt by the most, and the narrator can do nothing to stop that. Like the scene of rape, it is the easiest for him to see none of the scenes by his eyes. At that time, he could hold his eyes for some time. This time, he owes to the darkness that he can temporarily go blind for some time to make the scene less dramatic. The narrator reaches a point that invisibility is the only and best option for him while he is not aware that all those invisibility will come back and haunt him all his life. Invisibility makes the visible come back to the narrator in the form of a traumatic experience that awakens him about all the past incidents. In other words, the narrator has to face the visible incidents that he once chose to see as invisible and hidden, and they are the source of the invisible incident of the present time. At the time, he seeks a temporary relief and finds it through disnarration; "darkness" is an excellent feature to reveal this narrative technique to make what happens and does not happen; or in other words, to make the visible, invisible. All those show unfairness in the power distribution in which the suppressed has still to serve the oppressor, and it is an apparent existence of structural violence as well as the presence of cultural violence which is manifested through disnarration to make the oppressed vanish as a relieve act to the more powerful, not the oppressed. Darkness can be closely read with silence in this context, both of which take away the narration's clarity and a product of the narrator's ignorance. Thus, the oppressor is vanishing in the narrator's eyes, but his aim is more the oppressed as an act of feeling pity and having sympathy for him.

The war crime starts to be represented from the middle of the narration, and it becomes a part of the climax; it continues towards the denouement through the falling action. Those are all the outcomes of the war, including the sign signaling emergence of the Taliban. Women are seen as the honour of men in Afghan society, pushing men to act overprotective. Following the Soviet invasion, the narrator and his father flee Afghanistan and soldiers stop them at a checkpoint. The 
soldier's request to a married woman with her babe and husband trying to flee the country, "the soldier wanted a half-hour with the lady in the back of the truck" (Hosseini 2003, 106), is structural violence. The soldier represents the party in power, and the woman is the struggling Afghan society during wartime. There is no reference for being Pashtun or Hazara as all the Afghans here are treated equally by the invader during wartime. This is evidence representing all the citizens' equality during hard times, but it also shows that unfair power distribution has a primary role in discriminating individual rights. The driver is an Afghan, and like everyone, he says nothing due to fear from the soldier who holds the gun and represents the absolute power in the scene. Almost they are all involved in cultural violence act as they do not react even if they disagree with the soldier's act, but they remain silent; their excuse for their silence is the soldier's gun. Systemic violence creates spaces for oppression, not just using power, but more importantly, making use of objects of power; here a gun, the narrator himself is silent, but here he creates a hero and shows the reader that not everyone is involved in cultural violence. This also manifests that direct violence can be prevented by stopping structural violence and not letting it transform into direct violence through cultural violence. At a hopeless moment of the tears by the woman and her husband, Baba stands up and denies the act; when the soldier threatens him by shooting, "Tell him I'll take a thousand of his bullets before I let this indecency take place" (107). Baba's attitude rejects all the possible excuses made not to prevent violence. He also proves the possibility of violence prevention if there are a will and courage; Baba's brave attitude towards the soldier protects the woman from being raped, and "a thousand of his bullets" shows Baba's seriousness in stopping the violence even if it costs his own life. This storytelling act helps the narrator overcome past traumatic experiences (Nünning and Sommer 2011, 220).

Making an excuse for an act of violence is a violent act itself. Following all the these between the solider and other characters, the Russian officer arrives and prevents any undesired conclusion, but he still makes an excuse for the violent act of the armed man, "they are just boys, and when they come here, they find the pleasure of drug" (Hosseini 2003, 108). It is not the soldier who is to be blamed or to be sent for a discipline committee, but the commander's excuse is a drug that influences the soldiers to commit violent acts. The narrator represents violence like a chain where one step is responsible for another move to build a continual violence circle. 
Moreover, it is the narrator's direct violence, but all the other hidden steps of violence are manifested through linguistic and narratological elements. Not only that, violence is sometimes represented as a necessary action to bring justice or protect others. When the smuggler makes the people wait in bad conditions, and they may get stuck, Baba wraps his hands around the neck of the smuggler, and when he is told, "put him down, Agha, you're killing him" (109), and he responds "it's what I intend to do" (Hosseini 2003, 109). Baba has no choice, and there is not any legal system present to protect the civilians. The smuggler took his money, and he aims to leave them all to fate; Baba here steps up again to take the role of law and legal system to protect the civilians. Violence is not always harmful; it is indeed sometimes needed when there is no other option to keep justice.

In The Kite Runner, there is a balance of violence committed against both male and female characters. So, it is not a narration to be considered a story of mainly male or female struggle. Hence, the represented violence in various, especially when it comes to gender, is relative to the Afghan culture and society. Soraya, the narrator's wife, history remains with her, affecting her reputation in the USA's small Afghan community. Cultural and social codes accompany the characters wherever they go, and they continue to suffer. Hence, specific types of violence are found somewhere that may not exist in another setting. The narrator shows that setting is not essential for certain people who grew up in a specific backdrop like Afghanistan; being in the USA does not change much. Baba tells Amir, "all I've heard is that there was a man once, and things ... didn't go well" (131). The broken sentence represents a situation that is against the Afghan norms that are antinarratable. For a woman, it is taboo to be with a man out of marriage structure while for the men, it is not a problem as far as it is hidden, or in the western countries, it is no problem at all as far as it is not in a country like the one governed by Taliban as adulterers should be stoned regardless of their genders. When things do not go well with a man, the woman may have "no suitors" (Hosseini 2003, 131). Having no suitors is a sign for a woman who becomes a part of her identity in the community, and she is not desired anymore as she would be considered a dishonoured woman. This is explicit structural violence towards the woman as her rights and life are restricted due to not following certain norms. The issue is ignored not only by Amir but also Baba, which indicates the change of their characteristics and adapting another culture of the country where they live. 
Following what happened before, Baba cannot leave the fundamental norms he had in Afghanistan. Baba tells Amir to remember that about Soraya's father, "the man is a Pashtun to the root. He has nang and namoos" (Hosseini 2003, 134). Being a Pashtun becomes a priority again, while if he was a Hazara, the same words might not have been used. The Persian words are used to state the honour of a man in the Pashtun community, while there are no other references to measure a Pashtun man's honour. Referring a woman to the honour of a man is objectifying the female character, and this is a reference towards the existence of structural violence as a woman is not treated as a free human and is considered a belonging of someone else, more specifically, a male character. The discrimination continues towards female characters:

How did she know? I wondered if her father had told her, maybe she had asked him. I immediately dismissed both scenarios as absurd. Fathers and sons could talk freely about women. But no Afghan girl-no decent and mohtaram Afghan girl, at least-queried her father about a young man. And no father, especially a Pashtun with nang and namoos, would discuss a mojarad with his daughter, not unless the fellow in question was a khastegar, a suitor, who had done the honorable thing and sent his father to knock on the door. (Hosseini 2003, 136)

The narrator cannot escape from the norms he had learned from Afghanistan as a child and the ones he later learned from the USA's Afghani diaspora. He narrates the existence of violence through a clear and straightforward language structure. Amir narrates the social structure of Afghanis and the way they think about gender matters, and his thoughts represent the way that Afghanis consider. If there will be a difference in a son and a daughter's topics to discuss with parents, then a violent structural act breaches into individual rights. Furthermore, the narrator thinks like his father that a Pashtun father should not talk about a man with her daughter if the father considers himself honourable. According to their community, Soraya's father has a valid excuse to stop Amir from communicating with his daughter, "you see, everyone here is a story teller" (Hosseini 2003, 141). It is not Soraya's father directly committing direct violence towards her, but the Afghan community living in the diaspora makes him cautious about some social and cultural codes identified explicitly. Even in the diaspora, where the communication and flirting 
between a male and female can be seen as a regular act and individual freedom, the father is obliged to follow some small community rules.

Following their wedding with Soraya, the narrator disnarrates his past life, which has been lack of sexual activity, "All my life, I'd been around men. That night, I discovered the tenderness of a woman" (158). Not only that, but this statement disnarrates the absence of the mother figure in the life of the narrator. For the first one, socially and religiously, a man and woman cannot have any physical contact without being married to each other. Amir does not mean only a woman with sexual desire, but a woman is used generally, and his mother died while giving birth to him; those reasons both made Amir lack woman tenderness in his life. This narrated feeling disnarrates not only what has happened then, but it instead shows what has not happened in Amir's life when it comes to physical communication with the opposite gender. Here, an internal focalization is observed: the sexual desire, but the more profound emotion and feeling from a female character, especially a motherly one that he has never witnessed. Amir does experience an opposite gender intimacy through his wife and a motherly touch that he never experienced. This experience is different from the one with his father he always had.

The narrator uses the internal focalization technique to show women's pain sometimes due to male domination - the tears of Khanum Taheri, Amir's mother-in-law, evidence the internal focalization. According to his standards as an ex-high ranked military commander, General Taheri remains living on social services assistance rather than working in a position that may degrade him according to his standards. Not only that, but the narrator reveals some private information inside the house that he becomes aware of following getting married to Soraya. Amir tells the reader that General Taheri and "Khanum Taheri had slept in separate rooms for as long as she could remember" (Hosseini 2003, 162) and also Amir learns "that he could be petty, such as when he'd take a bite of the _qurma_his wife placed before him, sigh, and push it away. "I'll make you something else," Khanum Taheri would say, but he'd ignore her, sulk, and eat bread and onion. This made Soraya angry and her mother cry" (162). The act of crying represents the characters' internal focalization, but it manifests direct violence against both female characters due to the male domination in the Afghan society and the Afghan diaspora community. Hence, the narrator has an excuse for that, "the general suffered from blinding migraines that lasted almost a week. When the headaches struck, the general went to his room, 
undressed, turned off the light, locked the door, and didn't come out until the pain subsided" (162). Regardless of the health condition, General Taheri has no right to torture people around him, including his wife and daughter, and his health condition is not a valid excuse as he is different from other people outside his house. Through the internal focalization, the reader can realize the disnarration of what happens inside the house that all the other characters are not aware of.

Life after the Taliban regime does not seem like the prior, and it is just worse and more dangerous for everyone, including the Pashtuns. Amir is back in Pakistan meeting Rahim Khan and asks him if Afghanistan is still as bad as he heard, "Nay, it's worse. Much worse" (183). For Amir, what he was hearing has already been very inconvenient, and knowing that the situation worsened makes him feel pity for the people who live there. The deep division of the groups into two is the main issue according to Rahim Khan when he states, "they don't let you be human" (183); pointing at a skar, Rahim Khan narrates, "I was at a soccer game in Ghazi Stadium in 1998. Kabul against Mazar-i-Sharif, I think, and by the way, the players weren't allowed to wear shorts. Indecent exposure, I guess" (183). The external focalized narrator tells the reader about the community's divisions into two groups, a group following an extreme ideology and an opposite one that is more liberal. The division and different opinions are minor issues, while not letting the latter group practice the fundamental human rights, is representing the main issue as narrated to the reader. The structural violence is followed by cultural violence as no one in the stadium speaks out when, "Anyway, Kabul scored a goal, and the man next to me cheered loudly. Suddenly this young bearded fellow who was patrolling the aisles, eighteen years old at most by the look of him, walked up to me and struck me on the forehead with the butt of his Kalashnikov. 'Do that again and I'll cut out your tongue, you old donkey!'” (Hosseini 2003, $183)$.

Rahim Khan is physically hurt now, and no one around can protect him as the gunman is in absolute power supported by the regime's rules. No one even tries to prevent him by the use of words or any other means of stopping the violence, and this is the scene of which represents cultural violence. The "Kalashnikov" represents the power of the Taliban armed member who can imply the group's rules following an extreme ideology that oppresses anyone who goes against it. It discriminates against the rights, but calling an old man "old donkey" shows that a 
specific extreme ideology can remove all other human and social rules regarding respecting elderly people. Rahim Khan states that clearly, "I was old enough to be his grandfather, and I was sitting there, blood gushing down my face, apologizing to that son of a dog" (183-184). Following structural and cultural violence, direct violence takes place, and Rahim Khan is physically attacked. Calling the armed man "son of a dog" internally focalizes Rahim Khan's hate towards that man be he still has to apologize to him due to the imbalance of power and the absence of modern laws protecting everyone's rights equally. Visualizing the violence through words is an adequate representation mixed with the representations of hate, fear, and extremism.

The violence, either structural or direct, is not committed through the direct involvement of the individuals. Hosseini represents the issue in multi-dimensions that violence exists through different mediums. Land mines are a reason to represent violence through Hassan informs Rahim Khan that Ali and his cousin "had been killed by a land mine two years before" (191), and this is direct violence indirectly committed against them through the land mines used as traps. The ambiguity of the situation declares the target, which is unknown, and the clarity of the purpose makes the violence more brutal and crucial. The narrator shows this incident's unimportance by unnarrating the details as a "subnarratable" narration method. The only reason which can be argued for this is the identity of Ali and his cousin as Hazaras. Underestimating a character or treating different characters unequally is a violent act from the narrator. The narrator loses the reliability as unnarrating such a vital incident increases the chance of telling the untruth, making understatements or exaggerations about the other incidents.

In contrast to this direct violence, Rahim Khan becomes culturally violent, stating, "Is there a more Afghan way of dying, Amir jan?" (Hosseini 2003, 191). Although he is sad about the death, he admits the reality and factuality of the situation that may not be normal, but at least it is usual that people are victimized due to land mines. Hence, he is very inclusive, mentioning everyone, including Hazaras stating "Afghan way of dying." Rahim Khan represents an Afghan citizen who does not discriminate against anyone for their specific identity, including the racial and religious background. The narrator uses an external focalization, mainly when the Hazaras are the scene's characters; if the Pashtun characters were the land mine victims, there would be more details of the incident. Although Hazaras are becoming the victims of land mines, according to Rahim Khan, no other references are detected to argue on that. 
Taliban is represented as a destroyer demolishing anything; they dismantle anything which does not adhere to their rules. Even the kite running becomes an activity controlled by them, "the Taliban banned kite fighting" (Hosseini 2003, 197). This act of abandoning disnarrates the necessary essential individual freedom that each individual should have. Following this abandonment, the reader starts to imagine unimaginable from them, and nothing can surprise anymore. Being accustomed to violence makes the victims and witnesses normalize violence, which may even trigger further violence of earnest intensity. Disnarration helps prepare the reader for more brutal acts by stating that even fundamental rights are discriminated against, and this group can do anything. Following that, the reader is ready to read that; "in 1998, they massacred the Hazaras in Mazar-i-Sharif' (197) as nothing, and no one is safe anymore from the hands of the Taliban. Hassan, one of the most suffering characters representing the Hazaras, in his letter to Amir narrates post-war Afghanistan as a worse place, "in Kabul, fear is everywhere" (200). Hassan unnarrates the past as he sees the current situation worse; for him, old Afghanistan was much safer and more peaceful even as a Hazara regardless of all the suffering, "The savages who rule our watan don't care about human decency" (200). Using the word "watan", homeland, is an internal focalization of which Hassan shows his feeling about Afghanistan. Hassan now has a wife and son he is responsible for; that makes him narrate the new Afghanistan as a worse place, which makes him more scared. Here he narrates a situation consisting of all types of violence, namely structural, cultural, and direct:

... I accompanied Farzana Jan to the bazaar to buy some potatoes and _naan_. She asked the vendor how much the potatoes cost, but he did not hear her, I think he had a deaf ear. So she asked louder and suddenly a young Talib ran over and hit her on the thighs with his wooden stick. He struck her so hard she fell down. He was screaming at her and cursing and saying the Ministry of Vice and Virtue does not allow women to speak loudly. She had a large purple bruise on her leg for days but what could I do except stand and watch my wife get beaten? If I fought, that dog would have surely put a bullet in me, and gladly! Then what would happen to my Sohrab? The streets are full enough already of hungry orphans and every day I thank Allah that I am alive, not because I fear death, but because my wife has a husband and my son is not an orphan. (Hosseini 2003, 200) 
Even a man cannot stand against violence committed against his wife in fear of his child's future. Here, the disnarration technique makes the reader rethink blaming the characters, mostly if people around Rahim Khan were blamed for not supporting him in the stadium. The disnarration shows activities that do not appear in the scene; Hassan is not trying to protect his wife. His son is the reason, as Hassan is sure that he will be killed and his son will be an orphan, knowing that what happens to the orphans in Afghanistan. Disnarration explains Hassan's fears and concerns, which lead to direct violence towards her wife and becomes involved in cultural violence by not reacting.

Furthermore, the Taliban is harsher with Hazaras when their suffering is compared to Pashtuns in the armed group's hands. Regardless of the ideological difference between the Taliban and most Afghanis, Hazaras were in lower levels as they are seen as unfaithful people. Following being settled in the old house of Baba, Hassan and his wife are chased at the house by Taliban armed men stating that they had no right to live in the house, "The Talibs said he was a liar and a thief like all Hazaras and ordered him to get his family out of the house by sundown" (202). It is not only Hassan but all the Hazaras who are considered as dishonest people who do not tell the truth, although he tries to explain that Rahim Khan is away and they are the savants of the house. On the spot, the armed men of the Taliban are the law and the judge with no valid legal system except the oral ones implemented by the extremist group. The violent act of Taliban members in this scene is described as 'wolves looking at a flock of sheep' (Hosseini 2003, 200). The used metaphor states the violence and the status of power and greed. When the wolves look at the sheep, there is no escape from violence, which means the sheep's end. The quote signals the end of Hassan and his wife altogether. The violence is legalized and validated as "they told Hassan they would be moving in to supposedly keep it safe" (200) until Rahim Khan's return. Waiting for the return of the Pashtun shows mistrust of the Taliban in Hazaras. The scene manifests the inequality even among the oppressed people as a group is more marginalized than the other. Besides the oppressor, an oppressed group remains silent to the oppression towards the other oppressed group, "towards No one said a word about it. Most of it was fear of the Taliban, I think. But no one was going to risk anything for a pair of Hazara servants" (203). Hassan and his wife are Hazaras and servants, which pushes people to not risk anything by standing up to 
protect them. Being Hazara and servant is a disnarration that stops the people from being against the Taliban armed men and preventing them from murdering the husband and wife.

The availability of resources to individuals is another sign of the presence of violence. The family Amir meets on in Pakistan invites him to their house, "I'm sorry we can't offer you meat," Wahid said. "Only the Taliban can afford meat now" (Hosseini 2003, 220). Not affording meat is the disnarration of the absence of equality in the country in the Taliban's hands. Furthermore, meat is a metaphor representing the rich and powerful group. This is another example of internal focalization when the narrator is invited to the house and witnesses the situation. The internal focalization gives a detailed and reliable account of the situation making the reader get engaged in the story more. The lack of food also represents structural violence as the entire community is divided into two groups: rich and poor. The driver who transports Amir to Afghanistan tells him, "No shortage of police in this city But you won't find kites or kite shops on Jadeh Maywand or anywhere else in Kabul. Those days are over" (226). Here, the word "police" does not represent the guards of law as used, but rather the Taliban's armed men. They act like police now, and they are considered the guards regardless of whether people agree or disagree. There are absences of things like kite and kite shops, which is vital for the Afghans. Kite and kite running represent the leisure time of the people as well as showing their borderless ambitions. Kite running is an activity that crosses many limits, and it has more freedom than all the other activities, which becomes a symbol for the Afghans, symbolizing their thirst for freedom.

Cultural violence is a symbol of powerlessness in many parts of the narrative. When Amir tries to find Sohrab, Hassan's orphaned son, he meets Zaman, the orphanage's head. Amir learns that he sells children to the Taliban armed men to earn some money. When Amir gets annoyed by that, Zaman tells him, "what choice do I have?" (Hosseini 2003, 236). He argues that he has to feed other children, and there is no other solution. Having no choice disnarrates the entire situation of the absence of a proper legal system and the availability of adequate resources. He has to make few sacrifices to save many, and the lack of choices supports his commitment. Cultural violence remains silent and becomes a part of selling the children to the Taliban armed men, but having no other option makes the reader omit to blame him. Then, cultural violence becomes a survival method to the many according to the already existing forceful system. 
Additionally, even jokes become a part of cultural violence, and the narrator laughs at a discriminating joke not because it is funny, but how the jokes remained the same and full of violence. Female characters are the most oppressed in the jokes as well, "what Mullah Nasruddin did when his daughter came home and complained that her husband had beaten her?" [...] "What?" "He beat her too, then sent her back to tell the husband that Mullah was no fool: If the bastard was going to beat his daughter, then Mullah would beat his wife in return" (Hosseini 2003, 245). Being beaten twice shows male dominance in society. The joke is a sexist one discriminating gender and makes the males laugh at it. This act also disnarrates respect towards the females, especially the closest, and the beating becomes routine even by the males they do not know like the Taliban's militia. The narrator in the stadium, during stoning two adulterers, flashbacks a saying of Baba; "Piss on the beards of all those self-righteous monkeys. They do nothing but thumb their rosaries and recite a book written in a tongue they don't even understand. God help us all if Afghanistan ever falls into their hands" (248). Baba's cultural violence and people like him made the worse come to power as they could not prevent them. The flashback itself disnarrates people's powerless status like baba in the past, who could only predict without taking any action. The result is the destruction of the country, especially the social and cultural structure. During this flashback, a man and woman are stoned in the stadium publicly for disobeying the rules having a sexual affair out of the marriage constitution; Assef is the group's head. Baba is not an atheist, and believing in God to protect reveals that, but he distrusts the religious men and believes that they are not the right people.

Despite committing various types of violence, the violence against children remains the most traumatic to the characters and the readers in the novel. It is Assef who buys Sohrab and sexually abuses him, "How talented he is, nay, my Hazara boy!" (Hosseini 2003, 256). Narrating the abuse of Hazaras in society is clear to the reader, but a male child is new. Hence, the narrator himself unnarrates details as they are antinarratable during the social and cultural norms; the reader only can know that Sohrab dances and Assef kiss him from the neck. Unnarration is the disnarration method, and the sexual intercourses are not represented, and there is no reference for that. It is not about considering the readers' identity while this can be very obvious to the reader from almost all the societies and cultures, but the narrator considers the identity of the character as an Afghan of whom the image is always drawn as a man with no sexual abuse. Thus, the 
sexual abuse for a female can be represented easier, and even if not represented, there would be a reference towards that like pregnancy and giving birth. Assef asks Amir about his return and his purpose about Sohrab, "What do you want to do with him?" he said. Then a coy smile. "Or to him." (Hosseini 2003, 262). The linguistic usage states the purpose and aim as Amir can adopt him as a child to spend time with, but he can be harmful to him by sexually abusing him just like Assef. The smile symbolizes a hostile intention, and his entire talk is ironic.

Besides all the negativity of violence, it may help someone feel good and overcome long-term trauma. Assef starts hitting Amir brutally, but regardless of all the pain, he starts to laugh, "What was so funny was that, for the first time since the winter of 1975, I felt at peace" (265). Feeling at peace disnarrates the physical pain the narrator feels at the moment; thus, the disnarration makes the narrator heal the original trauma which he never could escape. Amir always felt that he had to step in when Hassan was caught and raped by Assef a long time ago, but he closed his eyes and left him alone to the unknown brutality. Since then, Amir never felt peace, and narrating the story is a part of the healing process, which results in healing at the end, "my body was broken just how badly I wouldn't find out until later - but I felt healed. Healed at last" (Hosseini 2003, 265-266). However, the violence now helps him feel peace; the cultural violence he committed against Hassan a long time ago now is receiving direct violence from the same person who committed a similar one against his closest friend. Hence, this act of violence heals a trauma caused by another violence. This shows that violence's negative results can be healed by violence and the need to stop violence sometimes by another act of violence; feeling peace disnarrates all those hidden knowledge.

The narrator structures the story to show that the same characters causing a trauma can help in healing. Not only that, some characters cannot change while it is possible for some others. Assef is a flat character who remains the same protagonist from the beginning to the narration. While Amir is a round character who is changing continuously, and in the end, he finds out about correcting his past mistakes following overcoming his traumatic experiences. Accepting a Hazara boy as a Pashtun man to his family shows the change in his personality. When General Sahib asks him about Sohrab and mentions how he can explain the adoption to the community, the narrator tells him, "you will never again refer to him as 'Hazara boy' in my presence. He has 
a name and it's Sohrab" (Hosseini 2003, 331). At the end of the story, the narrator shows the possibility of preventing violence if someone aims and is courageous enough to do it. 


\title{
5. Representing Violence and the Role of the Narrator in And the Mountains Echoed
}

\author{
"Out beyond ideas of wrongdoing and right doing, \\ there is a field. \\ I'll meet you there." \\ - Khaled Hosseini, And the Mountains Echoed
}

And the Mountains Echoed (2013) is the third published novel by Khaled Hosseini. In this novel, the author goes deep into the family structure, connecting it to society, culture, and the political system; accordingly, the family is the author's primary concentration structure. The novel is the story of two siblings, Abdullah and Pari, who have been separated from each other since their childhood giving Pari for adoption to a wealthy family because her own family could not look after her due to poverty. Pari leaves Afghanistan due to the country's security and problems and settles in France, where she becomes a successful writer while Abdullah flees the country to the USA and starts running a restaurant with his family. They find each other after a long time, but Abdullah is ill and cannot remember anything about the past. Family ties are among the main issues the novel explores. Violence is a prominent issue again, as in Hosseini's previous novels, but different types of violence are represented. The abundance of violence related to the state and other groups, but structural and cultural violence are more evident in this novel as the core issue the novel starts with is giving away a child for adoption due to poverty as a result of unfairness and injustice. Using "universal signifiers of myth and symbol" shows the effectiveness of Hosseini as a storyteller (Hore 2013). Hosseini uses fantasy as a myth at the beginning of this novel, a new technique that has not been used in his previous novels. On the other hand, according to Helen Brown's claim, Hosseini listens to his critics as he was criticized about his first two novels that they were ending unrealistically (Brown 2013); in this novel, he sums up his work more neatly. As a result, the ending becomes more peaceful while the previous novels ended more violently.

In this novel, Hosseini continues keeping the family stories the central point of his narration. He represents violence as it was in his previous works, but differently. This time, the structure of relations within the family is more focused. Hosseini says in an interview: "My new novel is a 
multi-generational family story as well, this time revolving around brothers and sisters, and how they love, wound, betray, honour, and sacrifice for each other" (Driscoll 2012). The social structure directly influences building the siblings' relationship as Pari is given up for adoption and is separated from her brother. The way society is structured violates the right of siblings and leads to them growing up separately; this is related to the power distribution within the same group of people of one country, Afghanistan: some become poor to the extent that they cannot look after their children, while some others are rich who can adopt the children of those who are less fortunate. The novelist attempts to explore the influence of such violence on the family formations and how the relations are built in the absence of justice and fair opportunities; hence, there are still other issues and types of violence represented in the novel such as invasion, terrorism, and war. Meanwhile, the family and committed violence against the family structure remains the novel's central issues.

Trauma is a prominent theme in this novel; the author shows the influence of trauma on Afghanis staying in Afghanistan and those who flee and those who return to the country (Linklater 2013). Marcela Valdes (Valdes 2013) critiques the novel and says that it is a work dealing with many emotional aspects such as honesty, loneliness, beauty, and poverty, and it is a novel of "the transformation of emotions into physical ailments." The theme of sacrificing as a reason for global unfairness and structural violence remains the most touching to the reader. The narrator states, "a finger had to be cut, to save the hand" (Hosseini 2013, 14). There is always something unwillingly done to let the others or more significant parts survive. Cutting a finger is one of the violent actions to be committed to preventing a giant act of violence, which is losing a hand, and this is the opinion of the narrator represented to the reader.

The narration model used is based on the narrator's approach to either build the narration on knowledge or opinion. Conviction narrative theory (CNT) is one of the theories allowing the narrator to experience and judge, which is used in this novel. According to Baxtin, "Conviction" focuses on "a definite set of values ... Only one voice sounds in it ... It exists in the ready-made, stably differentiated and evaluated world" (in Tjupa 2014). The narrator evaluates and assesses the situations and decides on the moral attitudes of the characters. CNT is a narrative model focusing on the opinions of the narrator rather than narrating the knowledge alone. Baxtin (in Tjupa 2014) names this "evaluative outsideness" that omniscience is not presupposed, but the 
narrator has a broader concept rather than being only a participant. In such narratives, the reliability is questionable, and the reader sees the narrator's judgments. This approach of narratology is sometimes used in the narration to show the opinion of the narrator.

Structural violence is a primary type of violence used in And the Mountains Echoed. It is the narrator sometimes creating structural violence using his interpretation of the existing knowledge. It is the narrator who discriminates against the genders assigning specific tasks to each gender. Pari's father has no problem changing the diapers of his daughter and waking up overnight to take care of his daughter, but it is the narrator who thinks "it wasn't Father's job to do - he was a man — and, besides, he was always too exhausted from work" (Hosseini 2013, 35). Using the word "man" is labeling a gender with specific tasks and replacing the tasks represents a non-acceptable situation. "Man" is used as a metaphor representing a group of people who are superior to the other by not being assigned any task which is unique to a group of people who are less superior to them. Although Parwana, the mother, is pregnant and has duties at her home to deal with and look after her elder son, the narrator makes the judgment, but the gender is still highlighted to show the task divisions. CNT is used here to show the narrator's opinion and judgment to the reader. Thus, this is true because the tasks are divided and gender roles seen in the country (Evason 2016). The word "man" in the quote dominates the whole context, like his work's tiredness. Man as gender is represented so that it is taboo or unacceptable for him to change a diaper, while if the same word in a Western context is used, it would be expected, and the narrator would not make it an issue. A child belongs to both parents and they both have responsibilities; it is their right and decision to divide the tasks. But when these tasks are divided by social and cultural norms, it compromises the individuals' privacy. It does not matter even if the man accepts undertaking the task; there is always some interference from the others commenting on the action against their social and cultural codes (Cooke 1996, 15).

In Afghan society, stalking a woman is an issue similar to many other societies. In some countries, the situation is more serious as the woman is accused of being gazed at and stalked. In conservative countries like Afghanistan, a woman is responsible for being gazed at by a man; the last person to be blamed is the gazer. The reason being that she reveals her appearance to a man who is legally or religiously not bound to her, or he is not a close relative, like father, brother, husband, or son. There are neither religious rules nor social norms to stop men from gazing at 
women temporarily or just as a matter of realization; in other words, men can gaze temporarily to recognize a female character's identity. However, many sayings ask the women to cover themselves, not excuse men to gaze at them. Those men would look at women, and they always may find a reason, and this is demonstrated in the novel:

In every corridor Parwana would see men's eyes snapping to attention when Masooma passed by. She saw their efforts to behave matter-of-factly, but their gazes lingered, helpless to tear away. If Masooma glanced in their direction, they looked idiotically privileged. They imagined they had shared a moment with her. (Hosseini 2013,71)

The male characters who are the gazers enjoy stalking Masooma. The female character should not even look in the direction of men; otherwise, she would be victimized more as the men would interpret that for their benefit, such as the female specifically looked at them as a sign of desiring that male character. Women are always expected to be extra cautious in such a culture to be protected from men who are the society's dominants. The men are more privileged as their desires have more chance to be met, sometimes forcefully. "Men's eyes" are the evidence when they snap attention to manifest the act of gaze without a female's consent. Here in this part of the novel, it is represented that the women are not happy to be under the men's gaze. This is opposite to the stereotypes saying that women feel precious, valuable, and pretty when they are gazed at by males, at least in masculine societies.

Class division is a significant issue in many developing countries, and Afghanistan is one of them, which is the narration's primary setting. Marriage is one of the elements affected by such a social structure. The main division is classifying individuals into two groups: honorable and dishonorable. The honor is identified based on a female character's past while the male is not at risk even if he had many known sexual and nonsexual affairs before. Nevertheless, it is not the same for the female as she is supposed to have a relationship only after marriage with her husband. If it is known about a female's past relationships, her life would be at risk; at least she will have a bad reputation, and she would be the last person a chosen man would choose for marriage. In the past, there was even a regulation that required a virginity test for women before accepting them, but then it was stopped following the international and Afghan advocacies (in 
D’Costa 2016, 418). The men are talking behind Nila when she marries Mr. Wahdati, and it is said that the marriage was not approved by his family because

\begin{abstract}
"it was well known in Kabul that she had no nang and namoos, no honor, and that though she was only twenty she had already been "ridden all over town" like Mr. Wahdati's car. Worst of all, he said, not only had she made no attempt to deny these allegations, she wrote poems about them.” (Hosseini 2013, 93)
\end{abstract}

She was just seen in a stranger's car, which is enough for society to talk about her as a dishonoured person. Having no "nang," "namoos," and "honor" are the metaphors of showing the characteristics of a female character; the narrator explicitly uses those words in the local Afghan language to indicate a specific setting, which is the place of a conservative society. She has done the same as the man who was the driver of the car she was riding in; hence, no one names the male character, and this becomes a problem only for the female, which influences her future and marriage life. Such an attitude of a man would remain unknown, while a woman can be revealed if she loses her virginity. The virginity of a woman is the proof of the honour of not only herself but the family as well; if she loses her virginity before marriage, the whole family will be disgraced, and it may end up murdering the woman as a matter of honour of the family (Moorst and Salvatore 2012, 94).

Society sees Nila as unacceptable due to her behaviour, which is now known by the people and is no longer a secret. She took that further by publishing poems about what she did. According to the speeches, it would have been better to deny her feelings and lied about her past actions while writing poems is manifesting her crime and considered worse. The most barbaric comment in the group is "one of the men remarked that in his village they would have slit her throat by now" (Hosseini 2013, 93); "slit her throat" is a severe opinion of a participant in the group. This shows that Afghanistan's villages can be worse places than cities for women as they may have to pay the price with their lives for something the society does not accept. It is not surprising that no punishment is mentioned for a man who does the same; moreover, his poems would be praised, and he would be considered a successful and romantic poet by expressing his emotions. In most parts of Afghanistan, a woman can be beaten or even killed by her brother/s and father if she is found to write poetry, especially love poems as they can be the proof of a relationship, while 
girls in Kabul have more freedom and writing poetry is more tolerated (Griswold 2012). It is said that Kabul is the city with the most freedom for women, but even in this city, it is dangerous for a woman to be a poet (Doucet 2013). Storytelling is an expression form for Afghan women that can help them express themselves and overcome gender-based violence (Mannella, Ahmadb, \& Ahmada 2018, 97). Gender discrimination is made more transparent through those words in the novel said by the men who are the society's dominants, the decision-makers. It is worth mentioning that the words "man," "men," and "male" cannot be generalized, and it is not the purpose here. Men are thinking differently, such as Mr. Wahdati who hears all the rumors and does not have the approval of his family but still gets married to Nila. The gender mentioned here with generalization looks at the typical situation seen as a reality of some societies where most males dominate.

Religious discrimination is another theme framing structural violence. Islam is the main religion of the majority of the people in Afghanistan. In the novel, most of the characters are Muslims, at least by birth, even if not by faith. Thus, religious differences are not bolded and considered mostly. In other words, Islam dominates most of the characters, and the religion and beliefs of the other faiths are mainly not taken into account. There is a conversation between a traveler and Mullah Shekib stating the religious discrimination based on an individual's personal belief:

"Now, one day a traveler was passing through, and, of course, he sat with Mullah Shekib for a meal that evening, as is custom. The traveler heard this story and he thought about it, and then he said, 'But, Mullah Sahib, with all due respect, I met a Jew once and I swear his palms bore the very same lines. How do you explain it?' And Mullah said, 'Then the Jew was a Muslim at heart."' (Hosseini 2013, 98)

According to the belief of the mullah, the palms of Jews are different from those of Muslims. The biological division is introduced to differentiate between people due to their religious beliefs, while religion has nothing to do with the physical appearance except some physical appearances such as growing a beard as a religious practice. The palm is another innovation of the Mullah in representing the existence of the structural division. There is an image drawn about Jews in the mullah's mind; the image itself clarifies the discrimination and manifests structural violence formulated by a community leader. When he is confronted, his claim continues by 
stating that the Jew has followed the Islamic religion by heart. The issue is that he continues his claim by giving weaker pieces of evidence. The traveler would not be able to argue more as he would be accused of confronting the religion itself as the mullah has a higher power status. In religious communities, religious people usually have more power, and they should be listened to; if not, those who confront can be accused of being against the religion.

Race as a structural violence tool is not escapable in this novel, as in other works by Hosseini. A Hazara woman is discriminated against by identifying her with her appearance, her face. Nabi, the driver, describes a woman who came to do the laundry at Mr. Wahdati's house, "there was a jowly-faced Hazara woman" (Hosseini 2013, 100). He does not talk about the cleaning lady negatively, but he cannot escape identifying her by her appearance and mentioning that she is a Hazara, a minority group in Afghanistan. As this group of people in the minority, they mostly face discrimination by being told that they are not the state's aboriginals as they are seen as immigrants from other countries. She is being identified as a Hazara, leading to discrimination, even if it does not identify her appearance. The narrator formulates this part of the narration to state the Hazaras' issue as a minority suffering. Otherwise, Nabi's character would mention the woman without describing her, but the woman is described to clarify her identity, primarily through her physical appearance, which is usually discrimination and a form of violence to comment on it. Furthermore, only the existing knowledge is narrated, and there is no reference stating the opinion of the narrator or Nabi. Subnarratable is seen as an unnarration here as the narrator sees some of the information as "needn't be told" (Warhol 2005, 222). The rest of the information is hidden from the reader as the narrator does not find them necessary.

The conflict over the land continues, and the power distribution difference is the key to deciding on the land's ruler. Usually, the parties who gain control following war and conflicts are the ones who start controlling everything. Strangely, they legalize their deeds while the system is in their favor as they bribe or influence the legal structure. Adel's father has controlled the lands belonging to others, but Adel does not know about that, and he has positive thoughts about his father as a hero in society:

“This was my family's tree. This was my family's land. It's been ours for generations. Your father built his mansion on our land. While we were in Pakistan during the war." He 
pointed to the orchards. "These? They used to be people's homes. But your father had them bulldozed to the ground. Just like he brought down the house where my father was born, where he was raised."

Adel blinked. (Hosseini 2013, 305)

Adel's father, the guards, and his mother tell him that his father is a great commander and works all the time for society's happiness and goodness. Although that is the one side of the narration, there is a sad fact on the other side. Adel's father, who becomes a powerful man following the power gain in Afghanistan, builds himself a mansion, and he starts to have factories and other businesses in which he grows drugs. The land and all his fortune are illegitimate; he builds his mansion on the land of the other people who fled the country because of war. Those people have no option but to negotiate and depend on the legal system as the only hope. Adel does not know these until he is told about the realities by a stranger, Gholam, who later becomes his friend.

Gholam's father, one of the victims whose land is taken forcefully, tries to solve the issue through negotiations, but he is not allowed even to go close to the authority, whom he seeks his right to take from:

"You lied to him," Adel said.

"It's part of what I'm paid to do: protect your father from buzzards." (284)

The guard does not let him go close to the person who has taken the property of someone with less power. Although he is a victim, now he is a "buzzard" just because he seeks his rights. They are all identified as "buzzards" which is a bird symbolizing death and destruction. The class with less power is structurally violated just because there is a group more powerful, and there is no fairness in their relations. Using the word "buzzards" for people with less power represents structural violence, but it also manifests the inequality in society. The only option left is to approach the court; while they go after many hearings, the judge announces that all the legal documents of the land are burnt in a mysterious fire, and there are no more proceedings as there is the absence of any legal proof proving the ownership of the land that belongs to Gholam's father. The man believes that the judge is bribed as he sees a golden watch on his wrist in the last hearing announcing the decision while he was not wearing such a watch during the past hearings. 
The gold watch symbolizes the existence of bribery and unfairness as the legal structures do not function properly.

The man tries all the possible legal methods to get back his ownership rights over his lands, but he fails. The final solution which he is left with is a violent action against the powerful authority, but this turns against him as well:

Former Commander Escapes Assassination Attempt. Adel reads the story in his father's study, on his father's computer. The story described the attack as "vicious" and the assailant as a former refugee with "suspected ties to the Taliban." Midway through the article, Adel's father was quoted as saying that he had feared for the safety of his family. (Hosseini 2013, 313)

The man is identified as a "terrorist" while his attack was only stoning the Former Commander's house as he was left with no other option. The power makes the Former Commander a victim and hero, while the former refugee looking for his rights becomes a terrorist. No one hears back from him again, and he becomes one of the other victims of the unfair class and power division.

In the societies where polygamy is found, there is a rare type of structural violence among the same man's wives. Jealousy and sharing are the main reasons for the hatred between females. Sometimes the children become the victims as they have to take a side, but that is not necessarily the case all the time,

Adel's mother had delicate hands and feet, a small upturned nose, and a pretty face like an actress from one of Kabir's Bollywood films. She was lean, agile, and young-she had been only fourteen when she'd married Baba jan. Adel had another, older mother too, and three older half brothers, but Baba jan had put them up in the east, in Jalalabad, and Adel saw them only once a month or so when Baba jan took him there to visit. Unlike his mother and stepmother, who disliked each other, Adel and his half brothers got along fine. (286)

The wives' physical attraction and age decide their power status in such a situation as they become more desired by the husband. The husband holds absolute power, and a more significant portion of that is transferred to the most desired wife. It is the power of a man that leads him to 108 
marry a woman "like an actress" while the man has another wife and children. The more exciting part is the age of the only fourteen women, but she is still married to a man who is at least twice her age, if not three times or more. The reality changes nothing like the women who are victims themselves but still do not like each other and are in conflict; hence, the children are not supposed to be a part of this conflict. Polygamy is not acceptable when viewed from a Western perspective; thus, it is expected from some cultural, religious, and social perspectives. As polygamy and marriage underage is not an issue in the novel, we can look at the conflict between two women as structural violence because it is the power distribution that creates unfairness. The power comes from the man, which is the injustice of gender balance, leading to making a female superior to another just because of the sexual desire of the male character. The narrator represents the story without adding any opinion, and this makes the story more reliable. This scene is like many other previous ones in that the reader does not read about the narrator's opinions and judgments. Once the narrator leaves the story to the reader to interpret and comprehend, the narrator becomes more reliable as a medium of transferring the knowledge.

"Othering" is another form of structural violence in which people are divided according to their lifestyle; being a citizen or resident of Afghanistan and France shows the global inequity. This is represented through an interview between Nila Wahdati and a journalist

NW: He was the best king they ever had. I find the remark of interest for its choice of pronoun.

EB: “They"? You don't consider yourself Afghan?

NW: Let's say I've divorced myself from my more troublesome half.

EB: I'm curious as to why that is.

NW: If he had succeeded, meaning King Amanullah, I might have answered your question differently. (Hosseini 2013, 205)

The word "they" is representing the "othering," and Nila does not want to be considered as one of them as she sees them as a "troublesome" part of the world. Her "half" is also indicating the deep division of societies and people. The word "divorced" makes an actual distance between the 
two groups of people named by this thesis writer: the troublesome and un-troublesome people. While the people of the developed countries are the un-troublesome as they have a higher standard of living, the developing countries' people are troublesome due to their living conditions. The global unfairness is represented by showing Afghanistan and France as two countries from the developed and developing world. Nila sees King Amanullah's failure to modernize Afghanistan due to structural violence leading to global unfairness making the country less developed and made people feel about their ties to the country as troublesome. This is an example of the novel's structural violence as Galtung explains the global unfairness as a reason for structural violence (Galtung 1969, 171). In other words, othering and labeling people on the basis of differentiating them as "they" and "we" is a form of structural violence.

In conclusion, structural violence in Johan Galtung's violence triangle is represented and clearly shown in And the Mountains Echoed by Khaled Hosseini. This type of violence is represented in the novel to show the global unfairness and injustice among various Afghanistan groups supposed to have the same rights. The violence is embodied in the novel showing that the narrative represents the nonfictional context of Afghanistan. Moreover, it shows that the narrative can represent violence to let the reader witness suffering through an imagined world. The levels of discrimination and injustice vary between groups with different ethnicities, religions, gender, and economies. Due to the mentioned reasons, power distribution has a leading role in starting the discriminations leading to structural violence.

Structural violence occurs on a broad scale; in other words, it is the main issue that is the root of the more significant problems. It is essential to identify the issues from the origins in order to seek effective solutions. Identifying structural violence is among those efforts when it comes to conflict resolution and peacebuilding. Conflict is a severe disparity overvalues and perspectives among various groups with opposing ideologies claiming limited status, power, and resources. The existing norms constrain Inter-group relations and the hegemonic structures, and the inflexible nature of that structure propagates resentment, thereby creating a struggle between those groups to satisfy their exclusive needs and interests. Ethnic conflict arises between various ethnic groups based on their struggle on different social, economic, political, and cultural goals, which can be violent or non-violent. 
This novel gives the reader a significant opportunity to learn about the situation and life in Afghanistan. This can lead to the strangers' future campaigns to the country who may want to advocate for human rights. Thus, in the novel, the narrator has a broader view of the events, and there are opinions expressed commenting on the incidents on the one hand and using the description techniques on the other hand. This makes the narrative less reliable, considering information as knowledge; instead, it is a mixture of both knowledge and opinions. Furthermore, the novel is a fictional work, and it is analyzed accordingly in this article, but it can still be seen as an informative piece of writing to learn about life in the country.

Following analyzing the structural violence, the next section will discuss cultural violence in the novel. The novel mainly focuses on Afghan family ties and structures. Violence is a theme represented widely in fictional work. The text can be related to the nonfictional Afghan context when its social and cultural context is considered. Cultural violence has a role of mediation in Galtung's violence triangle theory. Structural violence can change to direct violence only through cultural violence as this type can stop the violence or make it progress and change into another type. Cultural violence is seen frequently and clearly in this novel.

Trauma influences cultural violence as the characters have a fear back in their mind created from their experience. Not merely restricted to this, the cultural violence itself creates possible future traumatic situations. The future regret resulting from remaining silent stays as a traumatic moment in the life of the characters. There will always be a wish to go back to stopping the violence rather than being a part of the action through cultural violence. The wish's impossibility remains a traumatic event with the character, and s/he keeps narrating the past in the search for a remedy.

The second part of the violence triangle is cultural violence, which demonstrates people's ignorance of structural violence. The difference in power distribution among the individuals of society and lack of freedom are the main reasons for this type of violence, but some individuals' ignorant characteristics are another reason for this type of violence. Some people may fear to react when they witness an unfair act around them, but others have normalized the act and consider it unstoppable. In the first case, the individual can be understood as a threat to him/her to stop structural violence, but there is no reason for the second type. Thus, in all cases, such 
ignorance is cultural violence as far as there is no commitment to stop structural violence, not to let it turn into direct violence on an individual basis.

In Hosseini's And the Mountains Echoed, cultural violence exists mostly because of the characters' interests, although there are some forcing factors at some point. The characters have to remain silent in many cases to preserve their interests, as disclosing secrets or their actions against the unfair happenings may negatively affect their interests. That is why they would rather accept the structural violence and ignore all the facts they know.

A child adoption or giving a child to another family due to poverty is a primary issue on which the novel's main points are based. Everything starts when a small child is given for adoption from a low-income family in a village to a wealthy family in a city. The low-income family decides that they cannot feed their child, and in order to make her life better and to let her have a better future, they give their small girl, Pari, for adoption. The uncle of the child, Uncle Nabi, made the deal, who roles as a mediator between the affluent and low-income family as he works at the house of the wealthy family, Mr. Wahdati. Uncle Nabi takes Pari and her children to meet the family first: "Uncle Nabi's head rolled back on his shoulders as he laughed. "That would be something. No, this is my employers' home. You're about to meet them. Be on your best manners, now" (Hosseini 2013, 41). His smile shows his acceptance of the situation. He does not think about any other way of helping his relative. Instead, he finds out this solution, which negatively affects a few individuals' lives from the beginning, and this continues for several years for the next generations. Besides the sadness of the siblings and the family who have to give their young daughter into adoption, the next generations face an identical loss as they all will have a new life very different from the one they are born. Adopting a child, especially an orphan, is a regular practice in Afghanistan in a condition of the religion of the family of which should be Islam, but non-Muslim children can be adopted by non-Muslim families too (Ijaz 2014, 235-236). Thus, according to the Islamic laws, the people who adopt a child can be only guardians, not parents, but it seems these rules are not strictly followed in Afghanistan (Richards 2013, 409-410).

It should not be easy for everyone to stay silent in front of a situation that is known as unfair. Nabi chooses to stay quiet: 
Pari was four years old at the time, but, despite her young age, there were forces in her life that needed to be reshaped. She was instructed not to call me Kaka Nabi any longer, for instance, but simply Nabi. And her mistakes were gently corrected, by me included, over and over until she came to believe that we bore no relation to each other. I became for her Nabi the cook and Nabi the driver. Nila became "Maman," and Mr. Wahdati "Papa." Nila set about teaching her French, which had been her own mother's tongue. (Hosseini 2013, 117)

The small child is trained to forget her memory and to be a new person. Nabi is a crucial character having a role in reshaping Pari's life. She is a child, but she already has some memories as she is four years old. Most memories are erased, but it will be seen towards the end of the novel that it was impossible to forget all the memories, especially some events related to her brother, Abdullah. They start with the relationships between her and Nabi as she is trained not to call him uncle anymore. Language is mentioned as a vital element of identity. Pari starts calling Nila "Maman" and Mr. Wahdati "Papa"; she starts to be taught French as well, and this is another stage in changing her identity after cutting her ties with her previous biological ties.

Nabi continues ignoring the situation and accepts the adoption rather than attempting to deal with the situation by any other means. He stops visiting his sister's house when he realizes that Saboor is not very happy about his visits: "Whatever the reason, I was, in the end, the instrument of his family's rupture. Saboor did not want to set eyes on me again, and I understood. I stopped my monthly visits. I never saw any of them again" (120). The adoption act causes a problem in family ties, and the two close relatives stop meeting. When the general picture is looked at, Nabi is one of the key people involved in the cultural violence stage and might have been able to stop the structural violence between the two social classes in the second stage, not to let it continue into direct violence. However, he instead ignores the situations even he stops his connections with his relatives. He deals with the situation in a strange way as he would support his sister's family and help them all live together, but he arranges for the adoption instead. There is no legal reference in the novel to understand the legitimacy of the situation according to Afghanistan's legal system at the given time. When it comes to the social and cultural norms, the action seems fair and acceptable; there is even no religious reference interpreting the situation as in Islamic 
religion; such an act is arguable. Nabi symbolizes society and religion; according to his acceptance, all those factors are seen as acceptable.

When there is a wish to stop structural violence in cultural violence, a possibility can be found easily even fear may disappear. Nabi succeeds this once he reacts against the rumors about Mr. Wahdati:

That was when I rose and told them that I had heard enough. I berated them for gossiping like a sewing circle of old women and reminded them that without people like Mr. Wahdati the likes of us would be back in our villages collecting cow dung. Where is your loyalty, your respect? I demanded. A brief moment of quiet passed during which I thought I had made an impression on the dullards and then laughter broke out. Zahid said I was an ass-licker, and perhaps the soon-to-be mistress of the house would ink a poem and call it "Ode to Nabi, the Licker of Many Asses." I stomped indignantly out of the shack to an uproar of cackles. (Hosseini 2013, 93)

Nabi willingly defends Mr. Wahdati when there are rumours about him and his prospectus wife. He highlights the class differences and what the less privileged class do without wealthy men like Mr. Wahdati. It is courageous to stop the gossiping, which is seen as impolite and not acceptable, but Nabi did not stand against his niece's adoption. His reason for adopting was to provide a better future for his niece while the child's best place is staying with the parents. The reason for stopping the gossiping can be to stop something unpleasant, but a question comes to mind, and it is not known if he would stop gossiping against anyone else or this case is unique to Mr. Wahdati alone. Such a paradoxical situation proves that an individual can resist unfairness if there is a will. Another claim would be it is easier to defend an influential person than defending a less fortunate person.

Sometimes, people see what is happening around them, but instead, they stay silent. The observant status shows acceptance towards the actions. The case concludes that it is not possible to stop or change a situation against the wills. So, the easiest is to help ourselves or people around: 
I can sum it up in one word: war. Or, rather, wars. Not one, not two, but many wars, both big and small, just and unjust, wars with shifting casts of supposed heroes and villains, each new hero making one increasingly nostalgic for the old villain. The names changed, as did the faces, and I spit on them equally for all the petty feuds, the snipers, the land mines, bombing raids, the rockets, the looting and raping and killing. Ah, enough! The task is both too great and too unpleasant. I lived those days already, and I intend to relive them on these pages as briefly as possible. The only good I took from that time was a measure of vindication about little Pari, who by now must have grown into a young woman. It eased my conscience that she was safe, far from all this killing. (Hosseini 2013, 138)

Nila is aware of all the "wars," but she is obliged to remain observant. It is not avoidable to be unfamiliar with all the familiar scenes caused by the "wars," but people may try to ignore all the results caused by the conflicts. While many people may suffer psychologically due to all those unpleasant events, they accept the facts, and the only attempt they can make is to protect their most beloved ones: for Nila, protecting Pari is the priority. That is understandable as everyone can do what they can. For the rest, without any control, there can only be verbal protests. It is the same situation for most of the other characters, including Masuma: "On the streets, the Taliban walked past me as though I were a grazing cow. I helped them in this by willfully taking on a muted bovine expression to avoid any undue attention" (142). Taliban was in power in Afghanistan, and even now, they are in control in some parts of the country. The organization is against all modern acts and human rights. It is not only difficult for people but almost impossible to react and take any action against them. In such a case, people cannot be blamed for remaining observant and committing cultural violence. Only to not be happy about uncontrollable and irresistible actions or scenes is a form of reaction. There is not only Taliban militia suppressing the people, but the Afghan military does the same, even if not the worse (Bincof \& Omar 2019, 21). Sometimes people may have no control over something, and because of the threats in undemocratic systems, they are muted. It is not the people to blame for cultural violence but the creators of the system. Thus, any unpleasant action should be first denied, even internally, and then voiced out when possible. 
Nila is stating her fears for her daughter in an interview again of which she left the country to make her daughter have a better life:

EB: Which was why you moved to France in 1955.

NW: I moved to France because I wished to save my daughter from a certain kind of life. EB: What kind of life would that be?

NW: I didn't want her turned, against both her will and nature, into one of those diligent, sad women who are bent on a lifelong course of quiet servitude, forever in fear of showing, saying, or doing the wrong thing. Women who are admired

by some in the West — here in France, for instance - turned into heroines for their hard lives, admired from a distance by those who couldn't bear even one day of walking in their shoes. Women who see their desires doused and their dreams renounced, and yetand this is the worst of it, Monsieur Boustouler-if you meet

them, they smile and pretend they have no misgivings at all. As though they lead enviable lives. But you look closely and you see the helpless look, the desperation, and how it belies all their show of good humor. It is quite pathetic,

Monsieur Boustouler. I did not want this for my daughter. (Hosseini 2013, 207)

International wars are beyond control as they depend on superpowers, which is something global and international. Even when they are denied and rejected, they still happen and are not stoppable. As a female, Nila is aware of the situation, and she knows that she cannot do anything against the situation but tries to protect her daughter. There are systematic and institutional barriers for a woman in Afghanistan to let her have an active role in the community (Samar 2019,154). The Iraqi war in 2003 was one of those incidents of which people had no control over:

The twenty or so guests sit on cushions around the room. The floor is covered with a burgundy red Afghan rug. The décor is understated, tasteful, what Idris has come to think of as "expat chic." A Nina Simone CD plays softly. Everyone is drinking, nearly 
everyone smoking, talking about the new war in Iraq, what it will mean for Afghanistan. The television in the corner is tuned to CNN International, the volume muted. Nighttime Baghdad, in the throes of Shock and Awe, keeps lighting up in flashes of green. (Hosseini 2013, 161-162)

The world watches the war, trying to understand it, but the most important was to see the war's influence on the future of themselves and their countries. It was a war in which more than a million people were killed in reality, and it happened in front of all the humans; everyone was observant, and no one could stop it either tried to. For a group of characters watching the news means finding a relation between the war and their country's future. An interesting element is seeing that they are just watching without even listening "volume muted." The horrific scenes of the war are watched without even listening to the words uttered about the fact. This shows that the characters are given less importance than just watching without fully comprehending the situation. The question can be even if they understand what is going on, what will happen? If not, why do they watch the scenes if they can do nothing to stop the war, which they even do not attempt to get into its details? This brings back a question and if human beings enjoy watching conflicts and instead remain observant alone without reacting. If this is the case, it is an apparent cultural violence act. It is evident that many characters are aware of what is going on: "What she says is true. She does follow the news, reads in the papers about the war, the West arming the Mujahideen" (Hosseini 2013, 260), but no one can do anything to stop the wars and conflicts, at some points even no one makes any effort.

It is not only that there is a minimal reaction towards unacceptable actions, but in cultural violence, sometimes the acts are legitimized, which is more dangerous than remaining silent due to fears:

They had done it for their country, Baba jan said, and they had done it for God. This was what jihad was all about, he said. Sacrifice. You sacrificed your limbs, your sight-your life, even - and you did it gladly. Jihad also earned you certain rights and privileges, he said, because God sees to it that those who sacrifice the most justly reap the rewards as well. (Hosseini 2013, 277) 
The war is legitimized in the name of religion. "Jihad" is the religious term used to make wars and fighting holly and memorable. Such an attitude makes a child character dream of being a character in such conflict:

Looking at the pictures, Adel wished he had been around to fight jihad alongside his father in those more adventurous days. He liked to picture himself and Baba jan shooting at Russian helicopters together, blowing up tanks, dodging gunfire, living in mountains and sleeping in caves. Father and son, war heroes. (277)

"War heroes" is the dream of a child who dreams of himself and his father. Adel has portrayed an image in his mind, which is fantastic to fight as he is told that jihad is religiously significant. He legitimizes the fight in his mind, and he even takes this further as he wants to be a part of that. Caroline Picart (Picart 2017) introduces the term "Jihadi Cool/Chic" in her recent book stating fighting in illegal/terrorist groups become more attractive nowadays due to using the most recent technological advancements, especially when it comes to filming their actions as well as the promotional methods of recruiting new members. Even a child cannot avoid committing cultural violence while he is directly under an adult's influence.

Thus, the representation of traumatic experiences and their symptoms may destructively impact the reader's imagination and can cause psychological wounds, and it can lead to the exposition of collective trauma. Wulf Kansteiner argues:

More important and more misleading is the implicit assumption that representations of symptoms of trauma replicate such symptoms in the minds of the audience and produce a collective trauma which unites many individuals who have never experienced or directly witnessed acts of extreme violence. (Kansteiner 2004, 207)

The stories traumatize the characters who witness the events through various mediums such as television and newspaper. The incidents create a collective trauma among the society members, and they indirectly become a part of the events. Some members support the ongoing violence, and others deny them while they all become a part of the story and are all traumatized. Nevertheless, the readers are partially traumatized, and they become a part of the story following witnessing the representations of the wars in Afghanistan and Iraq or any other conflicts. As a 
result, the representation of violence can negatively influence the readers by dragging them into a collective trauma by witnessing the traumatic experiences through the medium of narration, characters, and a narrator.

Structural violence can be stopped in the second stage of cultural violence if there is a desire which requires only some courage and will. Pari, the daughter of Abdullah, who is just a child, cannot remain audience to the adoption of her father's sister, and she cannot stand their separation:

The whole time we talked like this, a fantasy played out in my head. In it, I would save all my money, not spend a dollar on candy or stickers, and when my piggy bank was full - though it wasn't a pig at all but a mermaid sitting on a rock-I would break it open and pocket all the money and set out to find my father's little sister, wherever she was, and, when I did, I would buy her back and bring her home to Baba. I would make my father happy. There was nothing in the world I desired more than to be the one to take away his sadness. (Hosseini 2013, 401)

Any attempt, even very small, is better than no attempt. Pari has nothing except her piggy bank, but her thoughts are enough to see that she is devoid of cultural violence as she tries to solve an old issue resulting from structural violence as her father was separated from her aunt. If all the characters resist even at a deficient level like the small child, there would not be any cultural violence. All the characters need some courage and self-identification to see what they can do at their level. That is not enough to dislike discrimination or any violence on a structural level, but making commitments is essential.

Cultural violence is represented in Hosseini's novel And the Mountains Echoed. This type of violence leads to a traumatic experience, but it is also the result of traumatic events. Using religion as evidence to make a war leads to future traumatic events in the lives of the involved characters, but anyone else who is influenced by the war either directly or indirectly. Remaining silent toward the ongoing Iraqi war is another scene that shows that cultural violence results from the old traumatic experiences that all come from the invasion of Afghanistan by the USA, Soviet Union, and other civil wars and conflicts. The characters are traumatized by the old events as they know that they have no power over the situation. They can all be the only audience to the 
situation without becoming a part of the solution; they can only follow up with the developments to see how their lives will be affected by the wars and conflicts in their own country and outside of their borders.

Khaled Hosseini's And the Mountains Echoed has a complex narrative technique as there are multi narrators. The themes are quite different from his previous novels. Here, the author concentrates more on the relationship between two siblings who have been separated due to economic issues. The diaspora issues are more focused on now compared to the first novel, The Kite Runner. It is seen that no one can escape from past contented and bitter incidents.

Violence is a critical element in the novel, just like the other previous novels by Hosseini. However, the violent actions represented are pretty different in this 2013 published novel. Rather than domestic and war violence, it is more violence related to post-war, economic, and social issues. As usual, Hosseini attempts to fictionalize Afghans' non-fictional life both in their home country and their new life in the diaspora. "Disnarration" is a narrative method used to analyze this paper to show how it affects violence representation. Gerald Prince (1988) defines this term in his article "The Disnarrated." According to his definition, "disnarration" is not represented in fictional works and what is not happening in a narrative.

Monika Fludernik $(2009,2)$ argues that narrative is 'based on cause-and-effect relationships applied to sequences of events.' The events are the backbones of a narrative organized based on the reasons resulting them and their influences on the formation of the events or directing them into a dynamic story structured following putting some selected events into orders. Additionally, Fludernik (1996, 27) claims, "narrative is the one and only discourse that can portray consciousness." On the one hand, the narrator's consciousness is the unconsciousness of that person, as the unconscious mind is unlikely to be accepted if portrayed directly without fictionalizing. The unconscious stage of Freud is not easy to draw an image and represent. The narrative here helps represent the unconscious thought in someone's mind as the conscious might make it difficult to let it become visible or known by others.

On the other hand, consciousness can be the part of the narrator who is aware of the events, and $\mathrm{s} /$ he feels responsible towards them to make them visible and notable to the others. The narrator is conscious about some events, finding them all-important to make others become conscious and 
notify them. According to a claim of Fludernik (in Ryan 2009, 420), "Narrative is widely recognized as the discourse of human experience." As time, space, characters, and experience are all involved in structuring a narrative, the value of factuality should be considered either in fictional or none fictional narratives. Moreover, in this section, Johan Galtung's direct violence in his theory, named the violence triangle, will be used as a theoretical framework to identify direct violence.

Khaled Hosseini starts the beginning of And the Mountains Echoed with mythical scenes. It is rare to see such a technique in his works as he has always tried to deal with the actual events and issues related mainly to Afghan culture and society. A fantastic story character becomes a part of his narration, which is narrated as a story in his fictional work:

Do you have a wish to die? Surely you must, disturbing me in my home! What is your business?

"I have come here to kill you."

There came a pause from the other side of the gates. And then the gates creaked open, and there stood the div, looming over Baba Ayub in all of its nightmarish glory. (Hosseini 2013,9)

The story is narrated to a child in the novel, and it is full of violent actions. A child listening to such a story learns how to solve the problems violently, especially when disturbed at home. There are also lessons regarding how to solve the problems with someone who wrongs others. It is the monster threatening Baba, but in response, he threatens with killing due to the absence of law and any humanistic structure set to resolve conflicts. Such a children's story is not educational and appropriate for a child, but it is cultural, especially in the more violent ones caring less about rearing the children to be peaceful adults. The absence of the law and equal rights are the reasons as the strong and those fighting are always in a better position than those with no fighting and violent action skills.

On the other hand, children can learn from violent stories to observe violence and inequality. Ultimately, they can learn how to be more tolerant and solve conflicts by avoiding what is done in the stories (Todres 2018, 337). In general, violent actions and used words towards a child 
significantly influence a child's education, leading to negative behaviour in the adolescent period (Turanovic 2019, 125). There is an essential element, and it is the "disnarrated" here, which is the absence of the murdering action. The narrator clarifies through Baba's words that he is there to kill, but it does not happen. The verbal violence is already there; thus, the physical one remains hidden, making the scene less violent. "Disnarration" tells the audience that there is a worse violent act than threatening, and that is killing that may lead to more complicated issues. Narrating inappropriate stories continues in later parts of the novel by different characters:

Saboor was always coming up with stories, tales packed with jinns and fairies and demons and divs; often, village kids gathered around him and listened in absolute quiet as he made up fables for them. (Hosseini 2013, 64)

The children unconsciously listen to such stories as they all sound different and exciting, especially when they cannot relate the characters to the ones in real life. The storytelling of this genre is expected in the novel, and it is repeated in various parts of the novel: "He said ... and tell stories populated with jinns and fairies and divs" (398). Things like devils and monsters can only create traumatic experiences in the minds of children. Once those audiences are grown up, or during the childhood stage, they would like to imitate those imaginative characters while acting differently from reality. This may increase the violence and the damage caused by the violence inspired by those imagined stories. Most of the time, the traumatized child suffers from being haunted by those characters:

I was happy enough to be the vessel into which she poured her stories. She told me, for instance, of a hunting trip to Jalalabad she had taken with her father and how she had been haunted for weeks by nightmares of dead deer with glassy eyes. (100)

A child cannot choose a healthy story as the adult has to select the right things to tell suitable for each age group. The story was told to a child, and another child accompanied her father on a hunting trip. It is usual for a child to be affected and traumatized after seeing a dead animal. Her memories show how she is still affected and traumatized by the event following the years' passing while she narrates the story. Those incidents can only build weak characters who may commit violent actions, if not only harmful to themselves as they live all their lives with traumatized memories. Thus, those violations of child rights are explicit representations of direct 
violence in the novel. This example should remain "disnarrated," as a child can easily connect sympathetically to an animal while the dead image psychologically affects the child negatively. There are weaknesses of "disnarration" as the narrator conveys all the known knowledge to the audience, but at some points - especially when a child or immature audience is the target, "disnarration" becomes the strength of narration to make the transforming information healthy and proper.

The stories told during childhood leave traumatic impacts on a child's brain that returns during adulthood, turning into violent actions. Hearing about the experiences in the form of words and narration during childhood has influenced the adults' experiences at the later age periods (Steenbakkers, Steen, and Grietens 2019, 45). The youth are affected by traumatic experiences even though those experiences are not entirely remembered (48). During early ages, education and child care have a leading role in growing and shaping a child's future characteristics. The used words can cause traumatic experiences in the mind, and they would be used in later stages, which are seen in the behaviours. The traumatic experiences lead to violent actions in later stages of life. The novel shows a lack of educating the characters from early childhood by narrating violent stories and teaching them how they can defend themselves by only violent actions rather than communicating and using mild language. Hence, Dawn Mills Campbell advises people to be thankful to their parents and work on their personal developments rather than the negative and traumatic experiences (Campbell 2017, 50).

Typically, children are proud of their parents as role models. Narrating the parents' success stories is a part of that pride, but it becomes problematic when a child is proud of their violent stories. Adel talks about his father and narrates one of his stories:

Baba jan had been shot twice by the Russians during battle. He had shown Adel his wounds, one just under the left rib cage — he said that one had cost him his spleen — and one about a thumb's length away from his belly button. He said he was lucky, everything considered. He had friends who had lost arms, legs, eyes; friends whose faces had burned. (Hosseini 2013: 276-277)

Adel represents an Afghan child proud of his father's wounds during a battle and is told about their parents' violent stories. Adel's father talks about his wounds calmly, and it is due to luck 
that he did not lose any body parts like his other friends. All those attitudes come from the adults who narrate their violent stories to children, and they consider those stories as a matter of pride to let the children know to make them stronger. There is no doubt that children learn from their adult family members, and they try to imitate everything as they cannot differentiate between good and evil. Educating a child in such an environment, with similar methods, is clear, direct violence affecting the child's growth, negatively resulting in a violent adult. Miseducation is well represented and makes the reader consider the danger of such an education by the adult characters. Here, most of the scenes should be "disnarrated" due to the irrelevant or improper historical knowledge given to a child, but at the same time, "disnarration" becomes a valuable narrative method. The father did not lose a part of his body as others were less fortunate and lost their body organs. "Disnarration" is the Narratological technique here telling the audience what did not happen to show that a character is lucky and more fortunate, while this information becomes for the child a piece of good news as he realizes that there are worse in the life and he should be satisfied for what he owns.

Domestic violence is a regular practice, especially towards the children by the parents in developing countries. It is not always symptomatic of being destructive or violent parents, but they instead see the practice of hitting a child as a method to educate their children. Thus, conflict for the decades and poverty in Afghanistan remain the main reasons for the domestic violence against children (O'Learya et al. 2018, 95). At the very beginning of the novel, we see this practice:

Father had never before hit Abdullah. So when he did, when he whacked the side of his head, just above the ear-hard, suddenly, and with an open palm-tears of surprise sprung to Abdullah's eyes. He quickly blinked them back. (Hosseini 2013, 19)

As indicated, Abdullah has never been hit before, but his father sees the action of hitting as the last option to stop his son when he rebels over his sister entering adoption, approved by his father, mother, and uncle. As an adult, the father believes that he is the only one who can make the best decisions for his children's benefit. Hitting his son is one of those decisions to stop him from thinking about what the father thinks is not appropriate and reasonable. Moreover, he hits him with "an open palm," which makes the hitting action more violent and painful. It is cultural 
when a man opens his palm in the action of hitting; it means he wants to increase the degree of the pain or to make his action more powerful. Most citizens disapprove of interpersonal violence, especially adolescents and parents ( $\mathrm{Li}$ et al. 2018, 1691). Although domestic violence is committed against the children within the family due to the country's long-term issues, the violence is generally disapproved by most Afghan people. However, this scene in the novel represents the significant social and communal disapproval against domestic violence as the father only hits with his palm once without going more violent or hurting the child physically in a brutal way, such as with a more common stick.

The narrator is not only narrating the violence committed against humans, but the environment is taking its share as well:

Then he and the other men hacked away at the thick trunk until late afternoon, when the old tree finally toppled with a massive groan. Father told Abdullah they needed the firewood for winter. But he had swung his ax at the old tree with violence, with his jaw firmly set and a cloud over his face like he couldn't bear to look at it any longer. (Hosseini 2013: 51-52)

The trees are cut naturally, but swinging the ax violently gives the incident a different approach, making the reader think nothing is normal. Cutting a tree itself is a violent act as it is a commitment to harm the environment - especially in the modern era when there are alternative resources that are not or less harmful to the environment. Thus, this argument may not be considered in this context, as the story takes place in an older time with fewer resources, but structural violence is considered here as life would be different from a city which is more privileged than the life in a village where they have to cut the trees to use and survive. Not only poverty but also wars have direct relations to environmental issues. Soil and water pollution directly impact land productivity (Formoli 1995, 68); the way of cutting a tree that is affected by the environmental issues may change, and it may require more effort to cut a tree, in other words. The main thing here is using the word "violence" in the action of cutting a tree. The author only wants to show that violence is becoming such a regular practice that the characters are even committing it against nonhuman things such as a tree. Furthermore, the answer to a question as to why do they need a tree is prominent. They do not have any other energy resources available 
to use as fuel and gas, and renewable energy is not even a source to mention due to the undeveloped circumstances in the specific space and time. Mentioning the trees' cutting action is indirectly the "disnarration" of the existence of the other resources of energy.

Domestic violence towards the wife and children is a common issue in the novel. Nila is one of the characters showing a different type of violence committed by her father's ignorance. She explains how her father had some hobbies and indirectly indicates that he did not give his child enough attention and care:

My father slept in his own room, my mother and I in ours. Most days, he was out having lunch with ministers and advisers to the king. Or else he was out riding horses, or playing polo, or hunting. He loved to hunt. (Hosseini 2013, 223)

Nila's indications are indirect but very clear to the reader to sense that she complains about her father, who did not show any commitment towards his family obligations towards his daughter and his wife. It is narrated that what did not happen, not caring about the family members, was the father's duty to meet his wife and daughter's emotional needs. Nila does not state her complaints clearly, but it is evident to the reader. She tries to justify his busy schedules due to his meeting as a part of his political position and the other times by following his hobbies. Under any circumstance, family members should be prioritized particularly when it comes to the children; it is parents' absolute duty to fulfill the desires or needs, especially the emotional ones of their children. When they fail to undertake the necessary fulfillments, it is psychological violence towards the children, limiting their emotional growth due to the gap in the healthy relations that are supposed to be built between parents and their children.

Lying to someone else is another type of direct violence, especially when the lie is told to someone trying to meet an administrative personal. The bodyguard of Adel's father is the person undertaking this type of violence, "you lied to him," Adel said. "it's part of what I'm paid to do: protect your father from buzzards" (284). The bodyguard sees a group of people as unpleasant and unwanted while they have the rights, and it is his boss with administrative duties to deal with. However, the bodyguard puts a barrier for the citizens trying to access the administration to solve their issues. The bodyguard stops them from following up with their administrative works, but he humiliates them and labels them as "buzzards." Here, something does not happen, which 
is supposed to happen as the bodyguard is supposed to guard and maybe schedule the meetings. Naming someone as a buzzard symbolizes the name tag as greediness, disturbance, and uselessness as the buzzards live on creatures' dead bodies. Those people are degraded by being related and named with this type of bird; this is clear, direct violence towards human dignity. Treating someone shows the absence of proper treating, which does not happen.

Adel's father is not only protected by bodyguards who are ignorant towards human dignity, but he also bribes other people to take side with him:

And as he's telling us that there's nothing he can do now without the papers, do you know what he has on his wrist? A brand-new gold watch he wasn't wearing the last time my father saw him. (Hosseini 2013, 309)

Following a mysterious fire, Ghoulam's father loses all his rights due to the burnt shreds of evidence about the lands occupied by Adel's father. The gold watch symbolizes the structural unfairness, leading to direct violence committed against a person who seeks his rights in a court legally. The influential people manipulate the entire legal system, and the judge becomes a part of the unfair system. As a result, a man with legitimate rights loses all the ownership of a property belonging to him. Here, it is not only Adel's father responsible for the direct violence, but it is the judge who is the responsible person by becoming a part of victimizing the man. They both commit violence against Ghoulam's father. The judge makes having no evidence an excuse to stop the court case against a commander who has more power than an ordinary man. "Disnarration" here shows the reader that justice does not take place and the judge has to keep the justice in favour of the person, who is the victim, but this does not happen, and the judge becomes another character to victimize the victim for the second time. The violent action against an individual is a clear sign of being victimhood "the mere presence of violence, actual or symbolic, is routinely conflated with the presence of trauma, with the result that those exposed to violence are summarily turned into victims." (Kansteiner 2004, 214). The violence not only causes trauma for the characters, but it also entitles and identifies them as victims.

In conclusion, direct violence is visibly represented against children and all other characters in Hosseini's And the Mountains Echoed. "Disnarration" is a narratological category that has a primary influence on the represented violence. The audience can realize what did not happen 
while it could happen and change the story's consequences. The narrator makes it visible for the reader to realize the "disnarrated" information as through this knowledge, the audience can evaluate the events to see what could be better if some specific incidents happened or did not. Through this narratological technique, the reader becomes more involved in the novel to criticize the characters and the events and the narrator by indenting some incidents that should not have happened, or at least the narrator had to omit to narrate them. 


\section{The Literary Violence Triangle in the Novels of Khaled Hosseini}

The novelty of writing this thesis on Khaled Hosseini's works was to fill the gap in the literary studies canon on the reception of his works, mainly studying the representation of violence in selected novels of the author. I developed the paradigm of the literary violence triangle that I used to map to understand the representation of diverse forms of violence. The aim was to categorize the forms of violence based on their visibility and invisibility, arguing that visible direct violence manifests the other forms of violence which are invisible.

Representation of violence in Hosseini's novels takes place on various levels, visible and invisible, and portrayed using various narratological techniques. The setting is structured to portray the represented violence in different ways. The reader not only sees the violence on a visible level; they also imagine and see the hidden violence. Representing the common violence in a location such as Afghanistan to the global, especially western readers, is not easy due to the lack of cultural and social knowledge. The time comes that the represented scene is unimaginable and unspeakable when the reader's comprehension is the point. Stoning Maryam in A Thousand Splendid Suns or forbidding kite running in The Kite Runner is unimaginable and unspeakable to the reader. Hence, they are all representations of some common incidents in Afghanistan. There are exaggerations in the representations and structuring the entire narratives as there is less focus on the characters' everyday social lives, but this does not reduce the representations' validity. The narratives also have to use various literary tools and overstatements to make the text look more attractive to the reader. Therefore, the novels portray life in Afghanistan in a literary context, and they all represent violence on visible and invisible levels.

The invisible violence is a significant part of Hosseini's novels, and he uses it to represent the roots of violence. Both structural and cultural violence manifest in the existence of direct violence. They are also evidence that direct violence is not a single-point process, but it is a result of a more prolonged process that creates violence at the visible level. The representation of ethnic conflict in the novels is mainly an image to show structural violence. Structural violence is the starting point in the violence process occurring on the invisible level. The following quote represents the structural violence between two main ethnic groups of Afghanistan, Laila hears: 
Pashtun militiamen were attacking Hazara households, breaking in and shooting entire families, execution style, and that Hazaras were retaliating by abducting Pashtun civilians, raping Pashtun girls, shelling Pashtun neighborhoods, and killing indiscriminately. Every day, bodies were found tied to trees, sometimes burned beyond recognition. Often, they'd been shot in the head, had had their eyes gouged out, their tongues cut out. (Hosseini 2007, 159)

It is unknown who are the resources for Laila to get the news from, and it appears that there are only rumours. Hence, it is clarified by the narrator that it is the militiamen of Pashtun origin who commit the crime against the Hazaras. Nevertheless, the Pashtuns' image is scary for the Hazaras as there is a group, even a small one, massacring the Hazaras. This shows the ongoing structural violence between the Pashtuns and Hazaras, and the structural violence grows as the community is divided between two groups. Some people of the group discriminate against the rights of the other. As there is no solid constitution for protecting everyone in the country, the Pashtuns' image becomes less reliable in the Hazaras' eyes. This pushes the Hazaras to arm themselves and take action against Pashtuns. Ordinary people start to develop the fear, and they feel that they have to protect themselves against their enemies. As a result, direct violence develops, which mainly ends with physical harm in the analyzed novels.

Moreover, the violence manifested directly to the reader is not the whole process. The reader may only see the visibilities, not the invisibility. It is essential to analyze both the visible and invisible types to understand the entire process of violence. As discussed in the previous example, Hosseini indicates the image of invisible violence, and it becomes easy for the reader to track the origin of the violence. It is not difficult for the reader to understand Assif's hate towards Hassan once the reader is familiar with the conflict and historical facts about the issues between Hazaras and Pashtuns. When Rasheed mistreats Mariam, the reader knows that it is the class division causing her to grow up as an orphan ending with an underaged marriage; not only that, the reader is already well-equipped with knowledge related to gender inequality. Pari also becomes an adopted child due to her family's poverty and financial division in the country. Those are fundamental reasons and starting points progressing the development of the stories. The scenes are all connected, and the reader cannot understand the hate of Assef without having a fundamental understanding of the structural violence that has led to it. It is also challenging to 
understand Mariam's struggles and Pari's miserable life due to the adoption without knowing violence representations' structures. As a result, a proper framework to identify violence's progress becomes vital for the reader to explain the direct violence. The violence triangle is inclusive of all stages in developing violence, including the final shape of direct violence. Hence, in this thesis, the matter is not framed inclusively in other theories of violence by other scholars.

Furthermore, these all make the violence triangle a critical theory that is mainly considered a basic analysis framework. As mentioned before, this theory brings a novelty to the research in literary studies field as such an attempt using this theory has been absent. Building the research framework over the violence triangle considering narratological approaches and trauma theories has answered how all those fields interconnect in building narrative sequences. The framework also answers how violence develops chronologically in a narrative and how trauma interferes in the long process of violence creation. Besides all the invisible violence causing visible violence, other interpretations can be used to help understand direct violence. These include the significant quest theory, which happens on the invisible psychological level, wherein someone adapts the sense of being insignificant as the other may shame or dishonour the person. As a result, the person becomes an extremist committing violent acts, and in the worst case, the person may convert into a terrorist. Hence, all goes back to the same basic theory of violence triangle, which starts with structural violence that a group of people starts to behave as superior to a less privileged group due to global or local unfairness-absence of justice and law encourages the development of such a system.

Moreover, the theory of blaming the victim can explain this situation as the person committing violence can be the victim himself/herself. The theory typically discusses the people who are victims and whom people blame, such as a victim of the rape, rather than blaming the rapist, to blame the victim due to walking alone late at night or wearing sexy clothes. However, the person who commits violence is also a victim of social, cultural, and religious norms. The person is a victim of structural and cultural violence, pushing him to commit direct violence. Assef, for example, is a victim of the social developments and the rules constituting society. He is a child with teaching from outside sources building his personality and characteristics. Assef mentions Nazi Leader Adolf Hitler stating, "too late for Hitler ... but not for us" (Hosseini 2003, 38), and he has this knowledge while he is only a child. Being a child manifests the knowledge he has is 
received from someone else that there are other individuals raising him with hatred. The quote is one of those evidencing the status of the character as a victim. The education of Assef is problematic; the parents and community raise him as a Pashtun person to hate Hazaras, which leads to more crucial acts in the future when he becomes a Taliban member to stone people living against the rules set by them to obey.

Building on that argument, everyone is a victim of a society and community, specifically, another structure. It is not only a traumatic event that influences a character's life but also keeping the trauma repressed, which significantly affects the behaviours of the characters (Alexander 2004, 5). Many reasons force Amir to misbehave against Hassan as the community sees his friendly attitudes as not acceptable towards a Hazara. His father's parenting skills become an internal reason in the development of the characteristics of the son. When Amir plots a plan against Hassan by accusing him of stealing the watch, he is a victim trying to get his father's attention. According to his community's social codes, the father is also a victim of the social norms who grew up to be a tough man. Then, there is a circular chain that connects all these actions to each other, and they are all reasons for the following levels and steps of violence. Analyzing the violence that is committed on the visible level may not help the reader explore the violence's roots. Besides, the reader might be misled by portraying the visible level of social developments. The reader needs to explore what is happening by going into the depth of the issues. The entire process is like a tree that starts with the root, and visible violence becomes the fruit of the tree. The fruit, or product, cannot exist without all the other parts of the tree, including water, air, sun, and dirt. Direct violence on the visible level is a product of long process, an inclusive one containing all the necessary elements needed to develop the matter called violence, especially the visible one.

Structural and cultural violence remain invisible in this thesis's analyzed novels, just like they are in the violence triangle. Hence, they are not very difficult to spot out by using various narratological techniques and linguistic forms when a critical approach is adopted to interpret the novels. Different narrative modes help in that regard to make the invisibility more apparent to the reader. Unnarration and disnarration are two main narration modes that help readers to see representations of some forms of invisible violence. When a soldier tells Hassan, "I knew your mother, did you know that? I knew her real good. I took her from behind by that creek over 
there" (Hosseini 2003, 7), it is an unnarratable act adapted by the narrator. Here, the author uses a technique to hide a sexual taboo action, and it is not common to talk about this openly in the Afghani culture. Knowing a woman well and taking her from behind metaphorize the existence of a sexual affair. Hence, this sexual affair may look forced or an act of rape as there is no reference to the woman's consent. Hiding the entire scene from the reader is a violent action. When it comes to the disnarration, represented violence mainly shows what does not happen and its consequences. Violence happens because stopping violence is not happening; in other words, an evil one is happening because of the right action's absence. Disnarration and unnarration are both literary tools that make the representation more effective by making the reader see the deeper layers of the issue, especially the invisible one. Those literary tools demonstrated structural and cultural violence, and their reader can connect the direct violent act to those in the invisible level.

Hosseini also makes use of other narratological theories in his novels, and they all help in the representation of violence. Conviction narrative theory is an example. Through this narratological method, the narrator can commit violence by engaging his/her opinions and judgments. In And the Mountains Echoed, the narrator discriminates the gender by adding his opinion stating, “it wasn't Father's job to do — he was a man — and, besides, he was always too exhausted from work" (Hosseini 2013, 35). The narrator commits a violent act by structuring the genders and assigning their roles according to gender. The codes someone learns from culture and society remain unchanged regardless of education and social role. Such behaviour transfers the ideology behind the violent commitments to the next generations and readers. The narrator has committed direct violence, paving the path to structural violence in society and some readers' minds. As a result, direct violence can be the reason for structural violence, and the narrator has the leading role in this regard. Thus, the narrator's absence of opinions is essential, as the reader's assessments can take the narrator's words more into consideration rather than the characters' acts. Trauma connects narrative and violence. Those terms can be connecting points or cause each other. Violence is a result of trauma, and trauma causes violence. Hence, narrating the past experiences and stories helps in the healing process to overcome the traumatic experiences. The critical character who gets the benefit of the healing process is the narrator, as this is seen at the end of The Kite Runner when we see Amir, the narrator, feeling relieved following facing his 
past that haunted him through his life. Trauma has a prominent role in Hosseini's novels, and it is a form of manifestation indeed to show the existence of severer forms of violence in the lives of the characters. Looking at the traumatic experiences, the invisible forms of violence come up more clearly while the reader looks to answer the traumas' formulation questions. The reader's curiosity in searching for the traumatic experiences' reasons leads to unveiling the structural and cultural violence types. We comprehend direct violence better by considering trauma to explore more about the connections between them and see how they cause each other. Exploring the characters' traumatic experiences during childhood is essential to analyzing their psychology when they commit a violent act. Such an analysis is a primary reason to see trauma as a connection between narrative and violence.

Narratives are the representations of a series of imagined incidents. Alvin Plantinga and Robert Adams argue that possible worlds are strongly related to the real world (Ganguly 2016, 82). These fictional contexts have a direct relation to nonfictional ones in the form of representation. Hosseini's novels are fictional works; hence, they represent incidents produced from the author's imaginative world, but the cultural and social background of the author brings some significance to the fictional narratives he produces. All three novels discussed in this thesis are pieces of text that give the reader some knowledge about a setting known mostly from the media. Afghanistan was a world familiar to the reader through the news, mainly visual. In Hosseini's novels, the reader gets into various aspects of life in Afghanistan through the texts written by an author who comes from that culture and society. The reader experiences all the details through a fictional form by storytelling with literary tools used. In, A Thousand Splendid Suns, Leila's father claims the time of communist ruling to be better for women, "It's a good time to be a woman in Afghanistan" (Hosseini 2007, 232), and this was because of the civil war in Afghanistan between 1992 and 1996 when rape became the primary weapon used against the women from different ethnicities (Ahmad 2014, 15). Those stories were not pleasant to hear or engage with at some times in the near history, but they are now more engaging and attractive because of the literary tools used in producing the imaginary world. Analyzing issues like violence, narration, and trauma becomes more critical as the reader becomes engaged with an effective representation. I was interested in using the violence triangle theory, as non-literary contexts were mainly adapting it, but filling a gap in the field by applying it to literature. Using this theory showed that literature could be a form of representation to portray the real world, especially 
when communicating with people about global issues becomes difficult. The literature can communicate the reader by representing the issues, while through the nonfictional methods, this task will be more difficult.

Building on that, it would be very unimaginable when someone sees in the news that a fundamental activity such as running the kites becomes illegal by law. Hence, this happens in a country like Afghanistan ruled by the Taliban, and this becomes unspeakable. Hosseini portrays this incident's exact image in his first novel, "the Taliban banned kite fighting" (Hosseini 2003, 197), and the incident becomes more comprehensible for the reader as the author portrays the incident on a broader image. When the reader reads about the news incident, it is only a solo act of banning, and it may not make any sense due to the absence of information about the involved characters. In the literary text, The Kite Runner, the reader becomes familiar with the complete knowledge necessary to portray an act's image, especially following knowing about the Taliban implementing rules and laws that the reader in the western countries is not familiar with as a result of social, cultural and religious differences.

Another example is that it is difficult for a person in a country with strict rules banning underage marriage to understand how a fourteen-year-old can marry a man twice or three times her age. Hosseini represents this scene in And the Mountains Echoed:

Adel's mother had delicate hands and feet, a small upturned nose, and a pretty face like an actress from one of Kabir's Bollywood films. She was lean, agile, and young - she had been only fourteen when she'd married Baba jan. Adel had another, older mother too, and three older half brothers, but Baba jan had put them up in the east, in Jalalabad, and Adel saw them only once a month or so when Baba jan took him there to visit. Unlike his mother and stepmother, who disliked each other, Adel and his half brothers got along fine. (Hosseini 2013, 286)

So the author portrays an image to the reader, which is unimaginable, but at the same time, it is a fact happening in a country like Afghanistan. The woman's mentioned features represent a female character's objectification that a man takes her as a wife to please his desires. Although he has other women as a wife, he desires a younger female, and this causes conflict between all the wives. It is not easy for a reader to understand how such a thing can happen when the news broadcasts it, but it becomes easier to draw a different world through a literary context when the 
author portrays all the social, cultural, and religious differences. Such a marriage was imaginable and allowed according to the laws until the introduction of the Afghan Constitution, the "2004 Constitution," which was said to be a "well-developed document," that many rights were legally allocated to female Afghan citizens (Ahmadi 2015, 314). The law of Elimination of Violence Against Women, decreed in 2009 in Afghanistan, states that marriage before the legal age is a legitimate form of violence, and therefore punishable (Wimpelmann 2015, 102). The represented scene was once an actual incident that took place, and it was abolished later. There are still ongoing issues in the unspeakable and unimaginable country to some of the novel's readers. Then, the novels are a world representing another world, which is in the author's imagination.

The ban of kite running, stoning a woman, and child adoption due to hunger are actual incidents in some third world countries, Afghanistan as an example. This thesis has used factual data in some parts of the analysis to show how a representation could reflect the real world using the author's imagination and storytelling skills with the narrator's mediation. The novel is an effective form to use for representation, and this way, the reader sees the world, but they can also engage by witnessing the events by reading the linguistic forms of representations.

Although scholars explore violence differently, the violence triangle is a practical theory to analyze literary contexts because it contains all stages of the violence progress. Using this theory answered this thesis's question in ways that would not be possible by consulting other violence theories. Besides representing violence, it explores violence's invisibility, which has been a significant part of exploring and seeing its role in creating visible violence. This helps to comprehend better the represented committed violence in the form of literature. It is not direct violence represented in the novels, but there is also structural and cultural violence on the invisible levels. There are also other factors involved in the progress of violence, such as trauma. Narratology has the power to form and shape all those together to investigate how they can altogether create violence and how the issue can be represented in-depth to let the reader witness the issue from its root to the visible stage.

The violence triangle theory is a pioneering one that gives a detailed account of the process of creating violence. Three pillars are establishing the theory: structural, cultural, and direct violence. The first two types are invisible, and the last one is visible. Moreover, the visible type, direct violence, manifests the other two types on the invisible level. Choosing this theory in the 
analysis of the fictional works is a new attempt in the literary studies field, especially in the studies of Hosseini's works as the theory has been mainly used in cultural and political studies. Using a theory in fictional contexts of which mainly considered in nonfictional contexts, has been exciting and challenging at the same time. Exploring new ideas and analysis was significant to bring into the research field of the literary field. Violence was a vital theme to look at, especially in Hosseini's works, which represent stories in a geographical location with many conflicts throughout history. Many scholars have discussed violence in various contexts, including literary studies, and some of the well-known scholars are Pierre Bourdieu and Slavoj Žižek. They have divided violence into categories such as symbolic, objective, subjective, and soft. There are domestic, physical, verbal, sexual, mental, spiritual, and emotional violence types. Hence, the violence triangle became the leading theory in this thesis's theoretical background as it has a very inclusive form of dealing with most of the sides of violence formation. Besides, the violence triangle has not been used to analyze any literary text, especially Hosseini's works. Using this inclusive theory, for the first time, brings novelty and new research to the literary field and fills the gap of answering the questions related to the representation of violence in the fictional world.

Through this thesis, the term of the literary violence triangle has come to existence. The term is an umbrella connecting theories and approaches in narratology, trauma, and violence to study the representation of violence in the selected novels of Hosseini from a different perspective. The literary violence triangle looked at the representation of violence in Hosseini's novel on a typological method. I looked at the represented violence, categorizing them based on their visibility and invisibility levels: structural, cultural, and direct. This typology was connected with narratological theories to explore narrators' role in the violence committed against the characters by hiding the information of narratives from the reader, as the incidents would affect the reader's reception towards the personality, attitude, and behaviour of the characters.

Trauma also influences the narrators to decide what to narrate and what to hide due to various reasons. Also, violence leads to a traumatic experience, and the trauma can be a reason to push individuals to commit violence. Societies and cultures can be affected by trauma on a general level, and the trauma may cause long-term violent actions on visible and invisible levels. The importance of trauma in understanding the causes of direct violence have been some of the main 
reasons that lead to the birth of the literary violence triangle concept to be adopted in a critical analysis of Hosseini's novels.

An essential element of Hosseini's novels' representation is to look at issues in depth rather than just portraying an issue in a simple form to the reader. The underneath of the issues and their roots become a vital part of the narratives. Pointing at Johan Galtung's violence triangle in the novels is a practical approach to see the depth of representations considering all the aspects of an issue. It is essential to see an issue represented in a narrative, but it is more substantial to witness the issues' results and roots. The violence triangle aims to give an enhanced understanding of the experience, results, and roots of violence. Analyzing the theory in A Thousand Splendid Suns, The Kite Runner, and And the Mountains Echoed has shown that Hosseini represents violence powerfully in his novels; a deep representation or representing details of an issue helps a higher level of comprehension. A better understanding of the texts demonstrates that their structures are complicated enough to deal with a dense issue like violence. The author structures his novels in an organized manner. The division among the levels of violence brings some clarification to the complexity of violence; furthermore, it adds some chronological assets to the developments in the narrative events' building process. The story's developments are seen clearly through the growth of violence from invisible to a visible level. Hence, visible violence comes first to get the reader's attention, and readers come to comprehend invisible violence at later stages. So, the visible violence unearths the unspeakable and unimaginable, which are all the invisible violence. The represented visible violence references the invisible violence to make the reader think about the process's starting points leading to direct violence. The whole complicated process of representation avoids passing on the issues, and the reader starts to consider each state of the developments in the creation of violence. Overall, this thesis is a new reading in Hosseini's works, and narratives represent violence. The literary violence triangle is a key term in reading Hosseini's novels, but it will also be helpful in future research exploring representations of violence in literature. I created the literary violence triangle concept and tested it by analyzing the primary sources selected in this thesis. The concept can be used in the analysis of other novels to look at the representation of violence. After testing the concept, I concluded that it is a good working tool and can be used in other narratives. 


\section{Bibliography}

Abbott, Horace Porter. 2008. The Cambridge Introduction to Narrative. 2nd ed. Cambridge: Cambridge University Press.

Abrahams, Hilary. 2007. Supporting Women after Domestic Violence: Loss, Trauma and Recovery. London: Jessica Kingsley Publishers.

Ahmad, Lida. 2014. "Rape and Gang Rape in War and Postwar Afghanistan1." Revista TEMAS 3 (8): 11-25.

Ahmadi, Shafiqa. 2015. "Theory vs. Practice: Women's Rights and Gender Equity in Afghanistan." Transnational Law\& Contemporary Problems 24 (2): 313-32.

Alexander, Jeffrey C. 2004. "Toward a Theory of Cultural Trauma." In Cultural Trauma and Collective Identity, edited by Jeffrey C. Alexander, 1-30. Berkeley: University of California Press.

Andreasen, Nancy C. 2010. "Posttraumatic Stress Disorder: A History and a Critique." Annals of the New York Academy of Sciences 1208: 67-71.

Bal, Mieke. 2017. Narratology: Introduction to the Theory of Narrative. 4th ed. Toronto: University of Toronto Press.

Balaev, Michelle. 2014. "Literary Trauma Theory Reconsidered.” In Contemporary Approaches in Literary Trauma Theory, edited by Michelle Balaev. Hampshire: Palgrave Macmillan.

Bamberg, Michael. 2009. "Identity and Narration." In Handbook of Narratology, edited by Peter Hühn, John Pier, Wolf Schmid, and Jörg Schönert, 132-43. Berlin: Walter de Gruyter $\mathrm{GmbH} \& \mathrm{Co} . \mathrm{KG}$.

Barfield, T. 2011. "Afghanistan: The Local and the Global in the Practice of Shari'a." In Shari'a Politics: Islamic Law and Society in the Modern World, edited by Robert W. Hefner, 179206. Indiana: Indiana University Press. 
Barfield, Thomas J. 2012. "Shari'a in Afghanistan.” The Review of Faith\& International Affairs 10 (4): 45-52.

Biehl, Joao, Byron Good, and Arthur Kleinman. 2007. "Introduction: Rethinking Subjectivity." In Subjectivity: Ethnographic Investigations, edited by Joao Biehl, Byron Good, and Arthur Kleinman, 1-23. California: University of California Press.

Bincof, Israel Nyaburi, and Nyadera Mohamed Omar. 2019. "Human Security, Terrorism, and Counterterterrorism: Bokoharam and the Taliban." International Journal on World Peace $36(1): 7-32$.

Bourdieu, Pierre. 2003. "Symbolic Violence." In Beyond French Feminisms, edited by Roger Célestin, Eliane DalMolin, and Isabelle de Courtivron, 23-26. New York: Palgrave Macmillan.

Branigan, Edward. 1992. Narrative Comprehension and Film. London and New York: Routledge.

Bridgeman, Teresa. 2007. "Time and Space." In The Cambridge Companion to Narrative, edited by David Herman, 52-65. Cambridge: Cambridge University Press.

Brison, Susan J. 2002. Aftermath: Violence and the Remaking of a Self. Princeton: Princeton University Press.

Brooks, Courtney. 2012. “'Kite Runner' Author On His Childhood, His Writing, And The Plight Of Afghan Refugees." Accessed September 26, 2019. https://www.rferl.org/a/interviewkite-runner-afghan-emigre-writer-khaled-hosseini/24621078.html.

Brown, Helen. 2013. "And The Mountains Echoed, by Khaled Hosseini, Review." Accessed September 30, 2019. https://www.telegraph.co.uk/culture/books/10069515/And-TheMountains-Echoed-by-Khaled-Hosseini-review.html.

Campbell, Dawn Mills. 2017. "Against the Odds: Perspectives of an African American Woman Nurtured in a Single-Mother Home." In Telling Our Stories: Culturally Different Adults Reflect on Growing up in Single-Parent Families, edited by Donna Y. Ford, 45-52. 
Charlotte: Information Age Publishing.

Caruth, Cathy. 1996. Unclaimed Experience: Trauma, Narrative, and History. Baltimore: The Johns Hopkins University Press.

Catani, Claudia, Elisabeth Schauer, and Frank Neuner. 2008. "Beyond Individual War Trauma: Domestic Violence Against Children in Afghanistan and Sri Lanka." Journal of Marital and Family Therapy 34 (2): 165-76.

CharlieB. 2014. "The Kite Runner by Khaled Hosseini - Review." Accessed October 6, 2019. https://www.theguardian.com/childrens-books-site/2014/jul/30/review-khaled-hosseini-thekite-runner.

Cobley, Paul. 2014. Narrative. 2nd ed. London: Routledge.

Cooke, Miriam. 1996. Women and the War Story. Berkeley and Los Angeles: University of California.

Craps, Stef. 2013. Postcolonial Witnessing: Trauma Out of Bonds. New York: Palgrave Macmillan.

D'Costa, Bina. 2016. “Gender Justice and (In)Security in Pakistan and Afghanistan." Postcolonial Studies 19 (4): 409-26.

Dannenberg, Hilary P. 2008. Coincidence and Counterfactuality: Plotting Time and Space in Narrative Fiction. Lincoln and London: University of Nebraska.

—. 2014. "Gerald Prince and the Fascination of What Doesn't Happen." Narrative 22 (3): $304-11$.

Doucet, Lyse. 2013. “Dangerous ‘Truth': The Kabul Women's Poetry Club.” Acceessed October 20, 2019. https://www.bbc.com/news/world-asia-24608666.

Driscoll, Molly. 2012. “'Kite Runner’ Author Khaled Hosseini Will Release a New Novel This Spring." Accessed October 20, 2019. https://www.csmonitor.com/Books/chapter-andverse/2012/1030/Kite-Runner-author-Khaled-Hosseini-will-release-a-new-novel-this- 
spring.

Evason, Nina. 2016. “Afghan Culture." Cultural Atlas. Accessed October 5, 2019. https://culturalatlas.sbs.com.au/afghan-culture/references-d6173878-5901-4b4e-939661ef9271d419\#references-d6173878-5901-4b4e-9396-61ef9271d419.

Famous Authors. n.d. "Khaled Hosseini." Accessed October 10, 2019. https://www.famousauthors.org/khaled-hosseini.

Fisher, Betsy. 2015. "Why Non-Marital Children in the MENA Region Face a Risk of Statelessness." Harvard Human Rights Journal Oonline January: 1-8.

Fludernik, Monika. 1996. Towards a 'Natural' Narratology. London: Routledge.

—.2009. An Introduction to Narratology. London: Routledge.

Galtung, Johan. 1969. "Violence, Peace, and Peace Research.” Journal of Peace Research 6 (3): $167-91$.

_. 1990. "Cultural Violence.” Journal of Peace Research 27 (3): 291-305.

-2004. Transcend and Transform: An Introduction to Conflict Work. London: Pluto Press.

2005. Pax Pacifica: Terrorism, the Pacific Hemisphere, Globalisation and Peace Studies. London: Pluto Press.

Ganguly, Debjani. 2016. This Thing Called the World: The Contemporary Novel as Global Form. Durham: Duke University Press.

Genette, Gerard. 1982. "Frontiers of Narrative." In Figures of Literary Discourse, edited by introduced by Marie-Rose Logan translated by Alan Sheridan, 127-44. New York: Columbia Univ. Press.

Ghilzai, S. 2016. "Biography of Khaled Hosseini." Accessed October 5, 2019. https://www.afghan-web.com/biographies/biography-of-khaled-hosseini/. 
Gibbs, Andrew, Julienne Corboz Mohammed Shafiq Frozan Marofi, Anna Mecagni, Carron Mann, Fazal Karim, Esnat Chirwa, Charlotte Maxwell-Jones, and Rachel Jewkes. 2018. "An Individually Randomized Controlled Trial to Determine the Effectiveness of the Women for Women International Programme in Reducing Intimate Partner Violence and Strengthening Livelihoods amongst Women in Afghanistan: Trial Design, Methods and Baseline ." BMC Public Health 18 (164): 1-13.

Gibney, Mark, Rhoda E. Howard Coicaud, Hassmann Jean-Marc, and Niklaus Steiner. 2008. The Age of Apology. Facing Up to the Past. Philadelphia: University of Pennsylvania Press.

Goarzin, Anne. 2011. “Articulating Trauma.” Études Irlandaises 36 (1): 1-11.

Griswold, Eliza. 2012. "Why Afghan Women Risk Death to Write Poetry." Accessed October 5, 2019. https://www.nytimes.com/2012/04/29/magazine/why-afghan-women-risk-death-towrite-poetry.html.

Hall, Doris M. 1998. "The Victims of Stalking." In The Psychology of Stalking: Clinical and Forensic Perspectives., edited by Reid Meloy. San Diego: Academic Press.

Hamburger, Käte Translated by Marilynn J. Rose. 1993. The Logic of Literature. 2nd ed. Bloomington: Indiana University Press.

Harding, Jennifer Riddle. 2007. "Evaluative Stance and Counterfactuals in Language and Literature." Language and Literature 16 (3): 263-80.

Hartman, Geoffrey H. 1995. "On Traumatic Knowledge and Literary Studies." New Literary History 26 (3): 537-63.

Herman, David. 2003. "Stories as a Tool for Thinking." In Narrative Theory and the Cognitive Sciences, 163-92. Stanford: CSLI Publications.

_.2009. Basic Elements of Narrative. Oxford: Willey-Blackwell.

Herman, Judith. 1992a. Trauma and Recovery: From Domestic Abuse to Political Terror. London: Pandora. 
_. 1992b. Trauma and Recovery. New York: Basic Books.

Herman, Luc, and Bart Vervaeck. 2007. "Ideology." In The Cambridge Companion to Narrative, edited by David Herman, 217-30. Cambridge: Cambridge University Press.

Higgins, John. 2001. “Criticism and Democracy': An Interview with Edward W. Said.” Pretexts: Literary and Cultural Studies 10 (2): 153-61.

Hooks, Bell. 1998. "Representing Whiteness: Seeing Wings of Desire." In The Visual Culture Reader, edited by Nicholas Mirzoeff, 1-547.

Hore, Rachel. 2013. "Review: And the Mountains Echoed, By Khaled Hosseini." Accessed October 2, 2019. https://www.independent.co.uk/arts-entertainment/books/reviews/reviewand-the-mountains-echoed-by-khaled-hosseini-8622201.html.

Horgan, John. 2005. The Psychology of Terrorism. New York: Routledge.

Hosseini, Khaled. n.d. "Khaled Hosseini: Bio." Accessed October 10, 2019. https://khaledhosseini.com/bio/.

- 2003. The Kite Runner. New York: Riverhead Books.

—. 2007. A Thousand Splendid Suns. London: Bloomsbury.

_2013. And the Mountains Echoed. New York: Riverhead Books.

Hower, Edward. 2003. "The Servant." Accessed October 6, 2019. https://www.nytimes.com/2003/08/03/books/the-servant.html.

Ijaz, Kulsoom K. 2014. "Shifting Paradigms: Promoting an American Adoption Campaign for Afghan Children." Syracuse Journal of International Law \& Commerce 42 (1): 234-70.

Jahn, Manfred. 2007. "Focalization." In The Cambridge Companion to Narrative, edited by David Herman, 94-108. Cambridge: Cambridge University Press.

Jayakumar, Kirthi. 2019. "Redrawing the Galtung Triangle - Finding Place for Healing Trauma 
in Peace Work." $\quad$ Accessed 2019. https://www.transcend.org/tms/2019/06/redrawing-the-galtung-triangle-finding-place-forhealing-trauma-in-peace-work/.

Jefferess, David. 2009. "To Be Good (Again): The Kite Runner as Allegory of Global Ethics." Journal of Postcolonial Writing 45 (4): 389-400.

Jenkins, Brian Michael. 1987. "The Future Course of International Terrorism.” In Contemporary Research on Terrorism, edited by Paul Wilkinson and Alasdair M. Stewart. Aberdeen: Aberdeen University Press.

Kakutani, Michiko. 2007. “A Woman's Lot in Kabul, Lower Than a House Cat's.” Accessed December 18, 2019. https://www.nytimes.com/2007/05/29/books/29kaku.html.

—. 2013. "Siblings Haunted by the Past, and by Afghanistan's Cycle of Misery." Accessed December 18, 2019. https://www.nytimes.com/2013/05/21/books/and-the-mountainsechoed-by-khaled-hosseini.html.

Kansteiner, Wulf. 2004. "Genealogy of a Category Mistake: A Critical Intellectual History of the Cultural Trauma Metaphor.” Rethinking History 8 (2): 193-221.

Kilby, Jane. 2007. Violence and the Cultural Politics of Trauma. Edinburgh: Edinburgh University Press.

Kohistani, Arezo. 2005. "Khaled Hosseini. The Kite Runner. New York:Riverhead Books, 2003." Reason and Respect 1 (2).

Kruglanski, Arie W, Katarzyna Jasko, David Webber, Marina Chernikova, and Erica Molinario. 2018. “The Making of Violent Extremists." Review of General Psychology 22 (March): $107-20$.

Lambrou, Marina. 2019. Disnarration and the Unmentioned in Fact and Fiction. London: Palgrave Macmillan.

Laplanche, Jean, and Jean-Bertrand Pontalis. 1973. The Language of Psychoanalysis. Edited by 
Donald Translated by Nicholson-Smith. London: Hogarth Press.

Lapsley, Daniel K., and Paul C. Stey. 2012. “Id, Ego, and Superego.” In Encyclopedia of Human Behavior, edited by Vilayanur Ramachandran, 2nd ed. Cambridge: Academic Press.

Laqueur, Walter. 1996. “Postmodern Terrorism.” Foreign Affairs 75: 24-36.

Laureties, Teressa de. 1989. "The Violence of Rhetoric: Considerations on Representation and Gender." In The Violence of Representation: Literature and the History of Violence, edited by Nancy Armstrong and Leonard Tennenhouse, 239-58. London: Routledge.

Lee, Erwin. 2012. "Domesticating the Subaltern in the Global Novel in English." The Journal of Commonwealth Literature 47 (3): 325-39.

Leys, Ruth. 2000. Trauma: A Genealogy. Chicago: University of Chicago Press.

Li, Mengmeng, Krishna Rao, Kayhan Natiq, Omrana Pasha, and Robert Blum. 2018. "Coming of Age in the Shadow of the Taliban: Adolescents' and Parents' Views Toward Inter Personal Violence and Harmful Traditional Practices in Afghanistan." AJPH Opem-Themed Research 108 (12): 1688-94.

Linklater, Alexander. 2013. "And the Mountains Echoed by Khaled Hosseini - Review." $\begin{array}{llll}\text { Accessed } & \text { December } & 2019,\end{array}$ https://www.theguardian.com/books/2013/may/26/mountains-echoed-khaled-hosseinireview.

Lough, Oliver, Farokhloqa Amini, Farid Ahmad Bayat, Zia Hussain, Reyhaneh Gulsum Hussaini, Massouda Kohistani, and Chona R. Echavez. 2012. "Equal Rights, Unequal Opportunities: Women's Participation in Afghanistan's Parliamentary and Provincial Council Elections."

Luebering, J.E., and Richard Pallardy. n.d. "Khaled Hosseini American Author." Accessed October 10, 2019. https://www.britannica.com/biography/Khaled-Hosseini.

Mannella, Jenevieve, Lida Ahmadb, and Ayesha Ahmada. 2018. "Narrative Storytelling as 
Mental Health Support for Women Experiencing Gender-Based Violence in Afghanistan.” Social Science \& Medicin 214: 91-98.

Margolin, Uri. 2007. “Character." In The Cambridge Companion to Narrative, edited by David Herman, 66-79. Cambridge: Cambridge University Press.

McGrattan, Cillian. 2014. "Peace Building and the Politics of Responsibility: Governing Northern Ireland." Peace and Change 39 (4): 519-41.

McLoughlin, Kate, Lara Feigel, and Nancy Martin, eds. 2017. Writing War, Writing Lives. London and New York: Routledge.

Meister, Jan Christoph. 2009. "Narratology.” In Handbook of Narratology, edited by Peter Hühn, John Pier, Wolf Schmid, and Jörg Schönert, 329-50. Berlin: Walter de Gruyter GmbH \& Co. KG.

Merleau-Ponty, Maurice. 1968. The Visible and the Invisible. Followed by the Working Notes. Trans. Alphonso Lingis. Evanston: Northwestern University Press.

Moorst, Bianca R. van, and Rik H. W. van Lunsen Dorenda K. E. van Dijken Concetta M. Salvatore. 2012. "Backgrounds of Women Applying for Hymen Reconstruction, the Effects of Counselling on Myths and Misunderstandings about Virginity, and the Results of Hymen Reconstruction." The European Society of Contraception and Reproductive Health 17: 93105.

Morewitz, Stephen J. 2003. Stalking and Violence New Patterns of Trauma and Obsession. New York: Kluwer Academic/Plenum Publishers.

Murphy, Ann V. 2012. Violence and the Philosophical Imaginary. Albany: State University of New York Press.

Mustich, James. 2008. "Khaled Hosseini A Conversation with James Mustich." Accessed October 10, 2019. https://www.barnesandnoble.com/review/khaled-hosseini.

Nayebpour, Karam. 2018. "The Use of Storeytelling in Khaled Hosseini's The Kite Runner." 
Hacettepe University Journal of Faculty of Letters 35 (1): 52-60.

Netto, Vincent B. 2009. "Violent Geographies and Bruised Bodies: Khaled Hosseini's a Thousand Splendid Suns.” Teresian Journal of English Studies 1 (1): 54-60.

Norrick, Neal R. 2007. "Conversational Storytelling." In The Cambridge Companion to Narrative, edited by David Herman, 127-42. New York: Cambridge University Press.

Nünning, Ansgar, and Roy Sommer. 2011. "The Performative Power of Narrative in Drama: On the Forms and Functions of Dramatic Storytelling in Shakespeare's Plays." In Current Trends in Narratology, edited by Greta Olson, 200-231. Berlin: Walter de Gruyter.

O'Brien, Sarah. 2018. “Translating Trauma in Khaled Hosseini's The Kite Runner." Transnational Literature 10 (2): 1-12.

O’Learya, Patrick, Cate M. Camerona, Ali Lakhania, Jodie M. Osbornea, Luana de Souzab, Mohammad S. Naimib Kristen Hopeb, Hassan Khanb, Qazi S. Jawadb, and Sabir Majidib. 2018. "Violence against Children in Afghanistan: Concerns and Opportunities for Positive Change." Child Abuse \& Neglect 76: 95-105.

Ochs, Elinor, and Lisa Capps. 2001. Living Narrative. Cambridge: Harvard University Press.

Onega, Susana, and Jose Angel Garcia Landa, eds. 1996. Narratology: An Introduction. London: Longman.

Penguin Random House. n.d. "Khaled Hosseini: Author Essay.” Accessed September 25, 2019. https://www.penguinrandomhouse.com/authors/53251/khaled-hosseini/.

Petty, Richard E., and John Cacioppo. 1986. Communication and Persuasion: Central and Peripheral Routes to Attitude Change. Berlin: Springer-Verlag.

Phelan, James. 2018. "Contemporary Narrative Theory.” In A Companion to Literary Theory, edited by David H. Richter. Oxford: Wiley.

Phelan, James Clancy. 2017. Somebody Telling Somebody Else, a Rhetorical Poetics of Narrative. Columbus: Ohio State Press. 
Picart, Caroline Joan (Kay). 2017. American Self-Radicalizing Terrorists and the Allure of "Jihadi Cool/Chic." Newcastle upon Tyne: Cambridge Scholars Publishing.

Popova, Yanna. 2015. "Narrativity." In The Bloomsbury Companion to Stylistics, edited by Violeta Sotirova, 488-506. London: Routledge.

Poyesh, Naeem, Hussain Hassrat, Abdul Ahad Mohammadi, Jane E. Thorson, Zakiah Mirzaei, and Fatema Ahmadi. 2015. "Child Notice Afghanistan."

Prince, Gerald. 1982. Narratology: The Form and Functioning of Narrative. Berlin: Mouton.

—. 1988. "The Disnarrated." Style 22 (1): 1-8.

- 2003. A Dictionary of Narratology. Revised Ed. Nebraska: University of Nebraska Press.

Puckett, Kent. 2016. Narrative Theory: A Critical Introduction. Cambridge: Cambridge University Press.

Riaz, Muhammad, and M. Wakil Khan. 2015. "Structural Violence and Christian Minority in Pakistan: The Monolithic Image to Be Blamed.” The Dialogue 10 (4): 338-50.

Richards, Alice. 2013. "Bombs and Babies: The Intercountry Adoption of Afghanistan's and Iraq's War Orphans." Journal of the American Academy of Matrimonial Lawyers 25: 399424.

Rogers, R. W. 1975. “A Protection Motivation Theory of Fear Appeals and Attitude Change." Journal of Psychology 91 (1): 93-114.

Rothberg, Michael. 2009. Multidirectional Memory: Remembering the Holocaust in the Age of Decolonization. Stanford: Stanford University Press.

Ryan, Marie-Laure. 2009. "Space." In Handbook of Narratology, edited by Peter Hühn, John Pier, Wolf Schmid, and Jörg Schönert, 420-33. Berlin: Walter de Gruyter GmbH \& Co. KG. 
—. 2013. "Possible Worlds." In The Living Handbook of Narratology, edited by Peter Hühn, Jan Christoph Meister, John Pier, and Wolf Schmid. Hamburg: Hamburg University.

Ryan, William. 1971. Blaming the Victim. New York: Vintage Books.

Samar, Sima. 2019. "Feminism, Peace, and Afghanistan." Journal of International Affairs 72 (2): $145-58$.

Schaeffer, Jean-Marie. 2009. "Fictional vs. Factual Narration.” In Handbook of Narratology, edited by Peter Hühn, John Pier, Wolf Schmid, and Jörg Schönert, 98-114. Berlin: Walter de Gruyter GmbH \& Co. KG.

Schinkel, Willem. 2010. Aspects of Violence: A Critical Theory. London: Palgrave Macmillan.

Scholes, Robert. 1981. "Language, Narrative, and Anti-Narrative." In On Narrative, edited by W.J.T. Mitchell, 200-208. Chicago: University of Chicago Press.

Scholes, Robert, James Phelan, and Robert Kellogg. 1966. The Nature of Narrative. New York: Oxford University Press.

Schönert, Jörg. 2009. “Author.” In Handbook of Narratology, edited by Peter Hüh, John Pier, Wolf Schmid, and Jörg Schönert, 1-13. Berlin: Walter de Gruyter GmbH \& Co. KG.

Schönfelder, Christa. 2013. Wounds and Words: Childhood and Family Trauma in Romantic and Postmodern Fiction. Bielefeld: Transcript Verlag.

Sehin, Oleksandra, Joellen Coryell, and Trae Stewart. 2017. "Women's (Dis)Engagement in Change in Afghanistan." Adult Learning 28 (3): 91-98.

Steenbakkers, Anne, Steffie van der Steen, and Hans Grietens. 2019. "How Do Youth in Foster Care View the Impact of Traumatic Experiences?" Children and Youth Services Review 103: 42-50.

Stuhr, Rebecca. 2009. Reading Khaled Hosseini. California: ABC-CLIO.

Tjupa, Valerij. 2014. "Narrative Strategies." Accessed November 8, 2019. https://www.lhn.uni150 
hamburg.de/node/119.html\#Baxtin2002b.

Todres, Jonathan. 2018. "The Trump Effect, Children, and the Value of Humanrights Education." Family Court Review 56 (2): 331-43.

Toolan, Michael. 2009. "Coherence." In Handbook of Narratology, edited by Peter Hühn, John Pier, Wolf Schmid, and Jörg Schönert, 44-62. Berlin: Walter de Gruyter GmbH \& Co. KG.

Tranter, Kirsten. 2013. "Remaking Home." Accessed November 8, 2019. https://www.smh.com.au/lifestyle/remaking-home-20130527-2n60z.html.

Turanovic, Jillian J. 2019. "Heterogeneous Effects of Adolescent Violent Victimization on Problematic Outcomes in Early Adulthood." Criminology 57: 105-35.

Valdes, Marcela. 2013. "Book Review: Khaled Hosseini's 'And the Mountains Echoed."” Accessed November 8, 2019. https://www.washingtonpost.com/entertainment/books/bookreview-khaled-hosseinis-and-the-mountains-echoed/2013/05/20/7f693b46-c15e-11e2-bfdb3886a561c1ff_story.html.

VOA. 2009. "Controversial Film 'The Kite Runner' Hits Movie Screens.” Accessed November 8, 2019. https://www.voanews.com/archive/controversial-film-kite-runner-hits-moviescreens.

Walsh, Richard. 2005. "The Pragmatics of Narrative Fictionality." In A Companion to Narrative Theory, edited by James Phelan and Peter J. Rabinowitz, 150-64. Malden: Blackwell Publishing Ltd.

- 2007. The Rhetoric of Fictionality. Columbus: Ohio State University Press.

Walter, Natasha. 2007. "Behind the Veil." Accessed October 6, 2019. https://www.theguardian.com/books/2007/may/19/featuresreviews.guardianreview21.

Warhol, Robyn R. 2005. "Neonarrative; or, How to Render the Unnarratable in Realist Fiction and Contemporary Film." In A Companion to Literary Theory, edited by James Phelan and Peter J. Rabinowitz, 220-31. Malden: Blackwell Publishing Ltd. 
Whitehead, Anne. 2004. Trauma Fiction. Edinburgh: Edinburgh University Press.

Wimpelmann, Torunn. 2015. "One Step Forward and Many to the Side: Combating Gender Violence in Afghanistan, 2001-2014." Women's Studies International Forum 51: 101-9.

Witte, Kim. 1992. "Putting the Fear Back into Fear Appeals: The Extended Parallel Process Model." Communication Monographs 59: 329-49.

Yardley, Jonathan. 2007. “A Thousand Splendid Suns By Khaled Hosseini.” Accessed October 6 , 2019. http://www.washingtonpost.com/wpdyn/content/article/2007/05/17/AR2007051701932.html.

Žižek, Salvoj. 2006. The Pervert's Guide To Cinema.

Žižek, Slavoj. 2008. Violence. New York: Picador.

Zunshine, Lisa. 2006. Why We Read Fiction. Columbus: Ohio State University Press. 